Florida International University FIU Digital Commons

$2-12-2018$

\title{
Perceptions of Leadership and Climate in the Stressor-Strain Process: Influences on Employee Appraisals and Reactions
}

José F. Rodríguez

Florida International University, rodrigej@fiu.edu

DOI: $10.25148 /$ etd.FIDC006572

Follow this and additional works at: https://digitalcommons.fiu.edu/etd

Part of the Industrial and Organizational Psychology Commons

\section{Recommended Citation}

Rodríguez, José F., "Perceptions of Leadership and Climate in the Stressor-Strain Process: Influences on Employee Appraisals and Reactions" (2018). FIU Electronic Theses and Dissertations. 3697.

https://digitalcommons.fiu.edu/etd/3697 


\section{FLORIDA INTERNATIONAL UNIVERSITY}

Miami, Florida

\section{PERCEPTIONS OF LEADERSHIP AND CLIMATE IN THE STRESSOR-STRAIN PROCESS: INFLUENCES ON EMPLOYEE APPRAISALS AND REACTIONS}

A dissertation submitted in partial fulfillment of the requirements of the degree of DOCTOR OF PHILOSOPHY in PSYCHOLOGY

by

José F. Rodríguez 
To: Dean Michael R. Heithaus

College of Arts, Sciences and Education

This dissertation, written by José F. Rodríguez, and entitled Perceptions of Leadership and Climate in the Stressor-Strain Process: Influences on Employee Appraisals and Reactions, having been approved in respect to style and intellectual content, is referred to you for judgement.

We have read this dissertation and recommend that it be approved.

Chockalingam Viswesvaran

Asia Eaton

Lynne Webb

Valentina Bruk-Lee, Major Professor

Date of Defense: February 12, 2018

The dissertation of José F. Rodríguez is approved.

Dean Michael R. Heithaus

College of Arts, Sciences and Education

Andrés G. Gil

Vice President for Research and Economic Development and Dean of the University Graduate School

Florida International University, 2018 
C Copyright 2018 by José F. Rodríguez

All rights reserved. 


\section{DEDICATION}

I would like to dedicate this dissertation to my mother and the memory of my father, who came to this country seeking a better life with more opportunity and sacrificed so much in the process. They themselves had never completed any education

past early elementary school, and I am humbled and honored to be the first in my family to achieve this degree. I hope I have made them proud.

I would also like to dedicate this dissertation to all the other first-generation students across this nation who have defied the odds and have been able to move up the social and academic ladder, si se puede.

This dissertation is a testament to one of the few sayings my father had that has proved to be incredibly accurate, sólo sé que no sé nada. 


\section{ACKNOWLEDGMENTS}

My utter gratitude must first be given to my mentor, Dr. Bruk-Lee, without whom I would not be where I am today. Her guidance, patience, sense of humor, and openness have been indispensable to my successful completion of the doctorate and of this dissertation in particular. I am truly fortunate to have not only a major advisor, but a true mentor and friend.

Next, I would like to acknowledge my committee for their support and guidance throughout the years. I am truly grateful to have a committee that I know has my best interests in mind and want to see me succeed.

I would like to acknowledge the support of my family, but in particular, of my niece, Brianna Rodríguez, who so graciously allowed me to stay with her two summers in a row to work on my writing. Those cumulative two months plus in the northern reaches of California afforded me the solitude, peace, and tranquility to give my undivided attention to the writing process and produce this document.

I must also acknowledge several individuals from my undergraduate years, they set the seeds for my success in graduate school. First, I would like to acknowledge my very first mentor, and good friend, Dr. Ron Durán. I met Ron as a freshman and immediately began working in his research lab. Many of the theories that I use in this dissertation I first heard about from him. Next, I would like to acknowledge another mentor and friend, Dr. Victoria Noriega. It was, again, during my freshman year that I weaseled my way into her upper-division course on how to get into graduate school. Her guidance throughout my undergraduate years and beyond were invaluable. Dr. Diane Millette was another mentor and friend who sparked my interest in the field of 
communication, and although I ultimately went toward psychology, her passion for teaching and research along with her encouraging and positive attitude have always stayed with me. Last, Dr. Victoria Orrego-Dunlevy was the first faculty with whom I had published research. She too played an indelible role in developing my skills as a researcher. It was with her that I first learned about path analysis and confirmatory factor analysis.

I would like to acknowledge my colleagues at the Honors College here at FIU. Dr. Leslie Northup the former dean of the Honors College, Dr. JC Espinosa the current interim dean of the Honors College, and the staff of the Honors College, Lili, Rachelle, Umer, Rosie, Maria, Allen, Luli, Isabel, Juan, and any I may have missed. Your support throughout the years was truly appreciated and helped me get through many a tough day! Finally, I would be remised if I did not offer one last acknowledgement, and that is to Florida International University that has been my employer for over 13 years and allowed me to complete this program through its generous employee benefits package. 


\begin{abstract}
OF THE DISSERTATION
PERCEPTIONS OF LEADERSHIP AND CLIMATE IN THE STRESSOR-STRAIN

PROCESS: INFLUENCES ON EMPLOYEE APPRAISALS AND REACTIONS
\end{abstract}

by

José F. Rodríguez

Florida International University, 2018

Miami, Florida

Associate Professor Valentina Bruk-Lee, Major Professor

This paper attempts to place the role of transformational leadership within the stressorstrain process by investigating the potential indirect effects of the perceptions of transformational leadership on counterproductive work behaviors (CWBs) through its influence on perceptions of the communication climate and trust. Leaders perceived as being transformational will offer an ameliorating effect on employee appraisals of stressors (i.e., conflict). Non-task organizational conflict is a stressor that captures employees' perceptions of conflict with co-workers attributable to organizational factors (e.g., unclear or contradictory policies). Previous studies have found this type of stressor to be associated with negative health and workplace outcomes. Counterproductive work behaviors are a form of workplace incivility in which employees engage in minor acts of retribution. Transactional theories of stress place particular importance on appraisal mechanisms to explain the experience of stress and subsequent engagement in CWBs. Volumes of literature in the field of leadership have suggested that transformational leaders have the ability to influence the ways employees make meaning of events at work. However, few studies have investigated the mechanisms by which employees’ 
appraisals of stressors are influenced. This study investigated the potential role of trust in leadership and communication climate as possible mechanisms. Organizational climate research focuses on how employees, through their social interactions, create and ascribe meaning to work events. Communication climate specifically focuses on the supportive and defensive qualities of an organization's communicative norms and expectations. Previous research suggests trust to be a key factor in mitigating the experience of stressors and strains. Participants were primarily recruited from positions in higher education administration, using a sample of convenience, snowball sampling. Survey instruments were administered during two waves of data collection, for a full-panel sample of $N=123$. Results suggested transformational leadership indirectly effected engagement in CWBs through its influence on the experience of non-task organizational conflict. Trust in leadership was not a significant predictor. Communication climate provided a mixed picture. While perceptions of a more supportive communication climate were associated with less conflict and fewer CWBs, the data did not support the indirect effects of transformational leadership through communication climate. 


\section{TABLE OF CONTENTS}

CHAPTER

PAGE

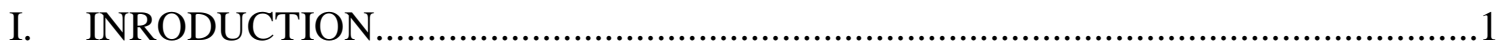

Stressor-Strain Processes in Occupational Health Psychology.................................1

Appraisal Theory and Transformational Leadership...............................................

Non-Task Organizational Conflict: A Different Kind of Interpersonal Conflict....6

Interpersonal Conflict and Counterproductive Work Behaviors...............................

Attributions of Control..................................................................................

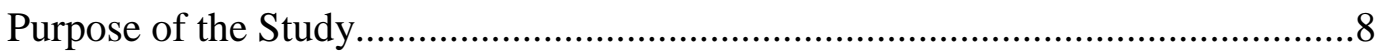

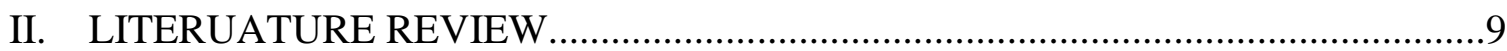

An Appraisal Perspective on Stressors and Strains...........................................

Interpersonal Conflict as a Social Stressor............................................................10

Counterproductive Work Behaviors as Strain Reactions to Interpersonal

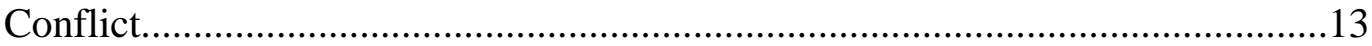

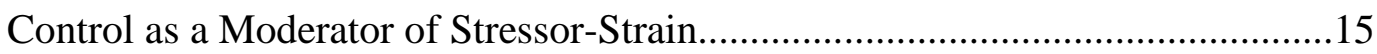

Leadership's Influence on the Appraisal Process...................................................17

Transformational Leadership and Counterproductive Work Behaviors..................21

Transformational Leadership within the Transactional Model of Stress................23

Transformational Leadership Builds Trust in Leadership......................................25

Transformational Leadership Influences Perceptions

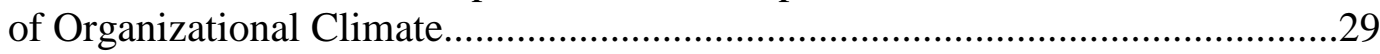

Linking Communication Climate to Leadership

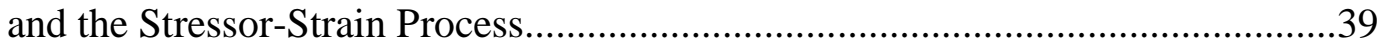

The Full Picture: Influencing Employees' Appraisals...........................................42

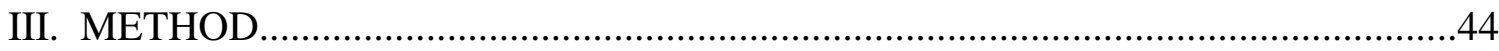

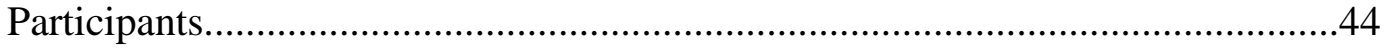

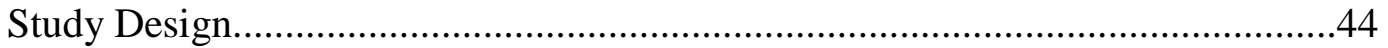

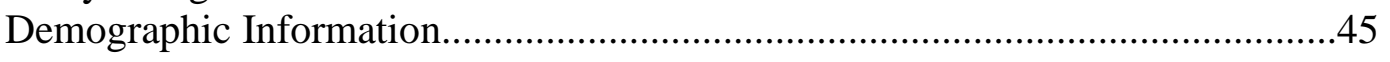

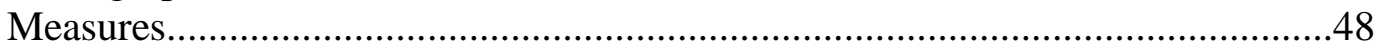

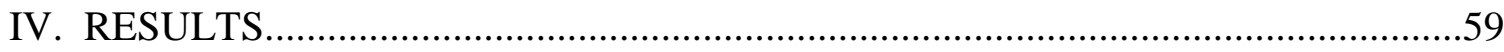

Assessment and Treatment of Missing Data........................................................59

Assessing Multivariate Assumptions, Outliers and Influencers.............................60

Data Analysis and Results.................................................................................60

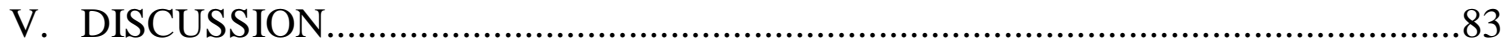

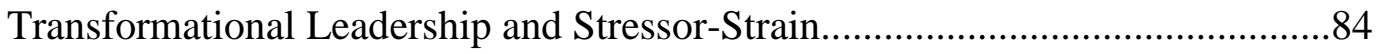

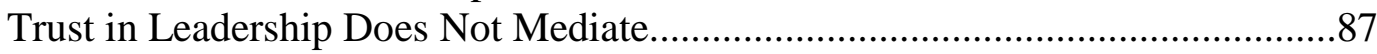

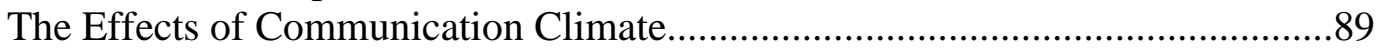

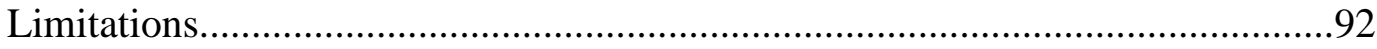

Future Research and Directions...................................................................100 


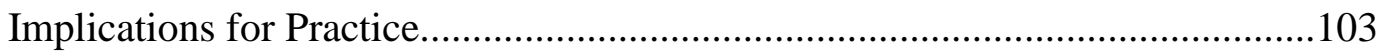

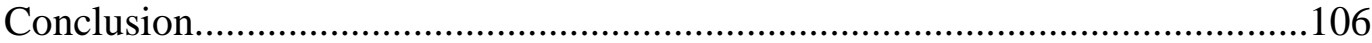

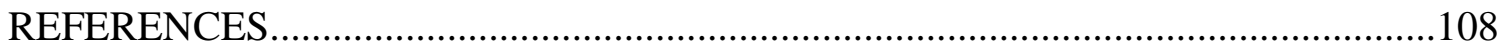

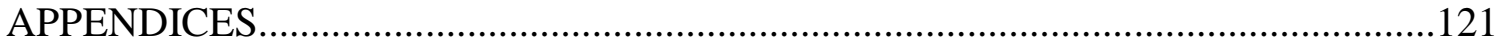

VITA 
1. Comparisons between Full Participants and $T_{1}$ Only Participants................................47

2. Confirmatory Factor Analysis: Transformational Leadership......................................49

3. Confirmatory Factor Analysis: Trust in Leadership.....................................................50

4. Confirmatory Factor Analysis: Communication Climate at Time 2...........................55

5. Confirmatory Factor Analysis: Non-Task Organizational Conflict................................56

6. Confirmatory Factor Analysis: Interpersonal Locus of Control....................................57

7. Confirmatory Factor Analysis: Counterproductive Work Behaviors..............................58

8. Summary of Intercorrelations, Means, and Standard Deviations for Full Panel

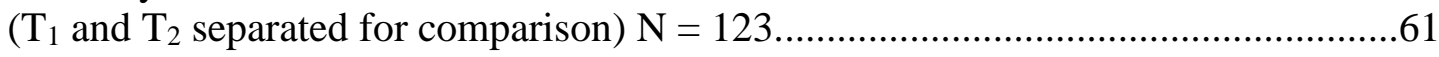

9. Moderation Analysis for Interpersonal Locus of Control.............................................62

10. Path Analysis: Transformational Leadership $\left(\mathrm{T}_{1}\right)$ and Counterproductive Work Behaviors $\left(T_{2}\right)$, Non-Task Organizational Conflict $\left(T_{1}\right)$ as Mediator...

11. Path Analysis: Transformational Leadership $\left(\mathrm{T}_{1}\right)$ and Counterproductive Work Behaviors $\left(\mathrm{T}_{2}\right)$, Non-Task Organizational Conflict $\left(\mathrm{T}_{2}\right)$ as Mediator.

12. Path Analysis: Transformational Leadership $\left(\mathrm{T}_{1}\right)$ and Non-Task Organizational Conflict $\left(\mathrm{T}_{2}\right)$, Trust in Leadership $\left(\mathrm{T}_{1}\right)$ as Mediator.

13. Path Analysis: Transformational Leadership $\left(\mathrm{T}_{1}\right)$ and Non-Task Organizational Conflict $\left(\mathrm{T}_{2}\right)$, Trust in Leadership $\left(\mathrm{T}_{2}\right)$ as Mediator.

14. Path Analysis: Transformational Leadership $\left(\mathrm{T}_{1}\right)$ and Counterproductive Work Behaviors $\left(\mathrm{T}_{2}\right)$, Trust in Leadership $\left(\mathrm{T}_{1}\right)$ as Mediator.

15. Path Analysis: Transformational Leadership $\left(T_{1}\right)$ and Counterproductive Work Behaviors $\left(T_{2}\right)$, Trust in Leadership $\left(T_{2}\right)$ as Mediator.

16. Path Analysis: Transformational Leadership $\left(\mathrm{T}_{1}\right)$ and Non-Task Organizational Conflict $\left(\mathrm{T}_{2}\right)$, Supportive Communication Climate $\left(\mathrm{T}_{1}\right)$ as Mediator.

17. Path Analysis: Transformational Leadership $\left(\mathrm{T}_{1}\right)$ and Non-Task Organizational Conflict $\left(\mathrm{T}_{2}\right)$, Supportive Communication Climate $\left(\mathrm{T}_{2}\right)$ as Mediator. 
18. Path Analysis: Transformational Leadership $\left(\mathrm{T}_{1}\right)$ and Counterproductive Work Behavior $\left(\mathrm{T}_{2}\right)$, Supportive Communication Climate $\left(\mathrm{T}_{1}\right)$ as Mediator.

19. Path Analysis: Transformational Leadership $\left(\mathrm{T}_{1}\right)$ and Counterproductive Work Behavior $\left(\mathrm{T}_{2}\right)$, Supportive Communication Climate $\left(\mathrm{T}_{2}\right)$ as Mediator.

20. Path Analysis: Transformational Leadership $\left(\mathrm{T}_{1}\right)$ and Non-Task Organizational Conflict $\left(\mathrm{T}_{2}\right)$, Defensive Communication Climate $\left(\mathrm{T}_{1}\right)$ as Mediator.

21. Path Analysis: Transformational Leadership $\left(\mathrm{T}_{1}\right)$ and Non-Task Organizational Conflict $\left(\mathrm{T}_{2}\right)$, Defensive Communication Climate $\left(\mathrm{T}_{2}\right)$ as Mediator....

22. Path Analysis: Transformational Leadership $\left(\mathrm{T}_{1}\right)$ and Counterproductive Work Behavior $\left(\mathrm{T}_{2}\right)$, Defensive Communication Climate $\left(\mathrm{T}_{1}\right)$ as Mediator

23. Path Analysis: Transformational Leadership $\left(\mathrm{T}_{1}\right)$ and Counterproductive Work Behavior $\left(\mathrm{T}_{2}\right)$, Defensive Communication Climate $\left(\mathrm{T}_{2}\right)$ as Mediator.

24. Path Analysis: Transformational Leadership $\left(\mathrm{T}_{1}\right)$ and Counterproductive Work Behavior $\left(\mathrm{T}_{2}\right)$, Trust in Leader and Non-Task Organizational Conflict as Serial Mediators

25. Path Analysis: Transformational Leadership $\left(\mathrm{T}_{1}\right)$ and Counterproductive Work Behavior $\left(\mathrm{T}_{2}\right)$, Supportive Communication Climate and Non-Task Organizational Conflict as Serial Mediators.....

26. Path Analysis: Transformational Leadership $\left(\mathrm{T}_{1}\right)$ and Counterproductive Work Behavior $\left(\mathrm{T}_{2}\right)$, Defensive Communication Climate and Non-Task Organizational Conflict as Serial Mediators 


\section{LIST OF FIGURES}

FIGURE

PAGE

1. Confirmatory Factor Analysis of Newly Constituted Supportive Communication Climate. .54

2. Confirmatory Factor Analysis of Original Authoritarianism Factor.

3. Model of Best Fit for Serial Mediation: Trust in Leadership and NTO.. 78

4. Model of Best Fit for Serial Mediation: Supportive Communication Climate and NTO. .80

5. Model of Best Fit for Serial Mediation: Defensive Communication Climate and NTO 82 


\section{INTRODUCTION}

The present dissertation will attempt to bridge two areas of organizational scholarship: occupational health psychology and leadership theory. Specifically, the purpose of the dissertation is to expand the conceptual framework from which to understand stressor-strain processes and consider the role of leadership in that process. What follows is a general introduction to the issues and identification of the salient variables under consideration, as well as to preview the contents of this dissertation.

\section{Stressor-Strain Processes in Occupational Health Psychology}

Research and theory into organizational stress has been advanced by the use of the stressor-strain paradigm. The concept of stress itself has been a point of contention for many years (Cooper, 1998); however, parceling the cause of the stress from the reaction is an important theoretical and practical distinction. From a stimulus-response perspective, a stressor is something physical or social, typically in the environment, that requires an adaptive response. Strains are the reactions and are typically construed as manifesting physiologically, affectively, and/or behaviorally (Koslowsky, 1998). While stressors can be either subjective or objective (Koslowsky, 1998), a strong case has generally been made for the salience of subjective appraisals of stress (Perrewé \& Zellars, 1999). The role of perception and appraisal will be addressed more fully later in this introduction.

Traditionally studied stressors: job characteristics. Researchers have typically investigated the effects of job characteristics (i.e., workload, role conflict and ambiguity) on employee outcomes (e.g., Keenan \& Newton, 1984). For example, in a longitudinal study of urban bus drivers, Rydstedt, Johansson, and Evans (1998) found that perceived 
increases in workload were positively related to increased exhaustion after work, psychosomatic symptoms, and to spillover effects at home, even after controlling for negative affect. A recent study by Brüggen (2015) that included objective measures found a curvilinear relationship between workload and quantitative task performance. Keenan and Newton (1984) found organizational characteristics, such as role conflict/ambiguity and workload, lead to frustration.

Acknowledging the social aspects of work and stress. While traditional sources of stress found in the job continue to be useful areas of inquiry, a growing body of research is focusing on the social aspects of work as a source of stress. In a study of reports of stressful incidents, Keenan and Newton (1985) found respondents reported interpersonal conflict to be the second most stressful incident, just behind incidents involving wasted time. Other characteristics, such as role conflict and ambiguity, only made up about four and one percent, respectively, of the proportion of stressful incidents. In an overview of conflict, health, and well-being, Spector and Bruk-Lee (2008) provide some rationale as to why interpersonal conflict can have detrimental outcomes. Specifically, they invoke appraisal and attribution theory to help understand individuals' reactions stating, "people who are having conflicts with others will appraise the situation as at least somewhat threatening and anxiety provoking” (p. 272). Individuals may see the cause of the conflict in the other person, "and they will assume the other person was able to control and avoid the conflict in the first place" (p. 272).

Antecedents to stressors. To understand better the conditions under which certain events are perceived as stressful, an expansion of the antecedents to stressors is necessary. Social support has been shown to buffer negative effects of interpersonal 
conflict (e.g., Iles, Johnson, Judge, and Keeney, 2011). In a recent study, Buttigeig and West (2013) found perceptions of the transformational leadership style of senior management influenced employee perceptions of social support and the quality of job design. However, a major drawback of their study was the lack of a theoretical grounding from which to explain the mechanisms by which transformational leadership influenced the stressor-strain process.

\section{Appraisal Theory and Transformational Leadership}

One framework from which to understand better stressor-strain relationships is the transactional model (Lazarus \& Folkman, 1984). Appraisals, that is, the meaning individuals make, are paramount to understanding the genesis of stressors. According to Lazarus (1991), appraisal is, "the way that [an] individual defines and evaluates relationships with the environment" (p. 10). Appraisals are the evaluations that individuals make about the "business of their lives." The process of appraisal is two-step: primary appraisal is related to goal relevance, goal congruence, and ego-involvement; secondary appraisal is related to blame/credit, coping, and future expectancy. During primary appraisal, the individual must perceive the environmental event as having either a threatening or challenging quality. Lazarus (1991) explains:

a threatening encounter makes one feel uneasy (anxious), which is not only unpleasant but is apt to constrict one's ability to think and perform. The constriction is connected with a strong effort to protect oneself from anticipated danger. In contrast, a challenge makes one feel good, and there is apt to be considerable expansion of one's functioning, with relevant thoughts coming easily 
and with the subjective impression that one is approaching the zenith of one's powers. (p. 18)

Key to understanding this appraisal process is understanding the "business of [peoples'] lives," specifically, the activities that characterize daily living and the ways by which individuals give meaning to those activities. Employee perceptions of certain types of leadership behaviors in their supervisors may influence the perceptual field from which more general employee appraisals are made.

Bass and Avolio (1994) contend that leaders can influence the interpersonal experiences of employees. Shamir, House and Arthur (1993) argue that transformational leaders motivate employees by targeting the motivational mechanisms that influence perceptions of self-consistency. Moreover, they state that transformational leadership requires two sets of behaviors: role modeling and frame alignment. Transformational leaders are aware that they must model (i.e., exhibit) the behavior that they extoll in their employees. Frame alignment occurs when the leader makes attempts, typically through communicative action, to reorient employees' frames of reference and interpretive structures. In a study of employee and coworker dyads, Kessler, Bruursema, Rodopman, and Spector (2013) found transformational leadership to be associated with decreased conflict with supervisors. Moreover, transformational leadership transmitted its effects onto counterproductive work behaviors indirectly through conflict with supervisor and negative emotions. They argue that transformational leadership may serve a social support function, creating a climate of mutual respect and trust.

Trust in leadership is another factor that may influence employees' perceptual fields and thus appraisals of stressors. Mirsha and Spreitzer (1998) found trust in 
management to shape employee threat appraisals during a downsizing. Specifically, they found that, "if survivors [of downsizing] do not trust that top management is concerned with the interests of all organizational stakeholders, is open and honest with employees, or is competent to lead the organization through the downsizing, then survivors are more likely to be threatened by the downsizing and to respond in destructive ways" (p. 568). Trust is defined as the willingness to be vulnerable to another party (Mayer, Davis, Schoorman, 1995). While the Mirsha and Spreitzer (1998) study did not investigate transformational leadership, per se, they do allude to it: “...communicating a clear vision of how the downsizing will benefit all stakeholders also reduces the threatening nature of the downsizing, because survivors can see hope for the future. This type of social account reframes the act of downsizing by placing it in a broader context that will legitimate the action..." (p. 577). Therefore, transformational leadership's role within the stressor-strain paradigm is best understood vis-à-vis the appraisal process. Through their actions, transformational leaders may help to reframe potential stressors and thus transmit desirable effects in reducing strains by altering the appraisal of the stressor.

Moreover, the organizational climate is also thought to be a factor influencing employee appraisal systems (Ashford, 1985). An underappreciated facet of the organizational climate is the communication climate; that is, the expectations employees have about the norms of engaging in communicative acts (Costigan \& Schmeidler, 1984). Communication climate has been considered from two dimensions: supportive and defensive (Gibb, 1961). It is possible that transformational leaders influence employees' perceptions of the communication climate, increasing their perceptions of a supportive communication climate, while simultaneously reducing their perceptions of a defensive 
communication climate. In particular, perceptions of a defensive communication climate may be a direct result of the experience of a defensive response (Gibb, 1961).

Transformational leaders, as argued above, have the capacity to reframe and may be successful in ameliorating the stressor-strain process through their ability to influence employee perceptions of the communication climate.

\section{Non-Task Organizational Conflict: A Different Kind of Interpersonal Conflict}

According to Spector and Bruk-Lee (2008), a leading form of social stress is interpersonal conflict at work. While research in interpersonal conflict has traditionally focused on the relationship and task dimensions (Jehn, 1995), recent studies have pointed to an additional form: non-task organizational conflict. This type of conflict is manifested in the perception that employees are in disputes with each other not because of personality clashes or disagreements about carrying out particular job tasks; rather, the origin of the disputes can be found in organizational factors (i.e., poor leadership, disagreements over policies, etc.; Bruk-Lee, Nixon, \& Spector, 2013). This type of perceived conflict with others may be particularly inimical as the root of the dispute is not found in either party but in the organizational features. It would stand to reason then that transformational leaders, through their use of speech acts that help to reduce uncertainty, make meaning, and facilitate human bonding (Sullivan, 1998), would be associated with reductions in the perception of this form of social stress. By focusing on motivating employees to excellence and building stronger trust ties, transformational leaders may be altering the perceptual frame of employees to reduce the threatening appraisal of stressors. 


\section{Interpersonal Conflict and Counterproductive Work Behaviors}

Counterproductive work behaviors are a common reaction to experiences of frustration at work (Marcus \& Schuler, 2004). Interpersonal conflict, in particular with co-workers, has been shown to be associated with subsequent engagement in counterproductive work behaviors (Bruk-Lee \& Spector, 2006). Non-task organizational conflict is a form of interpersonal conflict that is rooted in misunderstanding and differential interpretation of policies and procedures. Feelings of frustration may be aroused when experiencing such type of interpersonal conflict as the origin of the dispute is outside the dyadic interpersonal exchange. Two recent studies found non-task organizational conflict to be a strong predictor of counterproductive work behaviors (Nixon, Rodriguez, Bruk-Lee, 2013; Rodriguez \& Bruk-Lee, 2016b).

\section{Attributions of Control}

Control has been argued to be a salient feature of the stressor-strain process (Spector, 1998) as perceptions of control can serve an important moderating function either exacerbating or attenuating stressor-strain relationships (Spector \& Fox, 2005; Ng et al., 2006). Employee reactions of control are important to understanding the severity with which they may react to stressful stimuli (Spector, 1982). Locus of control generally refers to a person's expectations of causation (Paulhus, 1983). Internals tend to see causation resulting from their actions; externals tend to see causation outside of themselves. Interpersonal locus of control refers to a specific sphere, that of interpersonal contacts and relationships (Paulhus, 1983). Hahn (2000) argues that reactivity is the response to a stressor and that interpersonal locus of control will moderate that response. Hahn (2000) found that internals tended to endorse more problem-focused approaches to 
conflict. Mitchell and Ambrose (2012) found externals exhibited more retaliation toward aggressive supervisors and overall responded to aggression more destructively than internals.

\section{Purpose of this Study}

Transformational leadership research has rarely considered the paradigms of occupational health psychology when attempting to explain the mechanisms by which such leadership transmits positive outcome effects. Likewise, the literature in organizational stress has not consistently considered the conditions under which certain types of leadership may influence the evaluative process of stress. The present dissertation will attempt to bridge these two theoretical and practical areas of organizational research by placing the role of transformational leadership within the stressor-strain paradigm. The transactional model of stress is a parsimonious, yet robust model from which to frame the possible indirect effects transformational leadership may exert on employee perceptions of stressors at work and the reactions thereof. The following chapter will discuss the variables identified here in more detail, provide a more extensive review of the relevant literature, and provide a conceptual framework from which to understand their relationships. 


\section{LITERATURE REVIEW}

This section will begin with an overview of the appraisal process and its role in stressor-strain research. It is from this theoretical perspective that the role of transformational leadership, interpersonal conflict, and counterproductive work behaviors will be understood. Next, a review of interpersonal conflict and its role as a social stressor will be addressed. Following that, counterproductive work behaviors will be explored as a response to the experience of interpersonal conflict. Moreover, this relationship will be best understood within the context of control. Finally, transformational leadership's role within the stressor-strain paradigm will be considered from the perspective of appraisal processes and two factors that may influence these processes: trust in leadership and communication climate.

\section{An Appraisal Perspective on Stressors and Strains}

Research into stress and health at work has invoked numerous theories of work stress to explain underlying psychological mechanisms (Cooper, 1998). Appraisal theory has been particularly useful, given its focus on cognitive-emotive processes (Lazarus, 1991). My dissertation will invoke appraisal theory as the undergirding explanatory mechanism from which to evaluate the meaning of the data and understand the psychological processes at work.

Transactional models of job stressors and strains have provided a useful framework from which to understand the mechanisms by which individuals interact with their environment, particularly within the social context of the workplace. Of paramount importance to this framework is the individual's appraisal of stressors. Stressors are conditions or situations that employees perceive as requiring an adaptive response 
(Spector, 1998). According to Lazarus (1999), "[appraisal] is the meaning constructed by a person about what is happening that is crucial to the arousal of stress reactions" (p. 55). The process is twofold: primary appraisal is the evaluation of the person-environment encounter as either being threatening or challenging to one's goals and sense of self. Threats are enervating because they can hinder goal attainment; on the other hand, a challenge, "makes one feel good, and there is apt to be considerable expansion of one's functioning, with relevant thoughts coming easily and with the subjective impression that one is approaching the zenith of one's powers" (Lazarus, 1991, p. 18). Secondary appraisal is the response one decides to take and can either be adaptive or maladaptive. However, the terms primary and secondary do not necessarily refer to temporality or salience. Rather, it is about the "content of the appraisal" (Lazarus, 1999). Central to the idea of appraisal is the individual because appraisal is an individual act. Stressors do not elicit monolithic responses; individual differences in perception and evaluation will vary how one will react. While some research has attempted to measure appraisal per se (e.g., Lyons and Schneider, 2009), others have used the notion as an explanatory mechanism undergirding individuals' reactions (e.g., Holten \& Brenner, 2015) and provide an explanation of the psychological mechanisms. Despite the direct or inferred measurement of appraisal, the process serves as a useful theoretical framework from which to understand behavior in the workplace.

\section{Interpersonal Conflict as a Social Stressor}

Most workplaces seem to have two sources of stress for individuals: the work itself and the social context of the work. In the field of organizational psychology, volumes of research have investigated the effects of stressors such as job characteristics 
(i.e., work overload, role ambiguity, hours worked, among others) on health and wellbeing (Quick and Tetrick, 2010). However, as organizational life continues to be characterized by social interactions, the need to understand social stressors in the workplace is heightened. Social stressors are not a unique class of stressor; however, taking an appraisal framework of stress, it becomes clear that stress rooted in social interactions is even more ambiguous than stress due to, say, work overload. The contingent and dynamic nature of social interactions allow for greater variability in evaluation and interpretation. Interpersonal conflict in the workplace is often cited as a leading social stressor across occupations (Mazzola, Schonfeld, \& Spector, 2011) requiring an adaptive response from employees. Interpersonal conflict can be defined as, "a dynamic process that occurs between interdependent parties as they experience negative emotional reactions to perceived disagreements and interference with the attainment of their goals" (Barki \& Hartwick, 2004, p. 234). According to Spector and Bruk-Lee (2008), interpersonal conflict at work is a social stressor that can manifest outcomes similar to traditional stressors related to work overload and other factors about the job itself.

Interpersonal conflict has been operationalized both generally (i.e., Spector and Jex, 1998 interpersonal conflict at work measure) and specifically (i.e., Jehn, 1995 task and relationship conflict). While debate remains concerning whether conflict can be beneficial (Solansky, Singh, \& Huang, 2014), the preponderance of the evidence suggests that interpersonal conflict is generally construed as a stressor and produces negative outcomes. In her ground-breaking work, Jehn (1995) made the first rigorous attempt at defining interpersonal conflict at work and understanding the conditions under which 
conflict was detrimental to team functioning. Following the work of Pinkley (1990), Jehn developed a measure of task and relationship conflict that has been used in countless studies of interpersonal conflict (Jehn, 1995). Jehn's initial findings were promising: relationship conflict showed inimical effects across the board. However, task conflict painted a more complex picture. She found evidence of task conflict's curvilinear relationship with outcomes, "task conflict was positively related to performance up to a certain point...beyond which individual performance declines...” (p. 272). Interestingly, she also found conflict norms to influence the experience of conflict. Norms that promoted openness enhanced the beneficial effects of task performance while also reducing the negative effects.

In a meta-analysis on conflict research, de Witt, Greer, and Jehn (2012) found that interpersonal conflict influences distal versus proximal outcomes differently. For proximal outcomes, such as group member satisfaction and cohesion, task conflict was less negative than relationship conflict. In addition, the role of task conflict is, again, complicated: the influence of task conflict on group performance heavily depended on moderators. The literature has generally supported the inimical effects of relationship conflict. For example, de Wit, Jehn, and Scheeper (2013) suggest that relationship conflict may exacerbate task conflict. In a series of studies, they found perceptions of higher relationship conflict during task conflict were associated with employees reporting less motivation to process information, less likely to use the information provided by other group members, and more rigidly holding on to initial preferences during decision making. In a second study, the researchers manipulated the relationship conflict event and found the same results: the presence of relationship conflict during a task conflict made 
participants less collaborative. In a different study using a diary methodology, Meier, Gross, Spector and Semmer (2013) found relationship conflict to be more detrimental to well-being when task conflict was low.

While the literature has primarily focused on interpersonal conflict as construed via its task and relationship dimensions, other forms of disputes at work have recently received attention. Non-task organizational conflict, a form of interpersonal conflict in which one is in a dispute with others at work because of organizational factors (i.e., disagreements over policies, imbalances in organizational power, poor leadership), showed inimical effects on several outcomes including physical symptoms, job satisfaction, and negative emotions (Bruk-Lee et al., 2013). This form of interpersonal conflict is deceivingly insidious because the root of the dispute is not centered on the task at hand, nor the personalities of the parties involved. Rather, the source of the conflict is the organization itself through its practices and policies, and therefore difficult to influence.

\section{Counterproductive Work Behaviors as Strain Reactions to Interpersonal Conflict}

Interpersonal conflict has been found to be a strong predictor of aggression targeted at other employees and at the organization (Herchovis et al., 2007). Often considered a strain reaction to job stress (Fox \& Spector, 2005), counterproductive work behaviors encompass a slew of retaliatory, volitional acts that are targeted at either other employees, the organization, or both. Control has been a central factor in understanding the motivations for engaging in counterproductive work behavior (Hurrell \& Murphy, 1991; Perlow \& Latham, 1993). Kisamore, Jawahar, Liguori, Mharapara, and Stone (2010) found political skill to moderate the relationship between interpersonal conflict 
and counterproductive work behaviors, such that those who reported being more politically skilled had a stronger conflict-counterproductive work behavior relationship. They interpreted this finding to suggest that individuals may, "regain a sense of control to mitigate the effects of the interpersonal conflict they experience" (pg. 593). Fox and Spector (1999) argue that counterproductive work behaviors are best understood vis-à-vis frustration-aggression theory. They purport that employees who experience frustration because of goal impediment may react maladaptively as a way to cope with workplace stress. Non-task organizational conflict represents a phenomenon that is wholly out of the employees' sphere of control because the origin of the dispute comes from the organization itself; thus, it seems that counterproductive work behaviors would be a natural reaction to the experience of non-task organizational conflict. In two recent studies examining the role of non-task organizational conflict, in two different work samples (i.e., nurses and university administration), researchers found a consistent and strong relationship between non-task organizational conflict and counterproductive work behaviors (Nixon et al., 2013; Rodriguez \& Bruk-Lee, 2016b). In a different study looking at employee burnout, Rodriguez and Bruk-Lee (2016a) found that the effects of non-task organizational conflict on burnout have their origins in how employees access organizationally relevant information. Those employees who reported relying more on informal channels of communication (i.e., the grapevine) as opposed to formal channels (i.e., memos, emails, etc.) reported experiencing significantly higher amounts of non-task organizational conflict and thus higher reports of burnout. Non-task organizational conflict seems to tap into a different level of interpersonal disputes where the cause of the dispute may not entirely be in the hands of the employee. If employees are accessing 
incorrect or poor organizationally relevant information, then differential interpretations of policies and procedures may produce interpersonal conflict among employees. If this type of interpersonal conflict is evaluated as threatening, goal-impeding or even egodamaging, then according to frustration-aggression theory, the consequence will mostly likely be for the individual to react counterproductively.

Hypothesis 1a: Non-task organizational conflict will be positively related to reports of counterproductive work behaviors.

\section{Control as a Moderator of Stressor-Strain}

A key feature of the stressor-strain process is the role of control (Spector, 1998). According to Spector and Fox (2005), "perceived control is an important moderator of...behavioral reactions" (p. 158). Employee reactions of control are important to understanding the severity with which they may react to stressful stimuli (Spector, 1982). Studies in the control literature have focused on two aspects of control: control over job tasks and duties, synonymous with autonomy (Karasek, 1979) and control as a personality trait. Locus of control generally refers to a person's expectations of causation (Paulhus, 1983). Internals tend to see causation resulting from their actions; externals tend to see causation outside of themselves. Paulhus (1983) has argued that locus of control research, much like self-efficacy, needs to focus on specific spheres of control to be useful. When an individual attributes cause, locus of control may vary as a function of the sphere in which the actions occur: sphere of personal efficacy, sphere of interpersonal control, or sphere of sociopolitical control. Interpersonal locus of control refers to the specific sphere of interpersonal contacts and relationships. Previous research shows evidence of a moderating effect for work locus of control on the relationship between job 
stressors and counterproductive work behaviors (e.g., Sprung \& Jex, 2012). Work locus of control focuses on control attributions about work outcomes (e.g., performance rewards, promotion, etc.). While Sprung and Jex (2012) found work locus of control to moderate the relationship between interpersonal conflict and counterproductive work behaviors, the variance explained was small. It is possible that the conceptualization of locus of control needs to match with that of the conceptualization of the stressor. That is, interpersonal conflict is constituted by disputes between employees. It implies a large amount of social interaction. It follows, then, that an individual's interpersonal locus of control - their belief in the ability to interact with others and the causal attributions made of social interactions - would explain more variance in the stressor-strain relationship.

Several studies have specifically investigated the role of interpersonal locus of control. For example, Hahn (2000) argues that reactivity is the response to a stressor and that interpersonal locus of control will moderate that response. In that study, internals tended to endorse more problem-focused approaches to conflict. In an investigation of reactions to supervisor aggression, Mitchell and Ambrose (2012) found, in two studies, that externals exhibited more retaliation toward aggressive supervisors. In a third study, they found externals to respond to aggression more destructively than internals. In a meta-analysis of locus of control research, $\mathrm{Ng}$, Sorensen, and Eby (2006) found three major areas of locus of control influence: well-being (i.e., mental well-being, physical health), motivation (i.e., organizational commitment, self-efficacy) and behavioral orientation (i.e., social integration and relationships with supervisors). They claim, "locus of control is related to a variety of organizational phenomena and should not be minimized or ignored" (Ng et al., 2006, p. 1072). 
Given that non-task organizational conflict is rooted in misunderstanding and differential interpretation of policies and procedures (Rodriguez \& Bruk-Lee, 2016a), individual differences in interpersonal locus of control may moderate the intensity with which employees react to organizational issues that are wholly out of their control. In a sample of working nurses, Nixon et al. (2013) found that the relationship between nontask organizational conflict and counterproductive work behaviors was its strongest among those who reported an external interpersonal locus of control. Additionally, Rodriguez and Bruk-Lee (2016b) found the same moderation effect in a sample of university administrators.

Hypothesis 1b: The relationship between non-task organizational conflict and counterproductive work behaviors will be moderated by individual differences in interpersonal locus of control. That is, an external interpersonal locus of control will strengthen the relationship between non-task organizational conflict and counterproductive work behaviors, while an internal interpersonal locus of control will weaken it.

\section{Leadership's Influence on the Appraisal Process}

According to Koslowsky (1998), in order to fully understand the mechanisms underlying stressor-strain processes, an investigation of the weak or strong features of the work situation is imperative. Weak situations (i.e., those characterized by change or crisis) may make work goals and tasks more ambiguous; thus, "vague and ineffective organizational indicators force or push workers into disregarding certain stimuli in favor of others" (p. 24). By contrast, strong situations (i.e., organizational rules, leader instructions) can, "provide a guide for the employee regarding expected behaviors and 
attitudes" (p. 24). The author calls for researchers to, "gather information on workers' total environment before trying to gauge the various links in the stress-strain process" ( $p$. 29). Missing in much of the stressor-strain research, and with interpersonal conflict in particular, is an investigation of the conditions under which certain social interactions become stressful. Utilizing an appraisal framework, an understanding of the social conditions at work is necessary to better comprehend why some interactions are evaluated as being stressful. One such area of inquiry that is largely missing from the literature is the influence of leadership behaviors on employee perceptions of social stressors. In a meta-analysis of the predictors of workplace aggression, Herchovis et al. (2007), found poor leadership to be a strong predictor of supervisor- and coworkertargeted aggression and interpersonal conflict to be a strong predictor of both individual and organizationally-targeted aggression. In a study of customer incivility and wellbeing, Arnold and Walsh (2015) posited that leadership, specifically transformational leadership would, "have the potential to impact the primary appraisal process of employees. A leader who exhibits inspirational motivation may encourage employees to re-frame the experience of customer incivility, such that employees see dealing with incivility as contributing to a greater goal in line with a compelling vision" (p. 368). They found that employee perceptions of the manager's use of transformational leadership behaviors buffered the effects of the experience of customer incivility on wellbeing. Even under conditions of high customer incivility, those employees who reported having a more transformational leader also experienced higher levels of wellbeing. In order to further explore the role of leadership in the stressor-strain process, an overview of the relevant literature on transformational leadership is now provided. 
Transformational leadership: a brief overview. Research and practice in the field of leadership have identified the transformational leadership style as one of the most effective in motivating positive employee work outcomes (Bass, 1998; Bass \& Avolio, 1994). Bass (1998) originally identified a four-factor model of transformational leadership: inspirational motivation (i.e., providing meaning and challenge), idealized influence (i.e., charisma, being a role model), intellectual stimulation (i.e., stimulate innovation and creativity), and idealized consideration (i.e., paying attention to individual needs for achievement and growth). Later, Rafferty and Griffin (2004) identified a fivefactor model of transformational leadership: vision (i.e., the expression of idealized future based on organizational values), inspirational communication (i.e., us of appeals and emotional-laden statements to arouse followers' emotions and motivation), intellectual stimulation (i.e., behaviors that increase followers' interest in developing new solutions to problems), supportive leadership (i.e., showing respect and concern for followers' feelings and needs), and personal recognition (i.e., praise and acknowledgement of effort for achievement of specified goals).

According to Shamir et al. (1993), transformational leadership "transforms the needs, values, preferences, and aspirations of followers from self-interests to collected interests" (p. 577). However, few studies have investigated the role of transformational leadership in the stressor-strain process; instead, studies have focused on leadership and conflict management styles, along with its influence on group dynamics (e.g., Hütterman \& Boerner, 2011; Zhang, Cao, \& Tjsvold, 2011; Yang, 2014). If transformational leadership affects strains, it is most likely through stressors, vis-à-vis the stressor-strain process. 
Transformational leadership is thought to be effective because it tends to focus on employees' motivational systems. Implicating employee self-concepts will provide stronger commitment to the attainment of institutional goals. Shamir et al. (1993) argue that transformational leaders, therefore, motivate employees by targeting the motivational mechanisms that influence perceptions of self-consistency: increasing the intrinsic valence of effort, increasing expectancies of self-accomplishment, increasing the valence of goal accomplishment, instilling faith in a better future, and creating personal commitment. Moreover, transformational leadership requires two sets of behaviors: role modeling and frame alignment (Shamir et al., 1993). Transformational leaders are aware that they must model the behavior that they extoll in their employees. Frame alignment occurs when the leader makes attempts, typically through communicative action, to reorient employees' frames of reference and interpretive structures.

Bono and Judge (2003) found that transformational leadership influenced employees' feelings of self-concordance. While the relationship was heightened in lab studies, it was found, albeit on a smaller magnitude, in the field as well. When employees experience increased self-congruence, they also report more job satisfaction and are more willing to help out. In an experimental study with a military sample, Dvir, Eden, Avolio, and Shamir (2002) showed that commanders trained in transformational leadership had soldiers who exhibited greater gains in self-efficacy and extra effort. They also outperformed the control group in various areas of military performance. This replicates the findings of Bycio, Hackett, and Allen (1995), who reported that transformational leadership was positively associated with employee extra effort and increased affective commitment. Piccolo and Colquitt (2006) report that transformational 
leadership can influence how employees see their job characteristics (e.g., variety, identity, significance, autonomy and feedback). They found that transformational leadership influenced occupational citizenship behaviors and task performance through its influence on job characteristics and intrinsic motivation. Liao and Chuang (2007), in a multi-level analysis of employees in the retail industry, found transformational leadership to be positively related to employee self-efficacy, affective commitment, and job satisfaction, at the individual-level. Store-level results showed that transformational leadership increased store-level positive service climate. That is, transformational leadership not only influences the individual but the work environment as well. Corroborating this, Menges, Walter, Vogel, and Bruch (2011) found that climate-level transformational leadership positively influenced overall employee productivity, aggregated task performance behavior, and aggregated organizational citizenship behavior, indirectly through other climate-level variables (i.e., positive affect and trust). Finally, Kessler et al. (2013) found transformational leadership reduced the experience of conflict. Additionally, Gelfand, Keller, Leslie, and de Dreu (2012) reported that leaders can influence the conflict culture of organizations and thus the employees' experience of interpersonal conflict.

Hypothesis 2a: Perceptions of transformational leadership will be negatively related to non-task organizational conflict.

\section{Transformational Leadership and Counterproductive Work Behaviors}

The transformational leadership literature has been limited in its understanding of employee destructive behavior, such as counterproductive work behaviors. Holtz and Harold (2013) investigated leader consideration and structure on perceptions of justice 
and reports of counterproductive work behaviors. They found, for employee-reported data, the highest levels of counterproductive work behaviors were exhibited when structure was highest and consideration was lowest. Additionally, they did not find evidence that justice perceptions moderated the leadership-CWB relationship. They proposed that leaders' behaviors may have an unfiltered barring on employees' behavior, "managers have the power to directly influence the occurrence of CWBs by engaging in appropriate leadership behavior" (Holtz \& Harold, 2013, p. 511). However, in questioning this direct relationship, Yao, Fan, and Guo, (2014) did not find transformational leadership to moderate the relationship between work stress and negative work behaviors. They concluded that, "transformational leadership cannot weaken the influence of stress on negative behavior" (Yao et al., 2014, p. 120). Albeit, the evidence from the transformational leadership literature suggests that increased perceptions of that leadership style produce positive effects on employees and organizations (e.g., Liao \& Chuang, 2007; Lim \& Polyhart, 2004).

A substantial amount of research has investigated a specific subset of transformational leader behavior. The leadership literature in this area has focused on the concept of ethical leadership. As defined by Brown, Treviño, and Harrison (2005), ethical leadership is related to transformational leadership in that, "the idealized influence dimension has been defined as having an ethical component.” (p. 118). Additionally, Brown and Treviño (2006) state other key similarities such that, "transformational leadership and ethical leadership overlap in their focus on personal characteristics. Ethical and transformational leaders care about others, act consistently with their moral principles (i.e., integrity), consider the ethical consequences of their decisions, and are 
ethical role models for others." (p. 599). In a recent meta-analysis of ethical leadership, $\mathrm{Ng}$ and Feldman (2015) found a corrected correlation of $\rho=-.34$ between perceptions of ethical leadership and self-reported CWBs.

Den Hartog and Belschak (2012) found evidence of moderated mediation for the effects of ethical leadership on employee reports of counterproductive work behaviors. Perceptions of leadership were indirectly related to counterproductive work behaviors through work engagement (i.e., higher levels of perceived ethical leadership increased work engagement which then reduced incidences of CWBs). However, the relationship between ethical leadership and work engagement was itself moderated by perceptions of the supervisors' use of Machiavellian tactics. The perception of Machiavellian tactics attenuated the ethical leadership-work engagement relationship, thus indirectly increasing

CWBs. As Brown et al. (2005) contend, the ethical dimension of leadership is a subset of the transformational leader. Therefore, it stands to reason that one might also expect to find similar relationships between bona fide transformational leadership and CWBs.

Hypothesis 2b: Perceptions of transformational leadership will be negatively related to reports of counterproductive work behaviors.

\section{Transformational Leadership within the Transactional Model of Stress}

As Shamir et al. (1993) have purported, transformational leadership is about motivation and activating the positive motivational mechanisms of employees. The transformational leader, through his/her actions, will help employees to reframe and reinterpret their work environment. Taking an appraisal perspective, it seems that transformational leadership behaviors should influence the transactional process of stress by influencing the ways in which employees' frame and interpret interactions, appraising 
and reappraising potentially stressful situations (Arnold \& Walsh, 2015). Lazarus (1991) contents that stressors will be appraised as threatening if the individual believes there to be goal-irrelevance, goal-incongruence, or a negative implication of the self.

Transformational leadership, as defined by Bass (1998) and Rafferty and Griffin (2004), should influence exactly these factors. The personal consideration dimension has direct implications for influencing employee views about stressors that may implicate their own sense of self. The dimensions of vision, inspirational communication, and idealized influence may affect the perception of goal relevance and congruity. In a study of Israeli kibbutz-collectivist communes - researchers found individuals' perceptions of having a transformational leader directly influenced their appraisal of community social changes (Ben-Zur, Yagil, \& Oz, 2005). They report that transformational leadership was positively associated with challenge appraisals and negatively associated with threat appraisals. Also, appraisal mediated the relationship between transformational leadership and coping, such that higher transformational leadership was associated with less threat appraisal, which in turn was associated with higher reports of problem-focused coping. In an experimental manipulation study, Lyons and Schneider (2009) varied the leadership conditions under which participants engaged in tasks of varying difficulty (i.e., mental arithmetic tasks) and found that those individuals in the transformational leader condition reported the lowest threat appraisals, as compared to all other conditions. They found individuals in the transformational leadership condition reported, "higher social support perceptions, greater efficacy perceptions, lower threat appraisals, and generally less of an increase in negative affect in response to a stressor" (p. 743). Transformational 
leadership has the potential to influence the stressor-strain process through its influence on the appraisal mechanisms of individuals.

In the field of occupational health psychology, few studies have attempted to identify the role of transformational leadership within the transactional stress process (e.g. Kessler et al., 2013). In their study of employee and coworker dyads, Kessler et al. (2013) found transformational leadership to be associated with decreased conflict with supervisors. Moreover, transformational leadership transmitted its effects onto counterproductive work behaviors indirectly through conflict with supervisor and negative emotions. They argue that transformational leadership may serve a social support function, creating a climate of mutual respect and trust. Yang (2014) found cooperative conflict management to be both a mediator and moderator of the relationship between transformational leadership and trust. The effects of transformational leadership were indirectly imparted via its influence on the use of cooperative conflict management. Additionally, the relationship between transformational leadership and trust was strongest when the use of cooperative conflict management was highest.

Hypothesis 2c: Perceptions of transformational leadership will have a negative indirect effect on counterproductive work behaviors through its influence on reports of non-task organizational conflict.

\section{Transformational Leadership Builds Trust in Leadership}

As some of the previously reviewed studies note, transformational leadership may be effective in reducing the appraisal of stressors through its influence on trust, in particular trust in the supervisor. In a meta-analysis on the role of trust in leadership, Dirks and Ferrin (2002) found trust in leadership to be related to a slew of workplace 
attitudes and behaviors (i.e., job satisfaction, commitment, and organizational citizenship behaviors). They found a lack of trust to be particularly problematic, such that "a low level of trust in the leader is likely to be psychologically distressing when the leader has power over important aspects of one's job, and this distress is likely to affect one's attitudes about the workplace" (p. 613). Additionally, Harvey, Kelloway, and DuncanLeiper (2003) found trust in management served as a buffer between overload and strains. They contended that, "(dis)trust in decision makers serves to modify the way recipients experience and thus interpret events" (p. 307). Their findings showed that low trust in management seemed to have deleterious consequences across the board with increased perceptions of strain, regardless of workload perception. Moreover, Kelloway, Turner, Barling and Laughlin (2012) found trust in leadership to mediate the relationship between transformational leadership and psychological well-being. They framed employee trust in leadership from a leader-member exchange perspective, "employee trust in leadership... reflects an aspect of the quality of the leader-employee relationship" (p. 42). At the individual level of perception, they found indirect effects of transformational leadership on employee reports of well-being through their trust in the leader, even after controlling for such factors as liking of the leader and individual differences in reactivity (i.e., neuroticism). These findings corroborated a previous study by Liu, Siu, and Shi (2010) using a sample drawn from the People's Republic of China. Liu et al. (2010) found evidence for the indirect effects of transformational leadership on perceived work stress and stress symptoms (i.e., physiological symptoms) via its influence on trust in the leaders. The effects of transformational leadership onto outcomes was given through its effects on increased trust in the leader. Trust, therefore, may be an important mechanism 
through which transformational leadership transmits its effects onto the stressor-strain process.

Numerous studies have considered the antecedent leadership behaviors that contribute to trust perceptions; however, none have done so within the stressor-strain paradigm (e.g., Podsakoff, MacKenzie, Moorman, \& Fetter, 1990; Jung \& Avolio, 2000). In one of the first studies to propose that transformational leadership indirectly influenced extra-role behavior, Podsakoff et al. (1990) attempted to define the specific mechanisms that lead to increased trust in the leader. They found that core transformational behaviors, such as individualized support, accounted for the most variance in trust. Their findings showed that, at both the individual and aggregate level, trust served as a mediator between transformational leadership and reports of organizational citizenship behaviors. An experimental study by Jung and Avolio (2000) found that participants who were placed in the group with a transformational leader showed improved performance in terms of quality. The effects of the condition were mediated by trust and value congruence. Similarly, Gillespie and Mann (2004) found transformational leadership to be positively associated with team member trust in the leader. Specifically, idealized influence was one of the strongest predictors of trust. Idealized influence relates to the leader's ability to provide a clear and motivating vision (Bass, 1998).

While there is a clear relationship between transformational leadership and trust in the leader, the exact mechanisms by which this relationship functions are still vague. In attempting to understand the conditions that lead to appraisals of stress, an expansion of the perceptual paradigm is needed. As stated by Shamir et al. (1993), transformational leaders can influence the frame alignment of followers. Employees may be more inclined 
to listen to transformational leaders because these leaders instill trust. This trust in the leader may, therefore, be a crucial ingredient when employees appraise potentially stressful events. As Harvey, et al. (2003) point out, trust, or the lack thereof, can influence employees' interpretations of events.

As previously noted, transformational leaders can influence the perceptual repertoire of their employees through motivating appeals (Shamir et al., 1993), and this can serve to increase employees' sense of trust (Padsackoff et al., 1990). If, as Harvey et al. (2003) propose, trust in leader influences employees' interpretation of events, then it stands to reason that employee appraisals of social stressors (i.e., interpersonal conflict) may be influenced by their exposure to working under a transformational leader. That is, transformational leadership will indirectly reduce perceptions of interpersonal conflict (i.e., non-task organizational conflict) through its effects on increasing employees' trust in the leader. There is some evidence to support this, though the research in this area is scant. Mulki, Jaramillo, and Locander (2008) found that, within the context of an ethical climate, increased trust in leadership lead to reduced reports of interpersonal conflict. In a different conceptual vein, Kacmar, Bachrach, Harris, and Noble (2011) investigated the potential moderating effects of supervisor trust on employee relationship conflict and organizational citizenship behaviors. They found exacerbating effects of low trust in supervisor as the relationship between conflict and organizational citizenship behaviors was heightened under conditions of low supervisor trust.

Hypothesis 3a: Perceptions of transformational leadership will be positively related with perceptions of trust in leadership. 
Hypothesis $3 b$ : Perceptions of trust in leadership will be negatively related to reports of non-task organizational conflict.

Hypothesis 3c: Perceptions of transformational leadership will have a negative indirect effect on non-task organizational conflict through its influence on trust in leadership.

Hypothesis 3d: Perceptions of trust in leadership will be negatively related to reports of counterproductive work behaviors.

Hypothesis 3e: Perceptions of transformational leadership will have a negative indirect effect on counterproductive work behaviors through its influence on trust in leadership.

\section{Transformational Leadership Influences Perceptions of Organizational Climate}

An underappreciated area of inquiry in stressor-strain processes is the role of organizational climate. While a full exploration of organizational climate research is beyond the scope of this dissertation, it is worth considering the possible mechanisms that may influence employee perceptions of stressors. While the history of climate research has been somewhat muddled in its differentiation from organizational culture (Denison, 1996), an emerging body of evidence points to climate's role in effecting employee perceptions (Ehrhart, Schneider, \& Macey, 2014). Specifically, theory and research point to the ameliorating effects positive leadership behavior may have on climate (Day, Griffin, \& Louw, 2014).

According to Ashford (1985), organizational climate is, "the shared and enduring molar perception of the psychologically important aspects of the work environment" ( $p$. 837). It is the meaning-making process of our everyday work events (Schneider \& 
Reichers, 1983). In this vein, the symbolic interactionist approach has been consistently invoked to explain the process by which climate is created. Symbolic interactionism states that humans create meaning out of the interactions we have with symbols. That is to say, meaning does not reside in things or people; rather, meaning is created when we interact with each other symbolically (through language, for example). Meaning, therefore, is a feature of the interaction. Climate represents the collective meaning that employees develop; it emerges from employee interactions with each other and the organization (Schneider \& Reichers, 1983). Furthermore, Ashford (1985) argues, "if meaning arises not out of things, but out of the interaction of people attempting to understand those things, then one must regard the 'episode' as the 'cause' of climate" (p. 838). The work day is full of these "episodes," these bounded interactions. Whether a formal, regularly scheduled meeting or a chance encounter at the coffee line, the work place is replete with events, practices, and encounters of related sets of events. Ehrhart et al. (2014) offer an additional perspective on climate stating that it captures the meaning employees infer from the policies, procedures, and practices of the organization. They contend that climate emerges through various organizational mechanisms (i.e., leadership), and the employees' interactions with the organization and its symbolic representatives. Moreover, Day et al. (2014), argue that leaders' actions in terms of the policies, practices, and expectations that they enact (or do not), and the attributions followers make about a leaders' beliefs and values, are vitally important for workplace climate.

The effect of leadership on climate is nothing new. One of the earliest studies by Lewin, Lippit, and White (1939) hinted at the influence various leadership styles had on 
climate. More recently, a growing body of evidence suggests that leadership is an antecedent to climate (Day et al., 2014). That is, leader behavior may help to shape climate perceptions (Kozlowski \& Doherty, 1989). While symbolic interactionism has been invoked as a theoretical explanation for the emergence of climate and the influence of leadership on said climate, climate as a mediator of employee outcomes has only recently received attention. In a recent review of the current state of climate research, Ehrhart, et al. (2014) proffers that, "policies and practices in organizations create process climates," that is, the mechanisms through which climate will emerge (p. 88). They argue that these process climates (e.g., justice, communication) "are the mediators in producing important organizational outcomes" (p. 88). The empirical evidence seems to support this claim. In an early study integrating climate and vertical-dyadic leadership, Kozlowski and Doherty (1989) found that employees who had better quality relationships with their leaders (i.e., in-group) reported a more positive organizational climate. In addition, climate perceptions of in-group members and leaders tended to converge more so than leaders and out-group members. The authors' findings suggest that, “...the leader may serve to mediate or filter the link between organizational features, events, and processes and subordinates' perceptions of the context" (p. 551). In another study of leadership-exchange relationships, Scott and Bruce (1994) found that those employees who reported having quality relationships with their leaders were more likely to perceive the organization as having a climate that supported innovation. They found that the relationship between the quality of leader-subordinate relations and employee innovative behaviors was mediated by the perceived climate for innovation. 
Likewise, other studies have found similar results with climates for innovation under transformational leaders (e.g., Eisenbeiss, Knippenberg, \& Boerner, 2008; Tafvelin, Armelius, \& Westerber, 2011). These studies have pointed to the role of transformational leaders in, "creating a climate where employees are encouraged to make improvements and to take initiative" (Tafvelin et al., 2011, p. 486). As previously stated in this literature review, transformational leaders are effective because they target and actively shape employee needs, values, and preferences (Shamir et al., 1993). In addition to climates for innovation, research findings have supported the transformational leaderclimate for safety relationship. Barling, Loughlin, and Kelloway (2002) found support for a full mediation of transformational leadership on safety outcomes, through its influence on safety climate. Transformational leaders increased employee perceptions of a climate for safety that, in turn, increased employee safety behaviors. In a more recent study, Smith, Eldrige, and DeJoy (2016) found, in a sample of firefighters, that specific safety-related transformational leader behaviors increased perceptions of safety climate, which in turn increased safety compliance and participation. They also found the opposite to be true for those who perceived leaders engaging in a more passive leadership style. They report that a passive leadership style lowered perceptions of safety climate, thus decreasing safety compliance and participation. The authors state that what makes transformational leadership so effective is the specific leader behaviors, "firefighters appreciate leaders that model safety behaviors, emphasize safety over risk taking, lead by example, effectively communicate safety expectations, exhibit concern for their wellbeing and safety and consider their needs at work" (p. 96). Dragoni (2005) offers a conceptual framework for understanding the specific ways leadership will influence 
climate. She focuses on the relationship between leadership and goal orientation, making the argument that when leaders behave in a consistent manner (i.e., an achievement pattern orientation), subordinate attention is directed to "the leader's preferred achievement priority, thereby encouraging the formation of individual climate perceptions that embody this priority" (p. 1086). She argues that the leader, through role modeling, continual guidance, and reinforcement, creates a climate that "signals the desired, emphasized, and expected achievement orientation and motivates individuals to adopt the ascribed achievement goal by clarifying behavior-outcome contingencies and the values approach to securing rewards" (p. 1087). Supporting this notion, in a study on transformational leadership during an acquisition, Nemanich and Keller (2007) found the relationship between transformational leadership behaviors and acceptance of the acquisition to be fully mediated by a climate for supporting new ways of thinking. Moreover, they report transformational leadership may indirectly influence job satisfaction by, "creating a climate of goal clarity and by creating a climate receptive to new ideas" (p. 64). Furthermore, they claim that their findings demonstrate that during moments of great uncertainty, such as an acquisition, the inspirational and motivational traits of transformational leaders facilitated employees' reframing of the "episode". This seems to be in line with Ashford's (1985) theorizing, when he stated that, "in the absence of social interaction, employees are apt to develop rather idiosyncratic perceptions of climate" (p. 844). Transformational leaders provided the necessary social interaction and reframing of a changing context through their creation of a climate for the receptivity of new ideas and goal clarity. Finally, Zohar and Tenne-Gazit (2008) argue that transformational leaders assist in ameliorating problems that arise from the incongruities 
between the formal policies of organizations and their enacted practices. They claim that, “...because enacted practices often diverge from formal policies, such priorities are frequently deduced by attending to situations presenting competing operational demands in which it is possible to identify true priorities" (p. 745). Thus, as was previously stated, transformational leaders provide consistency and guidelines for behavior in the face of uncertainty.

Facet-specific versus molar climate. In presenting the literature on leadership and climate, I have avoided the matter of facet-specific versus molar climates. I will briefly address the issue and provide my reasoning for conceptualizing climate via a facet-specific paradigm. It is well known in the field of industrial-organizational psychology that for theoretical, empirical, and practical value, predictors and criteria must be aligned; that is, specific predictor to specific criterion (Cascio \& Aguinis, 2011). Unfortunately, research in the climate field has been characterized by a muddled distinction between generic organizational climate and climate-specific for something (Ehrhart et al., 2014). Schneider (1975) was one of the earliest proponents of a facetspecific climate. He argued that, “...dimensions of practices and procedures will probably be differentially relevant depending upon the purpose of the study. This suggests that omnibus climate measures should not be indiscriminately used in hope of 'finding something"' (p. 471). He proposed that the type of climate to be investigated will depend on the aims of the research study. Moreover, Schneider and Reicher (1983) stated that because of the numerous "episodes" encountered in daily work activity, there is a potential for myriad climates to exist. Therefore, they argue, it is best to conceptualize climate in terms of something (e.g., safety, justice, communication). 
Empirical findings tend to support this line of thinking. When climate was specific, for example a climate for safety, fully mediated effects were discovered (e.g., Smith et al., 2016 and Barling et al., 2002). Ehrhart et al. (2014) goes so far as to state, "the focused climate approach has become the dominant approach to studying climate in the organizational sciences” (p. 97). They claim that facet-specific climates may unearth a better understanding of how organizational processes relate to specific desired outcomes.

Facet-specific climate: communication climate. The etiology of climate is said to be human interaction (Ashford, 1985; Schneider \& Reichers, 1983). That is, humans interacting with each other and the organization create the meaning that is then assigned to workplace events. According to Schneider and Reichers (1983), “...the symbolic interactionist approach maintains that people in communicative interaction with each other, respond to, define, and interpret elements of the situation in particular ways" ( $\mathrm{p}$. 33). If climate emerges from interactions, and those interactions are communicative in nature, then an understanding of the communication climate may be in order. Recall that the purpose of this dissertation is to expand the conceptual framework from which the stressor-strain process is understood. I have argued that a transactional model of stress proposes that employee reactions to workplace stressors begin with their appraisal of the stressor (Lazaurs, 1991). I have also established how transformational leaders utilize role modeling and frame alignment to influence employees' frame of reference (Shamir et al., 1993). Therefore, what is left to understand is how all these behaviors collectively influence the interpretive structures of employees. I argue that it is most likely through the creation of a supportive communication climate. 
Unfortunately, theory and research into the construct of communication climate is limited, at best, and ill-defined, at worst. Few scholars have attempted to make a theoretically rigorous paradigm of communication climate. Communication is a term with multiple meanings. Communication at work, in specific, can refer to a variety of activities and interactions, both formal and informal. Communication climate has been construed as the degree of open communication with one's superior (Rogers, 1987; Rapert \& Wren, 1998), reliability of information and upward communication (Guzley, 1992), and quality of information (Albrecht \& Travaglione, 2003; McMillan \& Albrecht, 2010). Dennis (1974) was one of the first to develop and test a measure of communication climate. Dennis' initial work seemed promising, he identified a fivefactor model of communication climate that included communication supportiveness (especially from the supervisor), receiving reliable and necessary organizational information, supervisor perceptions of subordinate communication, upward communication opportunities, and reliability of information from subordinates. Unfortunately, researchers have not been consistent in their use of Dennis' measure. For example, some studies adopted aspects of the Dennis measure but only a handful of items (see Bartels, Pruyn, De Jong, Joustra, 2007). Aside from not showing replicability of factor structure, the Dennis measure, and those similar to it, also suffers from a lack of conceptual rigor. The concept of communication climate has been confounded with satisfaction (see Pincus, 1983) and little thought has been given to connecting it with the broader line of thinking on climate that I previously reviewed. Be that as it may, I believe there is some promise yet to the utility of this concept. 
Another conceptualization of communication climate has focused on its supportive and defensive aspects (Gibb, 1961). This conceptualization proposes that defensive behavior, that is the reaction to a threat or perceived threat, will produce defensive communication acts (e.g., not listening). According to Gibb (1961), "as a person becomes more and more defensive, [they] become less and less able to perceive accurately the motives, the values, and the emotions of the sender" (p. 142). By contrast, supportive communication climates will reduce defenses and "the receivers become better able to concentrate upon the structure, the content, and the cognitive meanings of the message" (p. 142). Gibb goes on to proffer six pairs of defensive and supportive categories, based on years of interviews in varied settings: evaluation v. description, control v. problem orientation, strategy v. spontaneity, neutrality v. empathy, superiority v. equality, and certainty v. provisionalism. While Gibb did not offer any instruments to test his theory, Costigan and Schmeidler (1984) did develop a measure, based on the six pairs of categories. The Communication Climate Inventory (CCI) was developed with the purpose for use with practitioners in the field, to provide a quick and easy assessment of the communication climate (Costigan \& Schmeidler, 1984). Various studies have employed the CCI, for example Larsen and Folgero (1993) used it in a hospitality industry sample and found differences between employees who served on the cruise ships and those who worked on land in the administrative offices. All departments within the cruise ships reported more defensiveness while employees in the administrative offices reported the highest levels of supportiveness. They attribute these differences to differences in the working conditions and structures of both units. In a dissertation study looking at communication climate and conflict management, Scarpero (1999) found that, 
“...when individuals reported more supportiveness...there was also a greater interpersonal and organizational effort to manage communication and conflict processes strategically" (p. 119). Finally, the only study to submit the CCI to factor analysis was by Forward, Czech, and Lee (2011). In their study of the factor structure of the CCI, they were unable to reproduce the original six pairs of defensive-supportive categories. However, the factor structure did support a four-factor model comprised of collaboration, authoritarianism, descriptive orientation, and manipulation. These four factors seem to separate into clear supportive and defensive dimensions (i.e., supportive being collaboration and descriptive orientation; defensive being authoritarianism and manipulation).

Despite the paucity of research in communication climate, I believe the construct has yet untapped potential. Gibb's (1961) conceptualization of communication climate as being supportive and defensive provides an intuitive and parsimonious way of approaching a multidimensional construct like communication. Forward et al.'s (2011) factor analysis does provide some empirical grounding from which to use a more soundly developed instrument. I would proffer that climate for communication should focus on the practices of communication acts with others in a work setting and that it involves the appraisal of the expectations and norms related to engaging in conversation and the appropriateness of certain topics of conversation, either with co-workers or with supervisors. This is different from other forms of organizational communication that have focused more on its formal and informal qualities (see Rodriguez \& Bruk-Lee, 2016a). In this sense, communication climate is not necessarily the quality and quantity of communication, nor is it the flow of information, or the employee's ability to access 
organizationally relevant information. Communication climate instead reflects the expectations employees have for interacting with others in communicative acts. Given the description provided by Gibb (1961) of supportive and defensive communication climates, based on appraisal theory, it would stand to reason that supportive climates would reduce threat appraisals and thus decrease both non-task organizational conflict and counterproductive work behaviors. Conversely, defensive climates may be threatening and thus increase non-task organizational conflict and counterproductive work behaviors.

Hypothesis 4a: Perceptions of a supportive communication climate will be negatively related to reports of non-task organizational conflict.

Hypothesis 4b: Perceptions of a supportive communication climate will be negatively related to reports of counterproductive work behaviors.

Hypothesis 4c: Perceptions of a defensive communication climate will be positively related to reports of non-task organizational conflict.

Hypothesis $4 d$ : Perceptions of a defensive communication climate will be positively related to reports of counterproductive work behaviors.

\section{Linking Communication Climate to Leadership and the Stressor-Strain Process}

Of the limited studies using the communication climate construct, none have looked at the role of leadership and perceptions of stressors. Most have looked at traditional organizational outcomes (e.g., organization identification, Bartels et al., 2007; productivity, Rapert \& Wren, 1998; organizational commitment, Guzley, 1992). Other studies, however, have pointed to the positive effects of employing supportive communication strategies. Newton and Burgoon (1990) investigated the use of verbal 
influence strategies. In an observational study of dyadic interactions, they found that, “...prosocial strategies are preferred [when in a disagreement] and that positive results accrue when [prosocial strategies] are used" (p. 502). They also noted that, "defensive behavior, although uncommon during [the] disagreements [in this study], [were] likely when either partner was accused" (p. 504). Specific verbal tactics then can influence a person's reaction and elicit a defensive response. Winer and Majors (1981) in an attempt to understand the particulars of defensive and supportive communication conducted an experimental study in which they manipulated the use of provisional versus certainty verbs along with the ownership of a statement. Provisional verbs, "point out the probabilistic nature of a statement by qualifying the degree of rightness or wrongness in a statement" (p. 168). For example, seem, appear, and feel may produce more supportive perceptions than verbs of certainty such as, be, know, do. In addition, ownership can be implied in statements by differing the use of literal versus implied subjects. Results showed that in a positive feedback condition, certainty verbs created the most supportive reactions. In a negative feedback condition, provisional verbs created more supportive responses. In addition, literal subject statements, "I-You," in which neither subject is obfuscated, were seen as more supportive in both positive and negative feedback conditions. While neither of the aforementioned studies measure communication climate per se, it is clear that certain communication acts will engender more supportive versus defensive responses in a communicative interaction. Transformational leaders may employ such verbal tactics to influence the perception of the communication climate so as to increase perceptions of supportiveness and reduce defensiveness. If transformational leaders can influence the interpretive structures of employees, then it 
may be through their influence in mitigating defensive behavior. Gibb (1961) originally speculated that, "distortions become greater when defensive states exist..." (p. 142). Therefore, if transformational leadership can reduce defensive communication climates and increase supportive ones, then it is through this mechanism that perceptions of interpersonal conflict may be altered.

Ashford and Lee (1990) point out possible organizational (e.g., threat, ambiguity, and powerlessness) and individual (e.g., emotional exhaustion) antecedents to defensive behavior. In addition, they point to the role of the institution in the creation of defensive behaviors, "the institutionalization of defensive routines generates predictable long-run effects, including rigidity and stagnation, 'red tape,' insularity or detachment from the environment, politicization of the organization, a climate of distrust, and low morale" ( $p$. 642). Recall that non-task organizational conflict is rooted in the perception that employees are in disputes due to factors out of their control, at the organizational level. Therefore, it would seem that transformational leadership, communication climate, and perceptions of conflict (as is the focus of this dissertation) are interconnected. That is, to better understand why employees perceive conflict as a stressor, we need to understand the mechanisms that may lead to particular types of appraisals. Transformational leaders would influence the perception and appraisal of stressor through their influence on the communication climate. Specifically, their choice of particular leadership behaviors and communicative acts would increase the sense of a supportive communication climate (characterized by collaboration and a descriptive orientation) and reduce the sense of a defensive communication climate (characterized by authoritarianism and manipulation). By actively molding the appraisal of the communication climate, transformational leaders 
will then influence the stressor-strain process by indirectly altering appraisal of stressors and subsequent reactions.

Hypothesis 5a: Perceptions of transformational leadership will be positively related with perceptions of a supportive communication climate.

Hypothesis 5b: Transformational leadership will have a negative indirect effect on non-task organizational conflict through its influence on a supportive communication climate.

Hypothesis 5c: Transformational leadership will have a negative indirect effect on counterproductive work behaviors through its influence on a supportive communication climate.

Hypothesis 5d: Perceptions of transformational leadership will be negatively related with perceptions of a defensive communication climate.

Hypothesis 5e: Transformational leadership will have a negative indirect effect on non-task organizational conflict through its influence on a defensive communication climate.

Hypothesis 5f: Transformational leadership will have a negative indirect effect on counterproductive work behaviors through its influence on a defensive communication climate.

\section{The Full Picture: Influencing Employees' Appraisals}

Transformational leadership will provide the environmental conditions for more positive appraisals of stressors. Through its influence on trust in the leader and communication climate, transformational leadership will influence primary mechanisms of appraisal of interpersonal conflict. Leadership will set the stage from which the 
stressor-strain process will playout. Employee perceptions of transformational leadership will have an indirect effect on their experiences of strain through the influence these leaders will have in shaping the employees' frames of references. Appraisals of stressors, specifically conflict, will be influenced by employees' trust in their leader. Additionally, transformational leaders can influence appraisals by influencing the perceptions of the two dimensions of communication climate separately, increasing the perception of a supportive communication climate or diminishing the perceptions of a defensive communication climate. Transformational leadership indirectly effects counterproductive work behaviors through its influence on the appraisal processes of trust and communication climate.

Hypothesis 6a: Transformational leadership will have a negative indirect effect on counterproductive work behavior through its joint influence on trust in leadership and on non-task organizational conflict.

Hypothesis 6b: Transformational leadership will have a negative indirect effect on counterproductive work behavior through its joint influence on a supportive communication climate and on non-task organizational conflict.

Hypothesis 6c: Transformational leadership will have a negative indirect effect on counterproductive work behavior through its joint influence on a defensive communication climate and on non-task organizational conflict. 


\section{METHOD}

This chapter will provide a detailed description of the dissertation methodology, study design, and measures.

\section{Participants}

Utilizing a sample of convenience, snowball sampling, participants were recruited through professional contacts, social media outreach, and email forwards. Emails and social media posts described the study as an investigation into the influences on employee perceptions of stress and their subsequent reactions. The message provided an anonymous link to the survey instrument. Participants were encouraged to forward it to others.

Inclusion/exclusion criteria. Criteria for inclusion were for participants to work at least part time (i.e., no fewer than 20 hours per week) and to be at least 18 years of age or older.

\section{Study Design}

Method of data collection. Surveys were administered using the online survey software, Qualtrics. Primary recruitment came from individuals who work in the administration of FIU and other institutions of higher education. To minimize the effects of potential biases that might be present in cross-sectional design, two waves of data collection were obtained; both waves included all measures. There was a three- to fourweek time interval between the two-time points of data collection. While there is no established criterion for time intervals in designs used to minimize the effects of common source bias, Podsakoff, MacKenzie, Lee, and Podsakoff (2003) strongly recommend separating the collection of predictor and criterion. A three- to four-week time frame 
should have provided sufficient psychological separation from the first wave of data collection, thus reducing potential sources of bias (e.g., common rater effects). Follow up emails were sent to participants from time $1\left(\mathrm{~T}_{1}\right)$ who provided an email, approximately three to four weeks after completion of the first survey. Submitted responses were screened for attention-item response and amount of completion. Only cases that met the following criteria were included for further analysis: obtaining four out of five correct attention items and having completed at least $50 \%$ of the survey.

Compensation. As an incentive to participate, a five-dollar Starbucks gift card was sent to all survey completers at both time points of data collection, for a total compensation of $\$ 10$. Participants received their e-gift cards via the email provided during both points of data collection.

\section{Demographic Information}

T1 participant characteristics and sample size. Of the 286 opened survey responses for $\mathrm{T}_{1}$, an initial 203 (or $71 \%$ ) usable responses were submitted. The other $29 \%$ were surveys that were started but never finished. In addition, surveys with a completion rate below $50 \%$ were not considered for analysis. Further data screening for attention-item response and completeness of the survey instrument left 199 usable cases (or $69.6 \%$ ) of the $\mathrm{T}_{1}$ sample. Participant characteristics ranged as follows: mean age of 39 years ranging from 21-69 years old; $67 \%$ have been in their current position for five years or fewer; $59 \%$ have been with the organization for five years or more; $36 \%$ report being in a mid-level administration position with some supervisory responsibilities; over $75 \%$ were female; over $52 \%$ reported belonging to a minority ethnic group (37\% indicated Latino/Hispanic-American; 9\% Black/African American; 7\% Other); over 65\% work at 
institutions of higher education; 64\% reported a graduate degree or equivalent as being their highest educational attainment.

$\mathbf{T}_{2}$ participant characteristics and sample size. Approximately three to four weeks after $\mathrm{T}_{1}$ completion, participants who provided an email address $(\mathrm{N}=167)$ were contacted to participate in time $2\left(\mathrm{~T}_{2}\right)$. Of these, 143 (or 86\%) survey responses were submitted. Further data screening for attention-item response and completeness of the survey instrument left $\mathrm{N}=129$ usable cases (or 77\%) for the $\mathrm{T}_{2}$ sample. Participant characteristics ranged as follows: mean age of 38 years ranging from 21-68 years old; $72 \%$ have been in their current position for five years or fewer; $55 \%$ have been with the organization for five years or more; $37 \%$ report being in a mid-level administration position with some supervisory responsibilities; over $78 \%$ were female; over $46 \%$ reported belonging to a minority ethnic group (31\% indicated Latino/Hispanic-American; 8\% Black/African American; 7\% Other); over 65\% work at institutions of higher education; $66 \%$ reported a graduate degree or equivalent as being their highest educational attainment.

Combined $T_{1}$ and $T_{2}$ participant characteristics and sample size. A third data file was created that combined responses from $\mathrm{T}_{1}$ with $\mathrm{T}_{2}$. Email was the only personally identifying information requested and was used to match cases between the two-time points. Of the 129 usable cases from $\mathrm{T}_{2}$, six cases did not have an exact match corresponding email in $\mathrm{T}_{1}$ and thus were not retained. Screening for attention-item responses and completeness of survey were already completed during the separate inspection of the $\mathrm{T}_{1}$ and $\mathrm{T}_{2}$ data, thus no additional cases were removed, leading to a final sample size of $\mathrm{N}=123$. Participant characteristics ranged as follows: mean age of 38 
years ranging from 21-67 years old; $78 \%$ have been in their current position for five years or fewer; $55 \%$ have been with the organization for five years or more; $37 \%$ report being in a mid-level administration position with some supervisory responsibilities; over $78 \%$ were female; over $46 \%$ reported belonging to a minority ethnic group (31\% indicated Latino/Hispanic-American; 8\% Black/African American; 7\% Other); over 65\% work at institutions of higher education; $66 \%$ reported a graduate degree or equivalent as being their highest educational attainment.

Attrition analyses. No major differences were found between those who participated in $\mathrm{T}_{1}$ but did not follow up with $\mathrm{T}_{2}$, save for one demographic variable (see Table 1). Those who did not participate in $\mathrm{T}_{2}$ were more likely to be in a higher-level administrative position (middle/senior administration vs. clerical) than those who completed both waves.

Table 1

Comparisons between Full Participants and $T_{1}$ Only Participants

\begin{tabular}{|c|c|c|c|c|c|c|}
\hline \multirow[b]{2}{*}{ Variables } & \multicolumn{2}{|c|}{ Full Participants } & \multicolumn{2}{|c|}{$\underline{T}_{1}$ Only } & \multirow[b]{2}{*}{$t$} & \multirow[b]{2}{*}{$p$} \\
\hline & $M$ & $S D$ & $M$ & $S D$ & & \\
\hline Transformational Leadership & 3.95 & .85 & 3.81 & .82 & -.57 & .571 \\
\hline Trust in Leadership & 3.95 & .85 & 4.02 & .81 & -.56 & .574 \\
\hline Supportive Communication Climate & 3.71 & .66 & 3.73 & .53 & -.30 & .766 \\
\hline Defensive Communication Climate & 2.78 & .86 & 2.88 & .82 & -.81 & .417 \\
\hline Non-Task Organizational Conflict & .77 & .71 & .80 & .86 & -.33 & .741 \\
\hline Interpersonal Locus of Control & 3.76 & .49 & 3.63 & .50 & 1.85 & .066 \\
\hline Counterproductive Work Behaviors & .53 & .37 & .50 & .43 & .62 & .535 \\
\hline Age & 37.74 & 11.03 & 40.68 & 12.27 & -1.67 & .096 \\
\hline Years at current job & 2.38 & 1.45 & 2.85 & 1.83 & -1.84 & .068 \\
\hline Total years worked & 5.02 & 1.77 & 5.35 & 1.70 & -1.22 & .224 \\
\hline
\end{tabular}


Total years at organization

Educational attainment

$5.35 \quad 1.01$

5.23

1.10

.78

.434

Note. Job level ranges from 1 = clerical staff, 2 = entry-level admin, 3 = mid-level admin, $4=$ senior-level admin, $5=$ professional $* p<.05$.

\section{Measures}

All measures were submitted to confirmatory factor analysis using both time points from the full panel of data (i.e., two sets of analyses). Goodness of model fit was evaluated using the rule of thumb discussed by Kline (2011).

Transformational leadership. Rafferty and Griffin's (2004) 15-item scale was used to measure transformational leadership. The measure is composed of five-subscales but can be used as a global measure of transformational leadership by taking the average of all the responses. All items are positively worded, save for one that required reverse coding; higher scores indicate higher levels of perceived transformational leadership. The average of all the responses was used as the global measure of transformational leadership. The following are examples of items from each of the subscales; respondents were asked to think about their immediate supervisor when completing an item. Vision (three-items; one reversed): has a clear understanding of where we are going; Inspirational Communication (three-items): says positive things about the work unit; Intellectual Stimulation (three-items): challenges me to think about old problems in new ways; Supportive Leadership (three-items): considers my personal feelings before acting; Personal Recognition (three-items): commends me when I do a better than average job. 
All items were answered on a five-point Likert scale of agreement. Previous studies have shown satisfactory internal consistency ( $\alpha=.95$; Syrek, Apostel, \& Antoni, 2013). CFA and reliability for transformational leadership. To verify the factor structure of the measure, a higher-order confirmatory factor analysis was run using AMOS 21 software. Table 2 below shows the model fit indices, after making modifications to allow for within factors covariation of error terms. Model fit indices indicate acceptable model fit (Kline, 2011) and replicated the five-factor model reported by Rafferty and Griffin (2004) for both time points of data. In this sample, reliabilities for the measure were $\alpha=.95$ for Time 1 and $\alpha=.94$ for Time 2 .

Table 2

Confirmatory Factor Analysis: Transformational Leadership

\begin{tabular}{lllllll}
\hline Model & $\chi^{2}$ & TLI & CFI & RMSEA & PCLOSE & SRMR \\
\hline Time 1 & 122.18 & .97 & .97 & .06 & .19 & .05 \\
Time 2 & 134.40 & .95 & .96 & .07 & .05 & .06 \\
\hline
\end{tabular}

Trust in leadership. Mayer and Davis's (1999) 17-item scale was used to measure trust in leadership. As with the measure of transformational leadership, participants were asked to think about their immediate supervisor when responding to the items in this measure. Mayer et al. (1995) define trust as, "the willingness of a party to be vulnerable to the actions of another party based on the expectation that the other will perform a particular action important to the trustor, irrespective of the ability to monitor or control that other party" (p. 712). Mayer and Davis (1999) contend that when trust is thusly defined, the interaction between persons becomes one of a, "willingness to engage in risk-taking behavior" (p. 124). The measure is composed of three-subscales but can be used as a global measure of trust in leadership by taking the average of all the 
responses. While most of the items are positively worded (i.e., higher scores indicate more trust), there are a few negatively worded items that required reverse coding. The following are examples of items from each of the subscales; respondents were asked to think about their immediate supervisor when endorsing an item. Ability (six-items): $m y$ supervisor is well qualified; Benevolence (five-items): my supervisor will go out of his/her way to help me; Integrity (six-items): I like my supervisor's values. Previous studies have shown satisfactory levels of internal consistency (full measure $\alpha=.95$; Clayton, 2013). All items were answered on a five-point Likert scale of agreement with higher scores indicating greater trust in leadership.

CFA and reliability for trust in leadership. To verify the factor structure of the measure, a higher-order confirmatory factor analysis was run. Table 3 below shows the model fit indices, after making modifications to allow for within factors covariation of error terms. Model fit indices indicate good model fit and replicated the three-factor model reported by Mayer and Davis (1999) for both time points of data. In my sample, reliabilities for the measure were $\alpha=.96$ for Time 1 and $\alpha=.96$ for Time 2 .

Table 3

Confirmatory Factor Analysis: Trust in Leadership

\begin{tabular}{lllllll}
\hline Model & $\chi^{2}$ & TLI & CFI & RMSEA & PCLOSE & SRMR \\
\hline Time 1 & 164.66 & .97 & .98 & .06 & .181 & .04 \\
Time 2 & 150.62 & .98 & .98 & .05 & .445 & .04 \\
\hline
\end{tabular}

Communication Climate. Costigan and Scheilder's (1984) 36-item inventory measured perceptions of the communication climate. Participants were asked to think in general terms about how employees in their unit interact with each other, making the referent of all items their perception of the unit rather than themselves. The original 
inventory was created using Gibb's (1961) conceptualization of supportive and defensive communication climates. An example item of supportive communication is, employees can express their ideas honestly and openly with others. An example item of defensive communication is, employees in my unit are dogmatic, it's useless to voice an opposing point of view. All items were answered on a five-point Likert scale of agreement with higher scores indicating greater levels of the construct.

Instrumentation calibration: EFA and CFA. In their examination of Costigan and Schmeidler's (1984) Communication Climate Inventory (CCI), Forward et al. (2011) performed a principle component analysis (PCA) after not finding support for Gibb's (1961) hypothesized model. Gibb had originally proposed that defensive communication climates had six characteristics: evaluation, control, strategy, neutrality, superiority, and certainty. Furthermore, supportive communication climates also had six characteristics: description, problem-orientation, spontaneity, empathy, equality, and provisionalism. Costigan and Schmeidler developed items ostensibly measuring each of these dimension; however, the CCI was never put to psychometric analysis until Forward et al. Their PCA produced a four-factor model, to which they assigned the following labels: collaboration, authoritarianism, descriptive orientation, and manipulation. While no additional confirmatory studies on this measure have since been published, Forward et al. (2011) assert that the factors they discovered attest to the underlying dimensions of supportive and defensive communication. They argued that the factors of collaboration and descriptive orientation reflected Gibb's (1961) conceptualization of supportive communication climate, and the factors of authoritarianism and manipulation reflected Gibb's (1961) conceptualization of defensive communication climate. Because of the 
tentative nature of the CCI, it was submitted to a confirmatory factor analysis using Time 1 data from the full panel data set.

First, supportive communication climate was tested by creating a higher-order model in which collaborative and descriptive orientation were the first-order factors to a higher-order supportive communication climate. According to Forward et al., collaborative consisted of 19 items, while descriptive orientation consisted of only five items. Unfortunately, this produced a model that was unidentified. Next, collaboration and descriptive orientation were tested but with no common higher-order factor. After making modifications to allow for within factors covariation of error terms, the resulting model produced a poor fit $\left(\chi^{2}=381.3, \mathrm{df}=237 p<.000, \mathrm{TLI}=.90, \mathrm{CFI}=.91, \mathrm{RMSEA}=\right.$ .07$, PClose $=.007$, SRMR $=.07)$. Second, defensive communication climate was tested by creating a higher-order model in which authoritarianism and manipulation were the first-order factors to a higher-order defensive communication climate. According to Forward et al., authoritarianism consisted of eight items, while manipulation consisted of three items. Unfortunately, much like the supportive communication model, an unidentified model was produced. Next, authoritarianism and manipulation were tested but with no common higher-order factor. This produced a model with negative variance suggesting the possibility of a Heywood case (Brown, 2006).

After failing to produce any adequate models, the CCI was submitted to an exploratory factor analysis. Principle Axis Factoring extraction was used along with Varimax rotation that produced a five-factor model. The Kaiser-Meyer-Olkin measure verified the sampling adequacy for the analysis, $\mathrm{KMO}=.90$. Bartlett's test of sphericity $\chi^{2}(595)=2700.62, p<.000$, indicated that correlations between items were sufficiently 
large for EFA. Five factors had eigenvalues over Kaiser's criterion of 1 and in combination explained $61.9 \%$ of the variance. Inspection of the rotated factor matrix revealed some distinct patterns. Only factor scores larger than .5 were considered (Fields, 2009). Of the four factors reported by Forward et al. (2011), authoritarianism and descriptive orientation held (minus one item from descriptive orientation); however, the collaborative factor split into three. In addition, there was no support for manipulation as the factor loadings were all well below the .5 threshold (Fields, 2009). Therefore, the manipulation factor from Froward et al. (2011) was dropped from all further analysis. See Appendix A for the full list of factor loadings. The three new factors were named after the cluster of items composing them. Factor 1 had five items related to openness of communication and flexibility; this factor was labeled Openness. Factor 2 had four items that related to being treated as an equal with minimal regard to status; this factor was labeled Egalitarian. Factor 3 had five items that related to communication that was overly critical (because of reverse coded items, the factor indicates a lack of speaking critically of others); this factor was labeled Being Uncritical. These three new factors, along with the original factor of Descriptive Orientation (now composed of four items), were submitted to confirmatory factory analysis to test the possibility that they are reflecting Gibb's (1961) conceptualization of supportive communication climate. A second-order model was tested with four first-order factors (see Figure 1). 
Figure 1

Confirmatory Factor Analysis of Newly Constituted Supportive Communication Climate

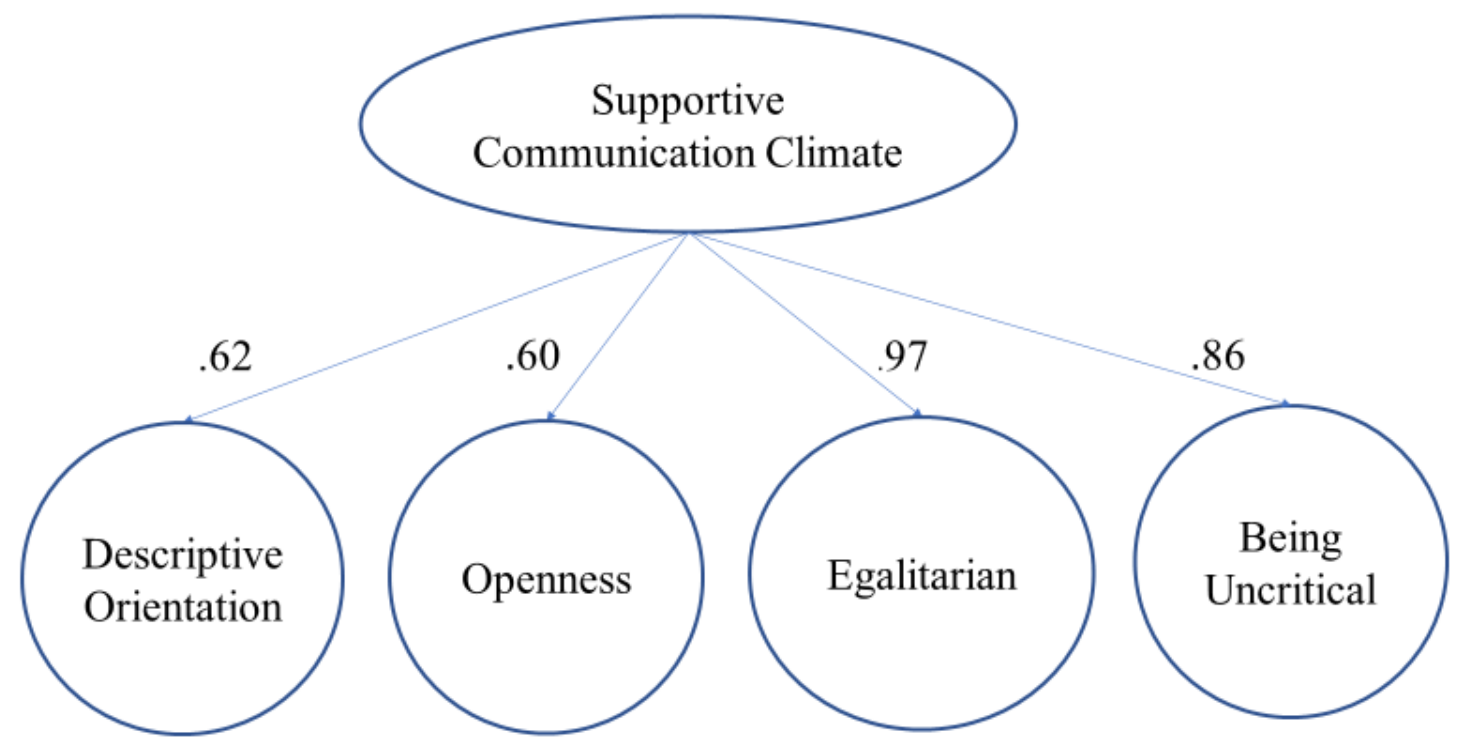

The resulting model showed adequate fit $\left(\chi^{2}=161.73, \mathrm{df}=114 p<.002, \mathrm{TLI}=.95, \mathrm{CFI}\right.$ $=.96, \mathrm{RMSEA}=.06$, PClose $=.242, \mathrm{SRMR}=.06$ ), suggesting a higher-order variable of supportive communication climate. All future analyses with supportive communication climate are constructed using the items and factors identified in this CFA.

Defensive communication was indicated by the original factor from Forward et al. (2011), authoritarianism (see Figure 2), composed of eight items. The CFA revealed good model fit for this construct $\left(\chi^{2}=23.02, \mathrm{df}=17 p<.149, \mathrm{TLI}=.98, \mathrm{CFI}=.99\right.$, $\mathrm{RMSEA}=.05$, PClose $=.414, \mathrm{SRMR}=.04)$. For clarity, I will refer to this factor as defensive communication climate, as it is in line with Gibb’s (1961) original conceptualization. Thus, the final communication climate measure contained 26 items, eight assessing defensive communication climate (one factor) and 18 assessing supportive communication climate (comprised of four factors). 
Figure 2

Confirmatory Factor Analysis of Original Authoritarianism Factor

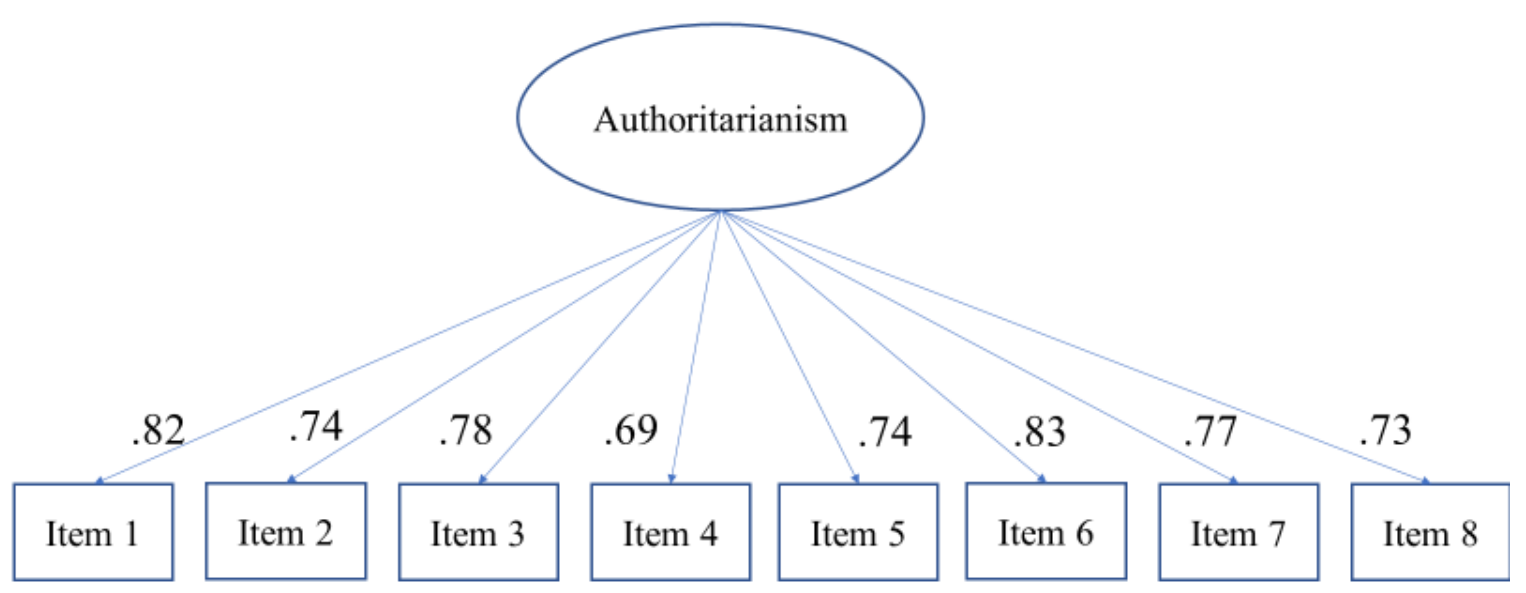

Confirmatory factor analysis for time 2 and reliabilities. To verify the factor structure of the measure at Time Two, additional confirmatory factor analysis was run using the Time 2 data from the full panel sample. Table 4 below shows the model fit indices, after making modifications to allow for within factors covariation of error terms. Model fit indices indicate good model fit and replicated the above findings. Reliabilities for supportive communication climate were $\alpha=.91$ for Time 1 and $\alpha=.92$ for Time 2 . Reliabilities for defensive communication climate were $\alpha=.92$ for Time 1 and $\alpha=.93$ for Time 2.

Table 4

Confirmatory Factor Analysis: Communication Climate at Time 2

\begin{tabular}{ccccccc}
\hline \multicolumn{1}{c}{ Model } & $\chi^{2}$ & TLI & CFI & RMSEA & PCLOSE & SRMR \\
\hline Supportive Communication & 3.36 & .98 & .99 & .08 & .280 & .03 \\
Defensive Communication & 16.12 & 1.00 & 1.00 & .01 & .727 & .02 \\
\hline
\end{tabular}


Non-task organizational conflict. The five-item disagreements subscale of the Interpersonal Conflict in Organizations Scale (Bruk-Lee, et al., 2013) was used to measure conflict. This measure taps into the perceptions of conflict in relation to organizational factors that contribute to disputes between co-workers that are not as a result of conflict over task differences or personality clashes. For example, an item may ask if the participant is, in a dispute with someone at work because of a company policy. Higher scores indicate more interpersonal conflict. All items are answered on a fivepoint frequency scale from lowest to highest: never, once or twice, once or twice a month, once or twice a week, every day. Rodriguez and Bruk-Lee (2016a) report acceptable internal consistency $(\alpha=.88)$.

CFA and reliability for non-task organizational conflict. Table 5 below shows the model fit indices, after making modifications to allow for within factors covariation of error terms and the deletion of one item for exhibiting a factor loading below .5 (Fields, 2009). Model fit indices indicate good model fit for both time points of data. In my sample, reliabilities for the measure were $\alpha=.82$ for Time 1 and $\alpha=.88$ for Time 2 . Table 5 Confirmatory Factor Analysis: Non-Task Organizational Conflict

\begin{tabular}{ccccccc}
\hline Model & $\chi^{2}$ & TLI & CFI & RMSEA & PCLOSE & SRMR \\
\hline Time 1 & 2.50 & .99 & 1.00 & .05 & .390 & .02 \\
Time 2 & 1.11 & 1.01 & 1.00 & .00 & .663 & .01 \\
\hline
\end{tabular}

Interpersonal locus of control. The 10-item subscale of the Spheres of Control Scale (Paulhus \& Van Selst, 1990) was used to measure interpersonal locus of control as a moderator of the stressor-strain relationship. This measure taps into how, "individuals 
interact with others in dyads and group situations" (Paulhus, 1983, p. 1254). Half of the items were reverse scored and required recoding. Items were answered on a five-point Likert scale of agreement. Higher values indicate a more external locus of control; that is, the individual sees the attribution of interpersonal interactions as occurring outside of his/her sphere of influence. Participants with a lower score exhibit a more internal locus of control indicating their perception of internal attribution to social interactions. An example item: I can usually steer a conversation toward the topics I want to talk about. Previous studies have found acceptable internal consistency $(\alpha=.71$; Spittal, Siegert, McClure \& Walkey 2002).

CFA and reliability for interpersonal locus of control. Table 6 below shows the model fit indices, after making modifications to allow for within factors covariation of error terms. Model fit indices indicate good model fit for both time points of data. In this sample, reliabilities for the measure were $\alpha=.77$ for Time 1 and $\alpha=.78$ for Time 2 .

Table 6

Confirmatory Factor Analysis: Interpersonal Locus of Control

\begin{tabular}{ccccccc}
\hline Model & $\chi^{2}$ & TLI & CFI & RMSEA & PCLOSE & SRMR \\
\hline Time 1 & 31.54 & 1.00 & 1.00 & .00 & .846 & .05 \\
Time 2 & 27.61 & 1.03 & 1.00 & .00 & .934 & .05 \\
\hline
\end{tabular}

Counterproductive work behaviors. The 10-item short version of the Counterproductive Work Behaviors Checklist (Spector, Bauer, \& Fox, 2010) was used to assess counterproductive work behavior (e.g., withdrawal, aggression, theft, sabotage). Each item refers to a specific behavior at work, for example, purposefully wasted employer's materials/supplies. Counterproductive work behaviors can be targeted at other individuals in the organization or at the organization itself. In this version, half of 
the items are targeted at other individuals, half at the organization, all items are negatively worded and do not require any reverse coding. The short version is intended to provide a global assessment of counterproductive work behaviors and thus global scores were averaged. Higher scores indicate more frequent engagement in counterproductive work behaviors. All items were answered on a five-point frequency scale from lowest to highest: never, once or twice, once or twice a month, once or twice a week, every day. Spector, et al., (2010) report acceptable internal consistency ( $\alpha=.78$ for employee sample).

CFA and reliability for counterproductive work behaviors. To verify the factor structure of the measure, I ran a confirmatory factor analysis. Table 7 below shows the model fit indices, after making modifications to allow for within factors covariation of error terms. Model fit indices indicate good model fit for both time points of data. In my sample, reliabilities for the measure were $\alpha=.70$ for Time 1 and $\alpha=.74$ for Time 2 .

Table 7

Confirmatory Factor Analysis: Counterproductive Work Behaviors

\begin{tabular}{ccccccc}
\hline Model & $\chi^{2}$ & TLI & CFI & RMSEA & PCLOSE & SRMR \\
\hline Time 1 & 26.57 & 1.00 & 1.00 & .01 & .782 & .05 \\
Time 2 & 31.72 & .94 & .97 & .05 & .505 & .05 \\
\hline
\end{tabular}

Previous research with checklists of this sort suggest that endorsement of such behaviors may have a low frequency (Spector, Fox, Penney, Bruursema, Goh, \& Kessler, 2006). 


\section{RESULTS}

\section{Assessment and Treatment of Missing Data}

The extent of missing data was analyzed using IBM SPSS 20 Missing Variables Analysis. Before combining the two time points, both sets of data were separately submitted for missing data analysis. Results showed missing data to be no more than $2 \%$ of the total data set in either time point. Little's test for data missing completely at random (MCAR) was not significant for either $\mathrm{T}_{1}$ or $\mathrm{T}_{2}$ (Little's test for $\mathrm{T}_{1}: \chi^{2}=1395.06$, $\left.\mathrm{df}=1356, p=.225 ; \mathrm{T}_{2}: \chi^{2}=279.10, \mathrm{df}=259, p=.187\right)$. This indicates that the probability of the missing values diverges from randomness is greater than $5 \%$ so that MCAR may be inferred.

Treatment of missing data. Baraldi and Enders (2010) have forcefully argued that traditional methods of dealing with missing data may have more advanced, modern alternatives. Historically, when respondents failed to answer all questions in a data set, or when a particular scale or item was missing data across various respondents, listwise/pairwise deletion or single imputation methods were employed to address the missing data. Baraldi and Enders (2010) provide a comprehensive review on the drawback of these two methods of dealing with missing data. Specifically, for deletion methods, this solution inadequate because both listwise and pairwise deletions, "attenuate estimates of variation and association" (p. 11). EM (Expectation-Maximization) methods “offer the simplest and most reasonable approach" (Tabachnick \& Fidell, 2013, p. 71). According to Tabachnick and Fidell (2013), the EM method of missing data imputation is appropriate when data are missing completely at random (MCAR) or missing at random (MAR). However, they warn that, "[this] strategy should be limited to data sets in which 
there is not a great deal of missing data" (p. 71). Thus, EM technique was used to impute missing data in the $\mathrm{T}_{1}$ and $\mathrm{T}_{2}$ data sets, separately. Thus, the merged file that was used for hypothesis and psychometric testing had no missing data.

\section{Assessing Multivariate Assumptions, Outliers and Influencers}

The data were assessed for assumptions of normality using IBM SPSS 20

Explore. Three variables evidenced non-normal distributions: non-task organizational conflict (positive skew), counterproductive work behaviors (positive skew), and transformational leadership (negative skew). For this reason, all future analysis will use bootstrapping methods to account for non-normal distributions.

The data were assessed for multivariate outliers and influencers via two methods: model and non-model based examinations (Tabachnick \& Fidell, 2013). Non-model based assessment defines outliers as any leverage scores that are four times greater than the average leverage score. Inspection of leverage scores in the merged data file revealed no leverage scores meeting this criterion. In addition, model-based assessment of outliers was also conducted. This model-based assessment considers standardized dfbeta values associated with each variable in the model. Standardized dfbetas greater than absolute values of one are considered outliers; no cases met this criterion. The results of the assessment for outliers and influencers suggests that all cases are valid and can proceed with the intact data set.

\section{Data Analysis and Results}

Table 8 reports the intercorrelations, means, and standard deviations of all study variables (both $\mathrm{T}_{1}$ and $\mathrm{T}_{2}$ ). 
Table 8

Summary of Intercorrelations, Means, and Standard Deviations for Full Panel $\left(T_{1}\right.$ and $T_{2}$ separated for comparison) $N=123$

\begin{tabular}{|c|c|c|c|c|c|c|c|c|c|c|c|c|c|c|c|c|}
\hline Variables & $M$ & $S D$ & 1 & 2 & 3 & 4 & 5 & 6 & 7 & 8 & 9 & 10 & 11 & 12 & 13 & 14 \\
\hline 1. $\mathrm{TL}_{\mathrm{T} 1}$ & 3.73 & .83 & $(.95)$ & & & & & & & & & & & & & \\
\hline 2. $\mathrm{TL}_{\mathrm{T} 2}$ & 3.72 & .77 & $.82 * *$ & (.94) & & & & & & & & & & & & \\
\hline 3. $\mathrm{TR}_{\mathrm{T} 1}$ & 3.95 & .85 & $.82 * *$ & $.77 * *$ & $(.96)$ & & & & & & & & & & & \\
\hline 4. $\mathrm{TR}_{\mathrm{T} 2}$ & 3.96 & .80 & $.76^{* *}$ & $.85^{* *}$ & $.88 * *$ & (.96) & & & & & & & & & & \\
\hline 5. $\mathrm{SCC}_{\mathrm{T} 1}$ & 3.70 & .66 & $.71 * *$ & $.60 * *$ & $.66 * *$ & $.59 * *$ & (.91) & & & & & & & & & \\
\hline 6. $\mathrm{SCC}_{\mathrm{T} 2}$ & 3.69 & .66 & $.54 * *$ & $.60 * *$ & $.58^{* *}$ & $.60 * *$ & $.75 * *$ & $(.92)$ & & & & & & & & \\
\hline 7. $\mathrm{DCC}_{\mathrm{T} 1}$ & 2.78 & .86 & $-.34 * *$ & $-.27 * *$ & $-.31 * *$ & $-.24 * *$ & $-.60 * *$ & $-.55^{* *}$ & $(.92)$ & & & & & & & \\
\hline 8. $\mathrm{DCC}_{\mathrm{T} 2}$ & 2.79 & .88 & $-.37 * *$ & $-.41 * *$ & $-.41 * *$ & $-.42 * *$ & $-.61 * *$ & $-.73 * *$ & $.62 * *$ & $(.93)$ & & & & & & \\
\hline 9. $\mathrm{NTO}_{\mathrm{T} 1}$ & 1.73 & .66 & -.09 & -.14 & -.18 & -.17 & -.15 & $-.20^{*}$ & $.19^{*}$ & $.25^{*}$ & $(.82)$ & & & & & \\
\hline 10. $\mathrm{NTO}_{\mathrm{T} 2}$ & 1.74 & .70 & $-.28 * *$ & $-.34 * *$ & $-.25 * *$ & $-.28 * *$ & $-.21 * *$ & $-.32 * *$ & $.22 *$ & $.33 * *$ & $.55^{* *}$ & (.88) & & & & \\
\hline 11. $\mathrm{ILOC}_{\mathrm{T} 1}$ & 3.76 & .49 & .13 & .04 & .03 & -.01 & .16 & .12 & -.15 & -.12 & .01 & .04 & $(.77)$ & & & \\
\hline 12. $\mathrm{ILOC}_{\mathrm{T} 2}$ & 3.70 & .49 & .15 & .14 & .14 & .12 & .18 & .16 & -.09 & -.15 & .04 & -.02 & $.66^{* * *}$ & (.78) & & \\
\hline 13. $\mathrm{CWB}_{\mathrm{T} 1}$ & 1.53 & .37 & $-.27 * *$ & $-.25^{* *}$ & $-.27 * *$ & $-.25^{* *}$ & $-.41 * *$ & $-.45^{* *}$ & $.41 * *$ & $.40 * *$ & $.32 * *$ & $.38 * *$ & $-.26^{* *}$ & $-.20^{*}$ & $(.70)$ & \\
\hline 14. $\mathrm{CWB} \mathrm{T}_{2}$ & 1.58 & .39 & $-.35 * *$ & $-.34 * *$ & $-.31 * *$ & $-.31 * *$ & $-.45 * *$ & $-.48 * *$ & $.39 * *$ & $.42 * *$ & $.41^{* *}$ & $.55^{* *}$ & $-.25 * *$ & $-.21^{*}$ & $.79 * *$ & (.74) \\
\hline
\end{tabular}

Note. Values on the diagonal are coefficient alphas. TL=Transformational Leadership. TR=Trust in Leadership. SCC=Supportive Communication Climate.

DCC $=$ Defensive Communication Climate. NTO Conflict $=$ Non-task organizational conflict. ILOC $=$ Interpersonal Locus of Control. CWB $=$ Counterproductive Work

Behaviors. Parentheses indicate alpha reliability.

$* * p<.01$

$* \mathrm{p}<.05$. 
To aid the reader, Appendix B provides a concise overview of all hypotheses, their description, and if they were supported by the results. For all subsequent analyses, it can be assumed that any Time 2 data will have had its Time 1 counterpart used as a control. This was done in order to reduce the effects of common method bias. Regression analyses used SPSS 20, while mediation was testing with path analysis used AMOS 21 with bootstrapping.

\section{Testing the relationship between non-task organizational conflict and}

counterproductive work behavior. Hypothesis 1a stated that non-task organizational conflict (i.e., NTO) will predict counterproductive work behavior (i.e., CWB). Results showed a significant change statistic, $F(1,120)=169.88, p<.000$; perceptions of NTO conflict at Time 1 were associated with subsequent increases in reports of CWB at Time $2\left(R^{2}=.66, \beta=.17, p=.002\right)$, in support of Hypothesis $1 \mathrm{a}$.

Hypothesis $1 \mathrm{~b}$ stated that the relationship between NTO and CWB would be moderated by individual differences in interpersonal locus of control (ILOC). Table 9 shows the results of a test of moderation. While the change the change statistic was significant, $F(3,118)=84.36, p<.000$, the interaction term was not significant $(\beta=-.02$, $p=.404)$; therefore, Hypothesis $1 \mathrm{~b}$ was not supported.

Table 9

Moderation Analysis for Interpersonal Locus of Control

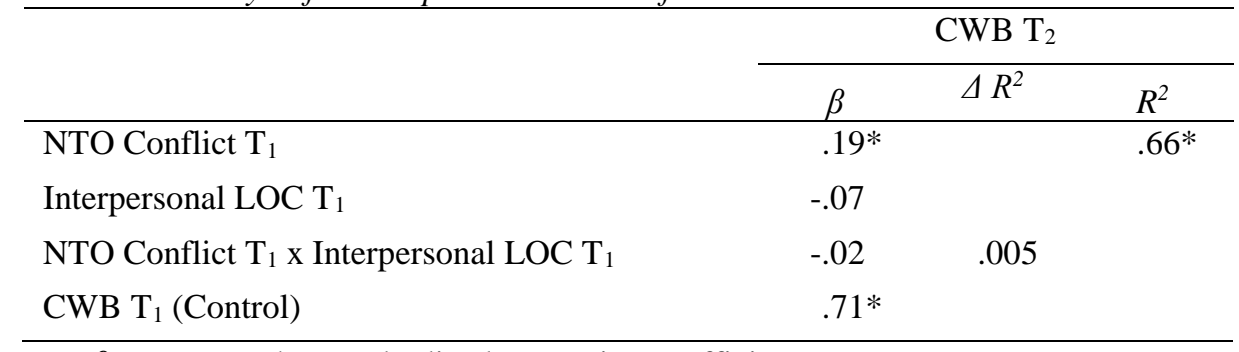

Note. $\beta$ represents the standardized regression coefficient. CWB $\mathrm{T}_{1}$ was used as a control with CWB $\mathrm{T}_{2}$ $* p<.05$. 


\section{Testing the influence of transformational leadership on the experience of}

stressor and strain. Hypothesis $2 \mathrm{a}$ and $2 \mathrm{~b}$ stated that higher perceptions of a transformational leadership would be associated with fewer reports of NTO and CWBs, respectively. Results showed a significant change statistic for both, $F(1,120)=52.55, p$ $<.000$ for NTO and $F(1,120)=179.44, p<.000$ for CWB; perceptions of transformational leadership at Time 1 were associated with subsequent decreases in reports of NTO conflict at Time $2\left(R^{2}=.36, \beta=-.23, p=.002\right)$, while perceptions of transformational leadership at Time 1 were also associated with subsequent decreases in reports of CWBs at time $2\left(R^{2}=.65, \beta=-.14, p=.012\right)$, in support of Hypotheses $2 \mathrm{a}$ and $2 b$.

Hypothesis $2 \mathrm{c}$ stated that the relationship between transformational leadership and CWBs was best explained through the effects of NTO. Since data are available for NTO at Time 1 and Time 2, this hypothesis was tested using both time points. Table 10 shows the results of the first path analysis that used two variables from Time 1 (i.e., leadership and NTO) and one from Time 2 (i.e., CWB).

Table 10

Path Analysis: Transformational Leadership $\left(T_{1}\right)$ and Counterproductive Work Behaviors $\left(T_{2}\right)$, Non-Task Organizational Conflict $\left(T_{1}\right)$ as Mediator

\begin{tabular}{|c|c|c|c|c|c|c|}
\hline Model & $\chi^{2}$ & TLI & CFI & RMSEA & PCLOSE & SRMR \\
\hline $\mathrm{TL} \mathrm{T}_{1}-\mathrm{NTO} \mathrm{T}_{1}-\mathrm{CWB} \mathrm{T}_{2}$ & 12.08 & .57 & .93 & .30 & .002 & .11 \\
\hline & Coefficient & $S E$ & $p$ & $L L C I$ & $U L C I$ & \\
\hline $\mathrm{TL}_{-N T O} \mathrm{~T}_{1}$ & -.05 & .07 & .316 & -.22 & .08 & \\
\hline $\mathrm{NTO} \mathrm{T}_{1}$-CWB $\mathrm{T}_{2}$ & .12 & .03 & .021 & .02 & .18 & \\
\hline $\mathrm{TL} \mathrm{T}_{1}$-CWB $\mathrm{T}_{2}$ & -.07 & .03 & .009 & -.12 & -.02 & \\
\hline
\end{tabular}

Note. $\mathrm{TL}=$ Transformational Leadership. NTO Conflict $=$ Non-task organizational conflict. $\mathrm{CWB}=$ Counterproductive Work Behaviors. Any $\mathrm{T}_{2}$ variables used $\mathrm{T}_{1}$ as control. LLCI/ULCI $=$ bias corrected lower/upper limit confidence interval calculated with 5,000 bootstrap samples. Reported path coefficients are unstandardized OLS regression coefficients. 
This model exhibited a poor fit (Kline, 2011). In addition, the indirect effect of transformational leadership was not significant (indirect ab effect $=-.02, \mathrm{CI}_{.95}-.08, .01, p$ $=.243$ ). However, when the data were analyzed using NTO at Time 2 a different set of results emerged (see Table 11).

Table 11

Path Analysis: Transformational Leadership $\left(T_{1}\right)$ and Counterproductive Work Behaviors $\left(T_{2}\right)$, Non-Task Organizational Conflict $\left(T_{2}\right)$ as Mediator

\begin{tabular}{|c|c|c|c|c|c|c|}
\hline Model & $\chi^{2}$ & TLI & CFI & RMSEA & PCLOSE & SRMR \\
\hline $\mathrm{TL} \mathrm{T}_{1}-\mathrm{NTO} \mathrm{T}_{2}-\mathrm{CWB} \mathrm{T}_{2}$ & 5.97 & .91 & .98 & .13 & .100 & .04 \\
\hline & Coefficient & $S E$ & $p$ & $L L C I$ & $U L C I$ & \\
\hline TL-NTO $\mathrm{T}_{2}$ & -.19 & .08 & .012 & -.35 & -.04 & \\
\hline $\mathrm{NTO}_{2}-\mathrm{CWB} \mathrm{T}_{2}$ & .15 & .04 & .000 & .09 & .22 & \\
\hline $\mathrm{TL} \mathrm{T}_{1}-\mathrm{CWB} \mathrm{T}_{2}$ & -.04 & .02 & .05 & -.09 & .000 & \\
\hline
\end{tabular}

Note. TL=Transformational Leadership. NTO Conflict $=$ Non-task organizational conflict. $\mathrm{CWB}=$ Counterproductive Work Behaviors. Any $\mathrm{T}_{2}$ variables used $\mathrm{T}_{1}$ as control. LLCI/ULCI = bias corrected lower/upper limit confidence interval calculated with 5,000 bootstrap samples. Reported path coefficients are unstandardized OLS regression coefficients.

The indirect effect of transformational leadership was significant (indirect ab effect $=$ $\left..06, \mathrm{CI}_{.95}-.14,-.01, p=.008\right)$. Thus, Hypothesis $2 \mathrm{c}$ was supported for the lagged effects of transformational leadership.

\section{Testing the role of trust in leadership in explaining the effects of}

transformational leadership on stressor-strain. Hypothesis 3 a stated that higher

perceptions of transformational leadership would be associated with higher perceptions of trust in the leader. Although regression analyses revealed a significant change statistic, $F(1,120)=114.28 p<.000$, perceptions of transformational leadership at Time 1 were 
not associated with subsequent perceptions of trust in leadership at Time $2\left(R^{2}=.78, \beta=\right.$ $.09, p=.211)$; thus, Hypothesis 3a was not supported.

Hypothesis $3 b$ stated that higher perceptions of trust in leadership would be associated with less NTO. Regression analyses showed a significant change statistic, $F(1,120)=48.01, p<.000 ;$ perceptions of trust in leadership at Time 1 were associated with subsequent lower scores of NTO at time $2\left(R^{2}=.33, \beta=-.17, p=.023\right)$, in support of Hypothesis $3 b$.

Hypothesis $3 \mathrm{c}$ stated that the relationship between transformational leadership and NTO was best explained through the effects of trust in leadership. Because data are available for trust at Time 1 and Time 2, the hypothesis was tested using both time points. Table 12 shows the results of the first path analysis that used two variables from Time 1 (i.e., leadership and trust) and one from Time 2 (i.e., NTO).

Table 12

Path Analysis: Transformational Leadership $\left(T_{1}\right)$ and Non-Task Organizational Conflict $\left(T_{2}\right)$, Trust in Leadership $\left(T_{1}\right)$ as Mediator

\begin{tabular}{lcccccc}
\hline \multicolumn{1}{c}{ Model } & $\chi^{2}$ & TLI & CFI & RMSEA & PCLOSE & SRMR \\
\hline TL T $_{1}-$ Trust $\mathrm{T}_{1}-\mathrm{NTO} \mathrm{T}_{2}$ & 3.81 & .91 & .99 & .152 & .087 & .04 \\
\hline & & & & & \\
& Coefficient & $S E$ & $p$ & LLCI & ULCI \\
\cline { 2 - 6 } & .84 & .07 & .000 & .71 & .96 \\
TL-Trust $\mathrm{T}_{1}$ & .08 & .13 & .532 & -.17 & .36 \\
Trust $\mathrm{T}_{1}-\mathrm{NTO} \mathrm{T}_{2}$ & -.26 & .14 & .058 & -.53 & .01 \\
TL T $_{1}-\mathrm{NTO} \mathrm{T}_{2}$ & & &
\end{tabular}

Note. $\mathrm{TL}=$ Transformational Leadership. Trust $=$ Trust in Leadership. NTO Conflict $=$ Non-task organizational conflict. Any $\mathrm{T}_{2}$ variables used $\mathrm{T}_{1}$ as control. LLCI/ULCI $=$ bias corrected lower/upper limit confidence interval calculated with 5,000 bootstrap samples. Reported path coefficients are unstandardized OLS regression coefficients. 
While the model showed a good fit, the path from trust in leadership to NTO was not significant, nor was the indirect effect of transformational leadership (indirect ab effect $=$ $.08, \mathrm{CI}_{.95}-.18, .35, p=.534$. A similar pattern emerged for trust in leadership at Time 2 (see Table 13).

Table 13

Path Analysis: Transformational Leadership $\left(T_{1}\right)$ and Non-Task Organizational Conflict $\left(T_{2}\right)$, Trust in Leadership $\left(T_{2}\right)$ as Mediator

\begin{tabular}{ccccccc}
\hline Model & $\chi^{2}$ & TLI & CFI & RMSEA & PCLOSE & SRMR \\
\hline TL T $_{1}$-Trust $\mathrm{T}_{2}$-NTO T & 2.03 & 1.00 & 1.00 & .01 & .467 & .01 \\
\hline
\end{tabular}

TL-Trust $\mathrm{T}_{2}$

\begin{tabular}{ccccc} 
Coefficient & SE & $p$ & LLCI & ULCI \\
\hline .09 & .08 & .259 & -.07 & .24
\end{tabular}

Trust $\mathrm{T}_{2}-\mathrm{NTO} \mathrm{T}_{2}$ $-.03$

$\begin{array}{lll}.12 \quad .806 & -.25\end{array}$

TL $\mathrm{T}_{1}-\mathrm{NTO} \mathrm{T}_{2}$ $-.170$

$\begin{array}{lll}.10 & .144 & -.39\end{array}$
.06

Note. TL $=$ Transformational Leadership. Trust $=$ Trust in Leadership. NTO Conflict $=$ Non-task organizational conflict. Any $\mathrm{T}_{2}$ variables used $\mathrm{T}_{1}$ as control. $\mathrm{LLCI} / \mathrm{ULCI}=$ bias corrected lower/upper limit confidence interval calculated with 5,000 bootstrap samples. Reported path coefficients are unstandardized OLS regression coefficients.

While the model also showed a good fit, the path from trust in leadership to NTO was not significant, nor was the indirect effect of transformational leadership (indirect ab effect $=$ $\left.-.004, \mathrm{CI}_{.95}-.07, .02, p=.556\right)$. Both sets of analyses did not find any significant effects for mediation; therefore, Hypothesis 3c was not supported.

Hypothesis $3 \mathrm{~d}$ stated that higher perceptions of trust in leadership would be associated with lowered reports of counterproductive work behaviors. Although regression analyses showed a significant change statistic $F(1,120)=179.28, p<.000$, perceptions of trust in leadership at Time 1 were not associated with subsequent reports of CWBs at Time $2\left(R^{2}=.64, \beta=-.11, p=.07\right)$; thus, Hypothesis $3 \mathrm{~d}$ was not supported. 
Hypothesis 3e stated that transformational leadership effects CWB indirectly, through its influence on trust in leadership. Table 14 shows the results of the first path analysis that used two variables from Time 1 (i.e., leadership and trust) and one from

Time 2 (i.e., CWB).

Table 14

Path Analysis: Transformational Leadership $\left(T_{1}\right)$ and Counterproductive Work Behaviors $\left(T_{2}\right)$, Trust in Leadership $\left(T_{1}\right)$ as Mediator

\begin{tabular}{ccccccc}
\hline Model & $\chi^{2}$ & TLI & CFI & RMSEA & PCLOSE & SRMR \\
\hline TL T $_{1}$-Trust $\mathrm{T}_{1}$-CWB T & 1.12 & 1.00 & 1.00 & .03 & .359 & .02 \\
\hline
\end{tabular}

TL-Trust $\mathrm{T}_{1}$

\begin{tabular}{ccccc} 
Coefficient & $S E$ & $p$ & LLCI & ULCI \\
\hline .84 & .07 & .000 & .71 & .96
\end{tabular}

Trust $\mathrm{T}_{1}-\mathrm{CWB} \mathrm{T}_{2}$ $\begin{array}{llll}.02 & .05 & .725 & -.09\end{array}$

.13

$\mathrm{TL} \mathrm{T}_{1}-\mathrm{CWB} \mathrm{T}_{2}$ $-.09$

$\begin{array}{lll}.05 & .123 \quad-.19\end{array}$
.03

Note. $\mathrm{TL}=$ Transformational Leadership. Trust $=$ Trust in Leadership. $\mathrm{CWB}=$ Counterproductive Work Behaviors. Any $\mathrm{T}_{2}$ variables used $\mathrm{T}_{1}$ as control. LLCI/ULCI $=$ bias corrected lower/upper limit confidence interval calculated with 5,000 bootstrap samples. Reported path coefficients are unstandardized OLS regression coefficients.

Although the model showed a good fit, the path from trust in leadership to CWB was not significant. In addition, the indirect effect of transformational leadership was not significant (indirect ab effect $=.04, \mathrm{CI}_{.95}-.17, .21, p=.709$ ). A similar pattern emerged for trust in leadership at Time 2 (see Table 15). 
Table 15

Path Analysis: Transformational Leadership $\left(T_{1}\right)$ and Counterproductive

Work Behaviors $\left(T_{2}\right)$, Trust in Leadership $\left(T_{2}\right)$ as Mediator

\begin{tabular}{lcccccc}
\hline \multicolumn{1}{c}{ Model } & $\chi^{2}$ & TLI & CFI & RMSEA & PCLOSE & SRMR \\
\hline TL T $_{1}-$ Trust $\mathrm{T}_{2}-\mathrm{CWB} \mathrm{T}_{2}$ & .80 & 1.01 & 1.00 & .00 & .744 & .01 \\
\hline & & & & & \\
& Coefficient & $S E$ & $p$ & LLCI & ULCI \\
\cline { 2 - 6 } & .09 & .07 & .259 & -.07 & .24 \\
TL-Trust $\mathrm{T}_{2}$ & -.01 & .04 & .799 & -.11 & .09 \\
Trust $\mathrm{T}_{2}-\mathrm{CWB} \mathrm{T}_{2}$ & -.06 & .04 & .202 & -.15 & .03 \\
TL T $_{1}-\mathrm{CWB} \mathrm{T}_{2}$ & & &
\end{tabular}

Note. $\mathrm{TL}=$ Transformational Leadership. Trust $=$ Trust in Leadership. $\mathrm{CWB}=$ Counterproductive Work Behaviors. Any $\mathrm{T}_{2}$ variables used $\mathrm{T}_{1}$ as control. LLCI/ULCI = bias corrected lower/upper limit confidence interval calculated with 5,000 bootstrap samples. Reported path coefficients are unstandardized OLS regression coefficients.

Even though this model also showed a good fit, the path from trust in leadership to CWB was not significant, nor was the indirect effect of transformational leadership (indirect $a b$ effect $=-.002, \mathrm{CI} .95-.04, .02, p=.530)$. Neither set of analyses found any significant mediation effects; therefore, Hypothesis 3e was not supported.

Testing the role of communication climate with stressor-strains. Hypothesis $4 \mathrm{a}$ and $4 \mathrm{~b}$ stated that higher perceptions of a supportive communication climate would be associated with fewer reports of NTO and CWBs, respectively. Regression analyses showed a significant change statistic, $F(1,120)=49.40, p<.000$; perceptions of supportive communication at Time 1 were associated with subsequent lower scores of NTO at Time $2\left(R^{2}=.33, \beta=-.15, p=.041\right) ; F(1,120)=151.16, p<.000$, with perceptions of supportive communication climate at Time 1 associated with subsequent reduction of CWBs at Time $2\left(R^{2}=.64, \beta=-.15, p=.013\right)$, providing support for Hypothesis 4a and 4b. 
Hypothesis $4 \mathrm{c}$ and $4 \mathrm{~d}$ stated that higher perceptions of a defensive communication climate would be associated with greater reports of NTO and CWBs, respectively. Results of regression analyses showed significant change statistics, $F(1,120)=48.13, p<$ .000 and $F(1,120)=158.10, p<.000$, respectively. Perceptions of defensive communication at Time 1 were not associated with subsequent experiences of NTO $\left(R^{2}=\right.$ $.32, \beta=.12, p=.124)$ nor CWBs $\left(R^{2}=.63, \beta=.08, p=.196\right)$ at Time 2 ; therefore, hypotheses $4 \mathrm{c}$ and $4 \mathrm{~d}$ were not supported.

Testing the role of transformational leadership in communication climates. Hypothesis 5a predicted that greater perceptions of transformational leadership would be associated with higher perceptions of a supportive communication climate. Even though a significant change statistic was found, $F(1,120)=72.12, p<.000$, perceptions of transformational leadership at Time 1 were not associated with subsequent perceptions of a supportive communication climate at time $2\left(R^{2}=.56, \beta=.02, p=.791\right)$; thus, Hypothesis 5a was not supported.

Hypothesis $5 \mathrm{~b}$ predicted that transformational leadership effects NTO indirectly, through its influence on the supportive communication climate. The hypothesis was tested using both time points. Table 16 shows the results of the first path analysis that used two variables from Time 1 (i.e., leadership and supportive communication climate) and one from Time 2 (i.e., NTO). 
Table 16

Path Analysis: Transformational Leadership $\left(T_{1}\right)$ and Non-Task Organizational Conflict $\left(T_{2}\right)$, Supportive Communication Climate $\left(T_{1}\right)$ as Mediator

\begin{tabular}{lcccccc}
\hline \multicolumn{1}{c}{ Model } & $\chi^{2}$ & TLI & CFI & RMSEA & PCLOSE & SRMR \\
\hline TL T $_{1}-$ SCC T $_{1}-\mathrm{NTO} \mathrm{T}_{2}$ & 1.67 & .97 & 1.00 & .07 & .262 & .03 \\
\hline & & & & & & \\
& Coefficient & $S E$ & $p$ & LLCI & ULCI & \\
\cline { 2 - 6 } TL-SCC T $_{1}$ & .56 & .05 & .000 & .45 & .66 \\
SCC T $_{1}-\mathrm{NTO} \mathrm{T}_{2}$ & .04 & .12 & .716 & -.18 & .26 \\
TL T $_{1}-\mathrm{NTO} \mathrm{T}_{2}$ & -.22 & .10 & .018 & -.42 & -.04
\end{tabular}

Note. $\mathrm{TL}=$ Transformational Leadership. $\mathrm{SCC}=$ Supportive Communication Climate. NTO Conflict $=$ Non-task organizational conflict. Any $\mathrm{T}_{2}$ variables used $\mathrm{T}_{1}$ as control. LLCI/ULCI = bias corrected lower/upper limit confidence interval calculated with 5,000 bootstrap samples. Reported path coefficients are unstandardized OLS regression coefficients.

While the model showed a good fit, and the path from transformational leadership to supportive communication climate was significant, the second path from supportive communication climate to subsequent NTO at Time 2 was not significant. However, the direct effects of transformational leadership on subsequent NTO at Time 2 were significant. A different pattern emerged for supportive communication at time 2 (see

Table 17).

Table 17

Path Analysis: Transformational Leadership $\left(T_{1}\right)$ and Non-Task Organizational Conflict $\left(T_{2}\right)$, Supportive Communication Climate $\left(T_{2}\right)$ as Mediator

\begin{tabular}{ccccccc}
\hline Model & $\chi^{2}$ & TLI & CFI & RMSEA & PCLOSE & SRMR \\
\hline TL T $_{1}-\mathrm{SCC}_{2}-\mathrm{NTO} \mathrm{T}_{2}$ & 4.62 & .95 & .99 & .10 & .170 & .03 \\
\hline
\end{tabular}

TL-SCC $\mathrm{T}_{2}$

\begin{tabular}{ccccc} 
Coefficient & SE & $p$ & LLCI & ULCI \\
\hline .02 & .07 & .772 & -.11 & .17 \\
-.14 & .10 & .147 & -.33 & .05 \\
-.15 & .08 & .064 & -.32 & .01
\end{tabular}

$\mathrm{TL}_{1}-\mathrm{NTO} \mathrm{T}_{2}$ 
Note. $\mathrm{TL}=$ Transformational Leadership. $\mathrm{SCC}=$ Supportive Communication Climate. NTO Conflict $=$ Non-task organizational conflict. Any $\mathrm{T}_{2}$ variables used $\mathrm{T}_{1}$ as control. LLCI/ULCI = bias corrected lower/upper limit confidence interval calculated with 5,000 bootstrap samples. Reported path coefficients are unstandardized OLS regression coefficients.

Both sets of analyses did not find any significant indirect effects (indirect ab effect $=.03$, $\mathrm{CI}_{.95}-.04, .02, p=.708 ;$ indirect ab effect $=-.003, \mathrm{CI} .95-.05, .02, p=.586$, respectively); therefore, Hypothesis $5 \mathrm{~b}$ was not supported.

Hypothesis $5 \mathrm{c}$ stated that the relationship between transformational leadership and

CWB was best explained through the effects of a supportive communication climate.

Table 18 shows the results of the first path analysis that used two variables from Time 1

(i.e., leadership and supportive communication climate) and one from Time 2 (i.e.,

\section{CWB).}

Table 18

Path Analysis: Transformational Leadership $\left(T_{1}\right)$ and Counterproductive Work Behavior $\left(T_{2}\right)$, Supportive Communication Climate $\left(T_{1}\right)$ as Mediator

\begin{tabular}{|c|c|c|c|c|c|c|}
\hline Model & $\chi^{2}$ & TLI & CFI & RMSEA & PCLOSE & SRMR \\
\hline $\mathrm{TL} \mathrm{T}_{1}-\mathrm{SCC} \mathrm{T}_{1}-\mathrm{CWB} \mathrm{T}_{2}$ & 13.60 & .67 & .95 & .32 & .001 & .09 \\
\hline
\end{tabular}

TL-SCC $\mathrm{T}_{1}$

$\mathrm{SCC} \mathrm{T}_{1}-\mathrm{CWB} \mathrm{T}_{2}$

$\mathrm{TL} \mathrm{T}_{1}-\mathrm{CWB} \mathrm{T}_{2}$

\begin{tabular}{ccccc} 
Coefficient & $S E$ & $p$ & LLCI & ULCI \\
\hline .56 & .03 & .000 & .45 & .66 \\
-.05 & .05 & .330 & -.13 & .05 \\
-.04 & .05 & .170 & -.11 & .02
\end{tabular}

Note. $\mathrm{TL}=$ Transformational Leadership. $\mathrm{SCC}=$ Supportive Communication Climate. $\mathrm{CWB}=$ Counterproductive Work Behavior. Any $\mathrm{T}_{2}$ variables used $\mathrm{T}_{1}$ as control. LLCI/ULCI = bias corrected lower/upper limit confidence interval calculated with 5,000 bootstrap samples. Reported path coefficients are unstandardized OLS regression coefficients. 
This model exhibit poor fit and the path from supportive communication climate to subsequent CWB at Time 2 was not significant. When analyzing supportive communication climate at Time 2, still no direct effects were detected (see Table 19).

While this model fit was better, there were no significant direct or indirect effects.

Table 19

Path Analysis: Transformational Leadership $\left(T_{1}\right)$ and Counterproductive Work Behavior $\left(T_{2}\right)$, Supportive Communication Climate $\left(T_{2}\right)$ as Mediator

\begin{tabular}{|c|c|c|c|c|c|c|}
\hline Model & $\chi^{2}$ & TLI & $\mathrm{CFI}$ & RMSEA & PCLOSE & SRMR \\
\hline $\mathrm{TL} \mathrm{T}_{1}-\mathrm{SCC} \mathrm{T}_{2}-\mathrm{CWB} \mathrm{T}_{2}$ & 7.13 & .92 & .99 & .15 & .062 & .05 \\
\hline
\end{tabular}

TL-SCC $\mathrm{T}_{2}$

$\mathrm{SCC} \mathrm{T}_{2}-\mathrm{CWB} \mathrm{T}_{2}$

$\mathrm{TL} \mathrm{T}_{1}-\mathrm{CWB} \mathrm{T}_{2}$

\begin{tabular}{ccccc} 
Coefficient & $S E$ & $p$ & LLCI & ULCI \\
\hline .02 & .07 & .772 & -.11 & .17 \\
-.07 & .04 & .065 & -.14 & .01 \\
-.05 & .03 & .111 & -.10 & .01
\end{tabular}

Note. $\mathrm{TL}=$ Transformational Leadership. $\mathrm{SCC}=$ Supportive Communication Climate. $\mathrm{CWB}=$ Counterproductive Work Behavior. Any $\mathrm{T}_{2}$ variables used $\mathrm{T}_{1}$ as control. LLCI/ULCI = bias corrected lower/upper limit confidence interval calculated with 5,000 bootstrap samples. Reported path coefficients are unstandardized OLS regression coefficients.

Because neither set of analyses found any significant indirect effects (indirect ab effect $=$ $-.003, \mathrm{CI} .95-.03, .02, p=.593$; indirect ab effect $=-.003, \mathrm{CI} .95-.05, .02, p=.586$, respectively), Hypothesis 5c was not supported.

Hypothesis $5 \mathrm{~d}$ stated that higher perceptions of transformational leadership would be associated with lower perceptions of a defensive communication climate. Regression analyses showed a significant change statistic, $F(1,120)=54.92, p<.000$; lower perceptions of transformational leadership at Time 1 were associated with subsequent perceptions of a defensive communication climate at Time $2\left(R^{2}=.41, \beta=-.19, p=\right.$ $.011)$; thus, Hypothesis 5d was supported. 
Hypothesis 5e stated that transformational leadership effects NTO indirectly,

through its influence on the defensive communication climate. Table 20 shows the results of the first path analysis that used two variables from time 1 (i.e., leadership and defensive communication climate) and one from time 2 (i.e., NTO).

Table 20

Path Analysis: Transformational Leadership $\left(T_{1}\right)$ and Non-Task Organizational Conflict $\left(T_{2}\right)$, Defensive Communication Climate $\left(T_{1}\right)$ as Mediator

\begin{tabular}{|c|c|c|c|c|c|c|}
\hline Model & $\chi^{2}$ & TLI & CFI & RMSEA & PCLOSE & SRMR \\
\hline 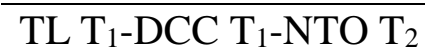 & 3.40 & .80 & .97 & .14 & 107 & .06 \\
\hline
\end{tabular}

\begin{tabular}{lccccc} 
& Coefficient & $S E$ & $p$ & LLCI & ULCI \\
\cline { 2 - 5 } TL-DCC T $_{1}$ & -.35 & .09 & .000 & -.52 & -.18 \\
DCC T $_{1}-\mathrm{NTO} \mathrm{T}_{2}$ & .04 & .06 & .515 & -.08 & .17 \\
$\mathrm{TL} \mathrm{T}_{1}-\mathrm{NTO} \mathrm{T}_{2}$ & -.18 & .08 & .014 & -.18 & -.03
\end{tabular}

Note. TL=Transformational Leadership. DCC $=$ Defensive Communication Climate. NTO Conflict $=$ Non-task organizational conflict. Any $\mathrm{T}_{2}$ variables used $\mathrm{T}_{1}$ as control.

LLCI/ULCI = bias corrected lower/upper limit confidence interval calculated with 5,000 bootstrap samples. Reported path coefficients are unstandardized OLS regression coefficients.

The model showed a mixed fit, and the path from transformational leadership to defensive communication climate was significant (as previously found), the second path from defensive communication climate to subsequent NTO at Time 2 was not significant. Nonetheless, the direct effects of transformational leadership on subsequent NTO at Time 2 were significant (as previously found). A similar pattern emerged for defensive communication at Time 2 (see Table 21). 
Table 21

Path Analysis: Transformational Leadership $\left(T_{1}\right)$ and Non-Task Organizational Conflict $\left(T_{2}\right)$, Defensive Communication Climate $\left(T_{2}\right)$ as Mediator

\begin{tabular}{|c|c|c|c|c|c|c|}
\hline Model & $\chi^{2}$ & TLI & CFI & RMSEA & PCLOSE & SRMR \\
\hline $\mathrm{TL} \mathrm{T}_{1}$-DCC $\mathrm{T}_{2}$-NTO $\mathrm{T}_{2}$ & 3.59 & .94 & .99 & .08 & .255 & .04 \\
\hline & Coefficient & $S E$ & $p$ & $L L C I$ & $U L C I$ & \\
\hline TL-DCC T 2 & -.21 & .09 & .027 & -.38 & -.02 & \\
\hline $\mathrm{DCC} \mathrm{T}_{2}$-NTO $\mathrm{T}_{2}$ & .10 & .07 & .155 & -.04 & .23 & \\
\hline $\mathrm{TL} \mathrm{T}_{1}-\mathrm{NTO} \mathrm{T}_{2}$ & -.15 & .08 & .043 & -.31 & -.004 & \\
\hline
\end{tabular}

Note. $\mathrm{TL}=$ Transformational Leadership. $\mathrm{DCC}=$ Defensive Communication Climate. NTO Conflict $=$ Non-task organizational conflict. Any $\mathrm{T}_{2}$ variables used $\mathrm{T}_{1}$ as control. LLCI/ULCI = bias corrected lower/upper limit confidence interval calculated with 5,000 bootstrap samples. Reported path coefficients are unstandardized OLS regression coefficients.

This model showed a substantial improvement with all indices suggesting a good fit; however, neither found a mediating role for defensive communication climate. Rather, both sets of data at different time points found direct effects. Transformational leadership decreased experiences of a defensive communication climate synchronously (at Time 1) and over time. Both sets of analyses did not find any significant indirect effects (indirect ab effect $=-.03, \mathrm{CI}_{.95}-.09, .004, p=.099 ;$ indirect ab effect $=-.003, \mathrm{CI}_{.95}$ $-.05, .02, p=.586$, respectively); therefore, Hypothesis 5e was not supported.

Hypothesis $5 \mathrm{f}$ stated that the relationship between transformational leadership and CWB was best explained through the effects of a defensive communication climate.

Table 22 shows the results of the first path analysis that used two variables from Time 1 (i.e., leadership and defensive communication climate) and one from Time 2 (i.e., CWB). 
Table 22

Path Analysis: Transformational Leadership $\left(T_{1}\right)$ and Counterproductive Work Behavior $\left(T_{2}\right)$, Defensive Communication Climate $\left(T_{1}\right)$ as Mediator

\begin{tabular}{lcccccc}
\hline \multicolumn{1}{c}{ Model } & $\chi^{2}$ & TLI & CFI & RMSEA & PCLOSE & SRMR \\
\hline TL T $_{1}-\mathrm{DCC} \mathrm{T}_{1}-\mathrm{CWB} \mathrm{T}_{2}$ & 15.91 & .45 & .91 & .35 & .000 & .12 \\
\hline & & & & & \\
& Coefficient & $S E$ & $p$ & LLCI & ULCI \\
\cline { 2 - 6 } TL-DCC T $_{1}$ & -.35 & .09 & .000 & -.52 & -.18 \\
DCC T $_{1}-\mathrm{CWB} \mathrm{T}_{2}$ & .02 & .03 & .572 & -.04 & .08 \\
TL T $_{1}-\mathrm{CWB} \mathrm{T}_{2}$ & -.06 & .03 & .024 & -.12 & -.008 \\
\hline
\end{tabular}

Note. $\mathrm{TL}=$ Transformational Leadership. $\mathrm{DCC}=$ Defensive Communication Climate. $\mathrm{CWB}=$ Counterproductive Work Behavior. Any $\mathrm{T}_{2}$ variables used $\mathrm{T}_{1}$ as control. LLCI/ULCI = bias corrected lower/upper limit confidence interval calculated with 5,000 bootstrap samples. Reported path coefficients are unstandardized OLS regression coefficients.

Not only did this model exhibit poor fit, but the path from defensive communication climate to subsequent CWB at Time 2 was not significant. When defensive communication climate was tested at Time 2, an improved model fit was evidenced but the path from defensive communication climate to CWB was still not significant (see Table 23).

Table 23

Path Analysis: Transformational Leadership $\left(T_{1}\right)$ and Counterproductive Work Behavior $\left(T_{2}\right)$, Defensive Communication Climate $\left(T_{2}\right)$ as Mediator

\begin{tabular}{|c|c|c|c|c|c|c|}
\hline Model & $\chi^{2}$ & TLI & CFI & RMSEA & PCLOSE & SRMR \\
\hline $\mathrm{TL} \mathrm{T}_{1}-\mathrm{DCC} \mathrm{T}_{2}-\mathrm{CWB} \mathrm{T}_{2}$ & 4.06 & .96 & .99 & .09 & .213 & .04 \\
\hline & Coefficient & $S E$ & $p$ & $L L C I$ & $U L C I$ & \\
\hline TL-DCC $\mathrm{T}_{2}$ & -.21 & .09 & .027 & -.38 & -.02 & \\
\hline $\mathrm{DCC} \mathrm{T}_{2}-\mathrm{CWB} \mathrm{T}_{2}$ & .04 & .03 & .168 & -.02 & .09 & \\
\hline $\mathrm{TL} \mathrm{T}_{1}-\mathrm{CWB} \mathrm{T}_{2}$ & -.06 & .03 & .047 & -.12 & -.001 & \\
\hline
\end{tabular}

Note. $\mathrm{TL}=$ Transformational Leadership. $\mathrm{DCC}=$ Defensive Communication Climate. $\mathrm{CWB}=$ Counterproductive Work Behavior. Any $\mathrm{T}_{2}$ variables used $\mathrm{T}_{1}$ as control. 
LLCI/ULCI = bias corrected lower/upper limit confidence interval calculated with 5,000 bootstrap samples. Reported path coefficients are unstandardized OLS regression coefficients.

While neither set of data found a mediating role for defensive communication climate, there was evidence of direct effects. Transformational leadership decreased experiences of a defensive communication climate over time (as previously stated). In addition, transformational leadership decreased the across-time reports of engaging in counterproductive work behavior. However, both sets of analyses did not find any significant indirect effects (indirect $a b$ effect $=-.01, \mathrm{CI}_{.95}-.07, .03, p=.525$; indirect $a b$ effect $=-.02, \mathrm{CI}_{.95}-.06, .002, p=.109$, respectively); thus, Hypothesis $5 \mathrm{f}$ was not supported.

Testing the full, serial mediation model. Hypotheses 6a-c were tested with three sets of temporal data for the two mediators, respectively. For all hypotheses, transformational leadership was tested at $T_{1}$ and counterproductive work behaviors at $T_{2}$ (with $\mathrm{CWB}_{1}$ as control). The temporal model with the overall best fit, as indicated by Kline (2011), is highlighted in figures that follow the tables below.

Hypothesis 6a stated that the relationship between transformational leadership and counterproductive work behavior would be best explained by the mediating effects, in serial, of trust in leadership and non-task organizational conflict. Table 24 below shows the comparisons of the three different temporal tests along with the path coefficients. Figure 3 shows the model with the best overall fit indices. Model 2 exhibited the best fit (Kline, 2011); however, the only significant path was that from NTO to CWB. Thus, Hypothesis 6a was not supported. 
Table 24

Path Analysis: Transformational Leadership $\left(T_{1}\right)$ and Counterproductive Work Behavior $\left(T_{2}\right)$,

Trust in Leader and Non-Task Organizational Conflict as Serial Mediators

\begin{tabular}{|c|c|c|c|c|c|c|}
\hline Model & $\chi^{2}$ & TLI & CFI & RMSEA & PCLOSE & SRMR \\
\hline 1) $\mathrm{TL} \mathrm{T}_{1}$-Trust $\mathrm{T}_{1}-\mathrm{NTO} \mathrm{T}_{1}-\mathrm{CWB} \mathrm{T}_{2}$ & 12.32 & .82 & .97 & .21 & .007 & .09 \\
\hline 2) $\mathrm{TL} \mathrm{T}_{1}$-Trust $\mathrm{T}_{2}-\mathrm{NTO} \mathrm{T}_{2}-\mathrm{CWB} \mathrm{T}_{2}$ & 8.92 & .98 & 1.00 & .06 & .339 & .03 \\
\hline \multirow[t]{2}{*}{ 3) TL $T_{1}$-Trust $T_{1}$ - NTO $T_{2}-\mathrm{CWB} \mathrm{T}_{2}$} & 10.46 & .93 & .98 & .12 & .088 & .05 \\
\hline & Coefficient & $S E$ & $p$ & $L L C I$ & $U L C I$ & \\
\hline TL $\mathrm{T}_{1}$-Trust $\mathrm{T}_{1}$ (models $1 \& 3$ ) & .84 & .07 & .000 & .71 & .96 & \\
\hline $\mathrm{TL} \mathrm{T}_{1}$-Trust $\mathrm{T}_{2}$ & .09 & .08 & .259 & -.07 & .24 & \\
\hline $\mathrm{TL} \mathrm{T}_{1}$-NTO $\mathrm{T}_{1}$ & .13 & .15 & .364 & -.15 & .45 & \\
\hline $\mathrm{TL} \mathrm{T}_{1}$-NTO $\mathrm{T}_{2}(\operatorname{model} 2)$ & -.17 & .12 & .144 & -.39 & .06 & \\
\hline $\mathrm{TL}_{1}-\mathrm{NTO} \mathrm{T}_{2}($ model 3 ) & -.26 & .14 & .058 & -.53 & .007 & \\
\hline Trust $\mathrm{T}_{1}-\mathrm{NTO} \mathrm{T}_{1}$ & -.24 & .14 & .092 & -.53 & .05 & \\
\hline Trust $\mathrm{T}_{2}-\mathrm{NTO} \mathrm{T}_{2}$ & -.03 & .12 & .806 & -.25 & .21 & \\
\hline Trust $\mathrm{T}_{1}-\mathrm{NTO} \mathrm{T}_{2}$ & .08 & .13 & .532 & -.17 & .36 & \\
\hline Trust $\mathrm{T}_{1}-\mathrm{CWB} \mathrm{T}_{2}$ (model 1$)$ & .04 & .05 & .347 & -.05 & .14 & \\
\hline Trust $\mathrm{T}_{1}-\mathrm{CWB} \mathrm{T}_{2}(\operatorname{model} 3)$ & .02 & .04 & .632 & -.06 & .11 & \\
\hline Trust $\mathrm{T}_{2}-\mathrm{CWB} \mathrm{T}_{2}$ & .01 & .04 & .915 & -.07 & .09 & \\
\hline $\mathrm{NTO} \mathrm{T}_{1-} \mathrm{CWB} \mathrm{T}_{2}$ & .10 & .03 & .012 & .02 & .17 & \\
\hline $\mathrm{NTO} \mathrm{T}_{2}-\mathrm{CWB} \mathrm{T}_{2}$ (models $2 \& 3$ ) & .15 & .04 & .000 & .09 & .23 & \\
\hline $\mathrm{TL} \mathrm{T}_{1}-\mathrm{CWB} \mathrm{T}_{2}(\operatorname{model} 1)$ & -.10 & .05 & .036 & -.20 & -.006 & \\
\hline $\mathrm{TL} \mathrm{T}_{1}-\mathrm{CWB} \mathrm{T}_{2}(\operatorname{model} 2)$ & -.05 & .04 & .174 & -.12 & .02 & \\
\hline $\mathrm{TL} \mathrm{T}_{1}-\mathrm{CWB} \mathrm{T}_{2}(\operatorname{model} 3)$ & -.06 & .04 & .154 & -.15 & .03 & \\
\hline
\end{tabular}

Note. TL=Transformational Leadership. Trust $=$ Trust in Leadership. CWB = Counterproductive Work Behavior. $\mathrm{NTO}=$ Non-task Organizational Conflict. Any $\mathrm{T}_{2}$ variables used $\mathrm{T}_{1}$ as control. LLCI/ULCI $=$ bias corrected lower/upper limit confidence interval calculated with 5,000 bootstrap samples. Reported path coefficients are unstandardized OLS regression coefficients. 
Figure 3

Model of Best Fit for Serial Mediation: Trust in Leadership and NTO

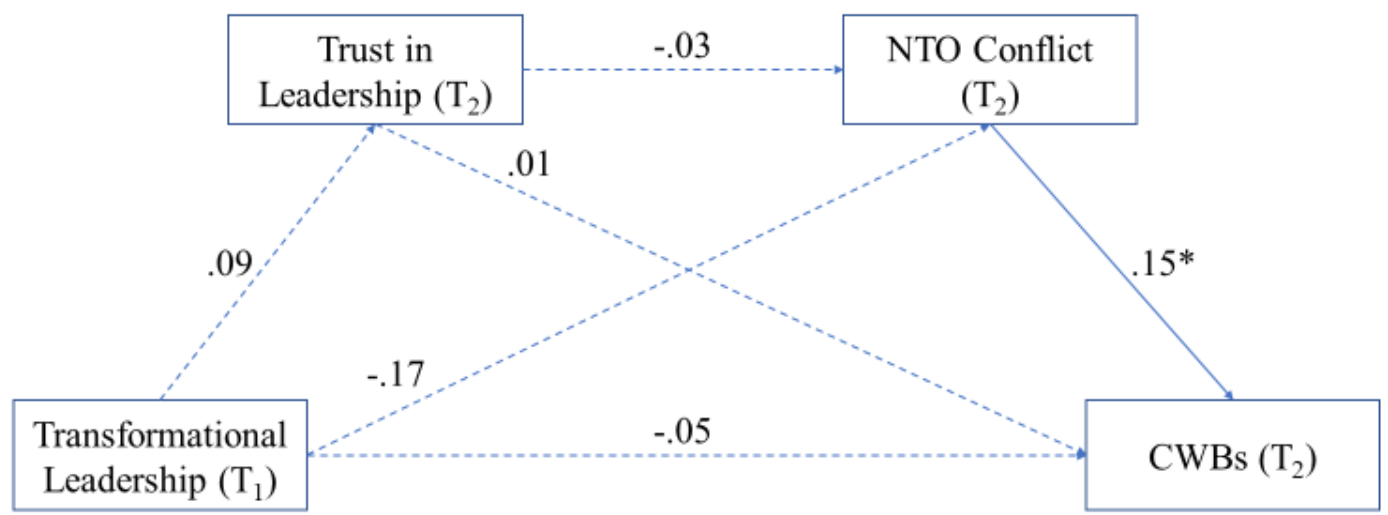

Note: ${ }^{*} p<.01$

Hypothesis $6 \mathrm{~b}$ stated that the relationship between transformational leadership and counterproductive work behavior would be best explained by the mediating effects, in serial, of supportive communication climate (SCC) and non-task organizational conflict. Table 25 below shows the comparisons of the three different temporal tests along with the path coefficients. Figure 4 shows the model with the best overall fit indices; however, it should be noted that this model had two fit indices beyond the ruleof-thumb cut offs (i.e., RMSEA was too high; Pclose was significant). Model 2 exhibited the best fit (Kline, 2011); however, again, the only significant path was that from NTO to CWB. Thus, Hypothesis $6 \mathrm{~b}$ was not supported. 
Table 25

Path Analysis: Transformational Leadership $\left(T_{1}\right)$ and Counterproductive Work Behavior $\left(T_{2}\right)$, Supportive Communication Climate and Non-Task Organizational Conflict as Serial Mediators

\begin{tabular}{|c|c|c|c|c|c|c|}
\hline Model & $\chi^{2}$ & TLI & CFI & RMSEA & PCLOSE & SRMR \\
\hline 1) $\mathrm{TL} \mathrm{T}_{1}-\mathrm{SCC} \mathrm{T}_{1}-\mathrm{NTO} \mathrm{T}_{1}$-CWB T $\mathrm{T}_{2}$ & 24.05 & .56 & .91 & .30 & .000 & .11 \\
\hline 2) $\mathrm{TL} \mathrm{T}_{1}-\mathrm{SCC} \mathrm{T}_{2}-\mathrm{NTO} \mathrm{T}_{2}-\mathrm{CWB} \mathrm{T}_{2}$ & 16.16 & .92 & .98 & .12 & .050 & .05 \\
\hline 3) $\mathrm{TL} \mathrm{T}_{1}-\mathrm{SCC} \mathrm{T}_{1}-\mathrm{NTO} \mathrm{T}_{2}-\mathrm{CWB} \mathrm{T}_{2}$ & 20.53 & .81 & .95 & .18 & .004 & .07 \\
\hline & Coefficient & $S E$ & $p$ & $L L C I$ & $U L C I$ & \\
\hline $\mathrm{TL} \mathrm{T}_{1}-\mathrm{SCC} \mathrm{T}_{1}$ (models $1 \& 3$ ) & .56 & .05 & .000 & .45 & .66 & \\
\hline $\mathrm{TL} \mathrm{T}_{1}-\mathrm{SCC} \mathrm{T}_{2}$ & .02 & .07 & .772 & -.11 & .17 & \\
\hline $\mathrm{TL} \mathrm{T}_{1}-\mathrm{NTO} \mathrm{T}_{1}$ & .02 & .09 & .871 & -.17 & .20 & \\
\hline $\mathrm{TL} \mathrm{T}_{1}-\mathrm{NTO} \mathrm{T}_{2}(\operatorname{model} 2)$ & -.14 & .08 & .070 & -.30 & .01 & \\
\hline $\mathrm{TL} \mathrm{T}_{1}-\mathrm{NTO}_{2}(\operatorname{model} 3)$ & -.22 & .01 & .018 & -.42 & -.04 & \\
\hline $\mathrm{SCC}_{1}-\mathrm{NTO}_{1}$ & -.17 & .11 & .160 & -.38 & .06 & \\
\hline $\mathrm{SCC} \mathrm{T}_{2}-\mathrm{NTO}_{2}$ & -.13 & .09 & .126 & -.30 & .04 & \\
\hline $\mathrm{SCC} \mathrm{T}_{1}-\mathrm{NTO} \mathrm{T}_{2}$ & .04 & .11 & .716 & -.18 & .26 & \\
\hline $\mathrm{SCC} \mathrm{T}_{1}-\mathrm{CWB} \mathrm{T}_{2}$ (model 1$)$ & -.04 & .04 & .351 & -.13 & .05 & \\
\hline $\mathrm{SCC}_{1}-\mathrm{CWB} \mathrm{T}_{2}$ (model 3) & -.06 & .04 & .160 & -.15 & .03 & \\
\hline $\mathrm{SCC} \mathrm{T}_{2-} \mathrm{CWB} \mathrm{T}_{2}$ & -.05 & .03 & .101 & -.12 & .01 & \\
\hline $\mathrm{NTO} \mathrm{T}_{1}-\mathrm{CWB}_{2}$ & .10 & .04 & .029 & .01 & .18 & \\
\hline $\mathrm{NTO} \mathrm{T}_{2}$ - CWB $\mathrm{T}_{2}$ (model 2) & .15 & .07 & .000 & .08 & .22 & \\
\hline $\mathrm{NTO}_{2}-\mathrm{CWB} \mathrm{T}_{2}(\operatorname{model} 3)$ & .16 & .04 & .000 & .09 & .22 & \\
\hline $\mathrm{TL} \mathrm{T}_{1}$-CWB $\mathrm{T}_{2}(\operatorname{model} 1)$ & -.05 & .04 & .655 & -.16 & .25 & \\
\hline $\mathrm{TL} \mathrm{T}_{1}$-CWB $\mathrm{T}_{2}$ (model 2) & -.03 & .03 & .269 & -.08 & .02 & \\
\hline $\mathrm{TL} \mathrm{T}_{1}$-CWB $\mathrm{T}_{2}(\operatorname{model} 3)$ & -.10 & .03 & .744 & -.08 & .05 & \\
\hline
\end{tabular}

Note . TL $=$ Transformational Leadership. Trust $=$ Trust in Leadership. $\mathrm{CWB}=$ Counterproductive Work Behavior. NTO = Non-task Organizational Conflict. Any T2 variables used T1 as control. LLCI/ULCI = bias corrected lower/upper limit confidence interval calculated with 5,000 bootstrap samples. Reported path coefficients are unstandardized OLS regression coefficients. 
Figure 4

Model of Best Fit for Serial Mediation: Supportive Communication Climate and NTO

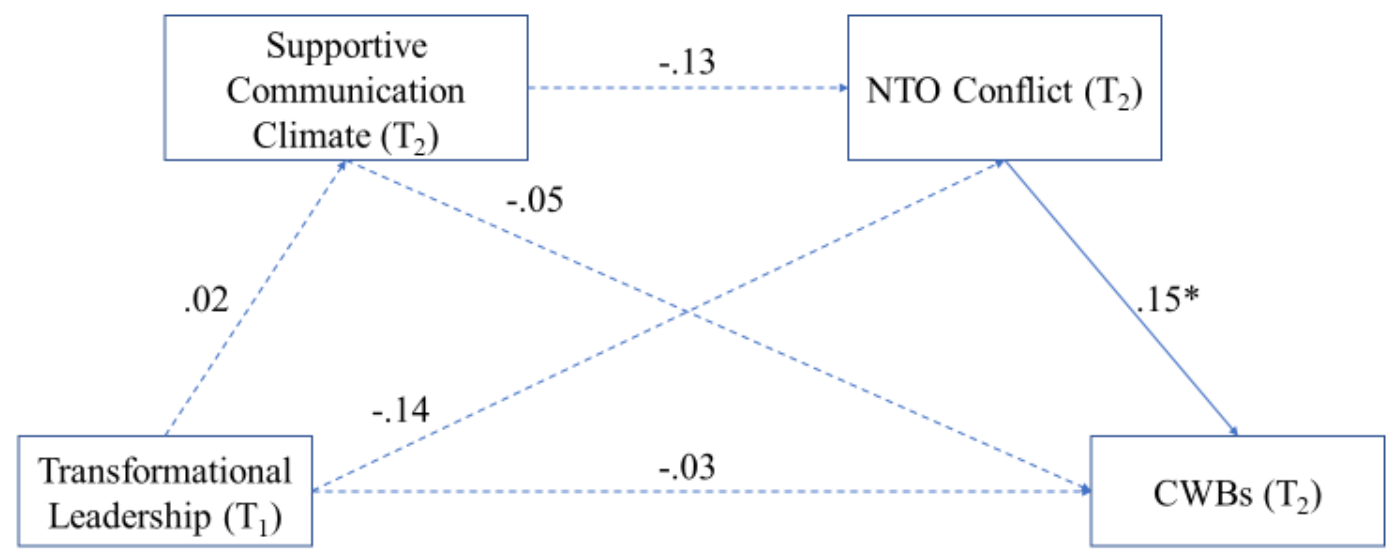

Note: ${ }^{*} p<.01$

Hypothesis $6 \mathrm{c}$ stated that the relationship between transformational leadership and counterproductive work behavior would be best explained by the mediating effects, in serial, of defensive communication climate (DCC) and non-task organizational conflict. Table 26 below shows the comparisons of the three different temporal tests along with the path coefficients. Figure 5 shows the model with the best overall fit indices. Model 2 exhibited the best fit (Kline, 2011); however, while the path from transformational leadership to defensive communication climate was significant, the path from defensive climate to NTO was not. In addition, the path connecting transformational leadership, NTO, and CWB were significant. Thus, Hypothesis 6c was partially supported. 
Table 26

Path Analysis: Transformational Leadership $\left(T_{1}\right)$ and Counterproductive Work Behavior $\left(T_{2}\right)$, Defensive Communication Climate and Non-Task Organizational Conflict as Serial Mediators

\begin{tabular}{|c|c|c|c|c|c|c|}
\hline Model & $\chi^{2}$ & TLI & CFI & RMSEA & PCLOSE & SRMR \\
\hline 1) $\mathrm{TL} \mathrm{T}_{1}-\mathrm{DCC} \mathrm{T}_{1}-\mathrm{NTO} \mathrm{T}_{1}-\mathrm{CWB} \mathrm{T}_{2}$ & 25.11 & .36 & .87 & .31 & .000 & .13 \\
\hline $\mathrm{TL} \mathrm{T}_{1}-\mathrm{DCC} \mathrm{T}_{2}-\mathrm{NTO} \mathrm{T}_{2}-\mathrm{CWB} \mathrm{T}_{2}$ & 10.94 & .95 & .98 & .08 & .209 & .05 \\
\hline \multirow[t]{2}{*}{$\mathrm{TL} \mathrm{T}_{1}-\mathrm{DCC} \mathrm{T}_{1}-\mathrm{NTO} \mathrm{T}_{2}-\mathrm{CWB} \mathrm{T}_{2}$} & 21.98 & .73 & .93 & .19 & .001 & .10 \\
\hline & Coefficient & $S E$ & $p$ & $L L C I$ & $U L C I$ & \\
\hline $\mathrm{TL} \mathrm{T}_{1}-\mathrm{DCC}_{1}(\operatorname{model} 1 \& 3)$ & -.35 & .09 & .000 & -.52 & -.18 & \\
\hline $\mathrm{TL} \mathrm{T}_{1}-\mathrm{DCC} \mathrm{T}_{2}$ & -.21 & .09 & .027 & -.38 & -.02 & \\
\hline $\mathrm{TL} \mathrm{T}_{1}-\mathrm{NTO} \mathrm{T}_{1}$ & -.03 & .08 & .731 & -.18 & .13 & \\
\hline $\mathrm{TL} \mathrm{T}_{1}-\mathrm{NTO} \mathrm{T}_{2}(\operatorname{model} 2)$ & -.15 & .08 & .043 & -.31 & -.004 & \\
\hline $\mathrm{TL} \mathrm{T}_{1}-\mathrm{NTO}_{2}(\operatorname{model} 3)$ & -.18 & .08 & .014 & -.34 & -.03 & \\
\hline $\mathrm{DCC} \mathrm{T}_{1}-\mathrm{NTO} \mathrm{T}_{1}$ & .14 & .07 & .048 & .001 & .26 & \\
\hline $\mathrm{DCC} \mathrm{T}_{2}-\mathrm{NTO} \mathrm{T}_{2}$ & .10 & .07 & .155 & -.04 & .23 & \\
\hline $\mathrm{DCC} \mathrm{T}_{1}-\mathrm{NTO} \mathrm{T}_{2}$ & .04 & .06 & .515 & -.08 & .17 & \\
\hline $\mathrm{DCC} \mathrm{T}_{1}-\mathrm{CWB} \mathrm{T}_{2}(\operatorname{model} 1)$ & .01 & .03 & .720 & -.05 & .07 & \\
\hline $\mathrm{DCC} \mathrm{T}_{1}-\mathrm{CWB} \mathrm{T}_{2}($ model 3$)$ & .02 & .03 & .615 & -.04 & .07 & \\
\hline $\mathrm{DCC} \mathrm{T}_{2}-\mathrm{CWB} \mathrm{T}_{2}$ & .02 & .02 & .488 & -.03 & .06 & \\
\hline $\mathrm{NTO}_{\mathrm{T}_{1}}-\mathrm{CWB} \mathrm{T}_{2}$ & .10 & .03 & .024 & .01 & .17 & \\
\hline $\mathrm{NTO} \mathrm{T}_{2}-\mathrm{CWB} \mathrm{T}_{2}(\operatorname{model} 2 \& 3)$ & .15 & .04 & .000 & .08 & .22 & \\
\hline $\mathrm{TL}_{1}-\mathrm{CWB} \mathrm{T}_{2}($ model 1$)$ & -.06 & .03 & .018 & -.12 & -.01 & \\
\hline $\mathrm{TL} \mathrm{T}_{1}-\mathrm{CWB} \mathrm{T}_{2}(\operatorname{model} 2)$ & -.04 & .03 & .102 & -.09 & .008 & \\
\hline $\mathrm{TL} \mathrm{T}_{1}-\mathrm{CWB} \mathrm{T}_{2}(\operatorname{model} 3)$ & -.04 & .03 & .119 & -.09 & .01 & \\
\hline
\end{tabular}

Note. TL=Transformational Leadership. Trust $=$ Trust in Leadership. $\mathrm{CWB}=$ Counterproductive Work Behavior. $\mathrm{NTO}=$ Non-task Organizational Conflict. Any $\mathrm{T}_{2}$ variables used $\mathrm{T}_{1}$ as control. LLCI/ULCI $=$ bias corrected lower/upper limit confidence interval calculated with 5,000 bootstrap samples. Reported path coefficients are unstandardized OLS regression coefficients. 
Figure 5

Model of Best Fit for Serial Mediation: Defensive Communication Climate and NTO

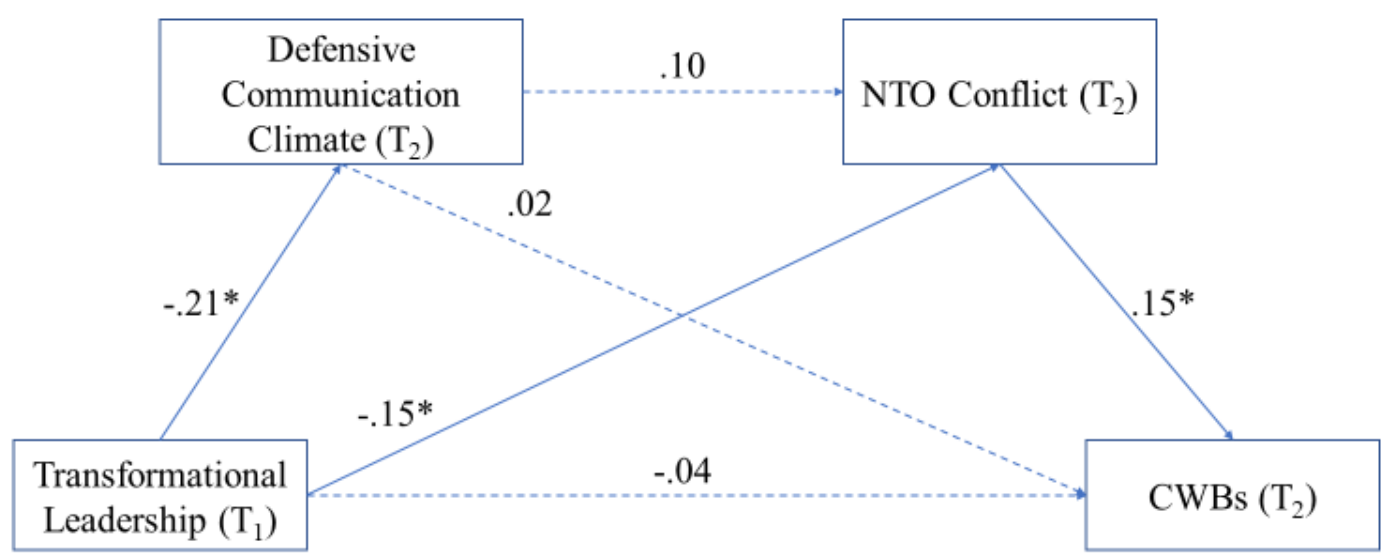

Note: $* p<.01$ 


\section{DISCUSSION}

This dissertation has attempted to bridge two areas of organizational research (i.e., occupational health psychology and leadership theory) that have historically had divergent trajectories. While a few studies have attempted to understand the role of leadership in the stressor-strain process (e.g., Kessler et al., 2013), there remains a paucity of scholarship in this area. Research in transformational leadership has generally lacked both theoretical reasoning and empirical evidence for its causal effects (Knippenberg \& Sitkin, 2013); research in transactional models of stress and well-being have generally ignored the wider context in which appraisals occur (Koslowsky, 1998). The present dissertation attempts to bridge the criticism of these two lines of research by placing the role of leadership within the context of employee transactional reactions to stress. Transformational leaders, through their appeals to positive motivational mechanisms, role modeling, and engagement in frame alignment (Shamir et al., 1993), would set the stage for employee appraisals that were less threatening. This could be accomplished by the influence transformational leaders may have on the organizational climate (i.e., communication climate). Improving climates may influence appraisal systems as "climates [can] afford an informational benefit... which in turn motivates group members to adapt accordingly" (Dragoni, 2005, p. 1087). The reduction in a threatened appraisal of a stressor would result in subsequent reduction of the expression of a strain. Some of the results of the reported in the previous chapter suggest this process. However, as will be discussed below, the picture that emerges may not be as straightforward. 


\section{Transformational Leadership and Stressor-Strain}

Transformational leadership and non-task organizational conflict. The results from chapter four indicate that transformational leadership may serve as a precondition to the experience of non-task organizational conflict (NTO), such that the perception of transformational leadership may reduce such experiences. In addition, the influence of transformational leadership seems to have an effect over time. After controlling for initial perceptions of NTO, the relationship between initial perceptions of transformational leadership and subsequent NTO remained negative, a month later, when a leader was perceived as being transformational, a month prior $(\beta=-.23, p=.002)$.

Although causality in the fullest sense of the term may not yet be invoked, the method utilized separated the collection of predictor from criterion, allowing for preliminary evidence of a causal relationship (Mathieu \& Taylor, 2006). Initial perceptions of transformational leadership continued to have an ameliorating effect approximately four weeks out. From the perspective of appraisal theory, employees who perceived their leaders as behaving transformationally were less likely to report having engaged in disputes that were rooted in disagreements over organizational policies and procedures. Through their ability to frame align (Shamir et al., 1993), it is possible that transformational leaders reframed and reinterpreted organizational policies for employees, thus reducing the likelihood of disputes with others that was rooted in the misinterpretation of said policies.

Transformational leadership and counterproductive work behaviors. The perception of transformational leadership influenced appraisals of the stressor, 
additionally it had a direct and lasting effect on the strain. After controlling for initial levels of counterproductive work behaviors (CWB), perceptions of transformational leadership, had a lagged effect on CWB, reducing employees reporting of engagement in such behaviors $(\beta=-.14, p=.012)$. Although this is an interesting finding in and of itself, given the paucity of research connecting transformational leadership with CWB, it does not explain the mechanisms by which this relationship might occur. A possible explanation for this finding could be that transformational leadership was seen as a form of social support, thus reducing the experience of CWB. Viswesvaran, Sanchez, and Fisher (1999), in a meta-analysis of the role of social support in work stress, found that, in general, social support reduced strains independent of its effect on stressors. However, while the perception of a transformational leader had effects across time in predicting the reduction of destructive behaviors, an appraisal perspective demands that a fuller mechanism be tested.

\section{NTO fully mediated the relationship between transformational leadership}

and CWB. Conceptualizing the role of leadership from an appraisal perspective would place it at the beginning of a causal chain of events, leading to stressor and then strain. The results supported this mediation hypothesis. Initial perceptions of transformational leadership indirectly influenced subsequent reports of CWB (fully) through its influence on NTO. That is, after controlling for the initial perceptions of NTO and CWB, initial perceptions of transformational leadership had a significant and across-time subsequent direct and indirect effect. From an appraisal perspective, the initial perceptions of transformational leadership altered the appraisal framework of the stressor (i.e., NTO) in such a manner as to make it less threatening (even at a later time). Moreover, o $\mathrm{n}$ the 
basis of frustration-aggression theory of CWB (Fox \& Spector, 1999), stressors appraised as less threatening reduce the experience of frustration; thus, aggressive reactions would subsequently diminish. The finding that non-task organizational conflict mediates the relationship between leadership perceptions and engagement in counterproductive work behaviors is important in that it expands the theoretical and empirical knowledge of the processes undergirding the ameliorating effects of transformational leadership. The results replicate the findings of a previous unpublished study using a similar sample (Rodriguez \& Bruk-Lee, 2016b). However, that study used a single time point, crosssectional design. The design used in this dissertation separated the collection of predictor from outcome and thus provides a more robust test that is less threatened by common method variance.

Recent studies and reviews of transformational leadership have emphasized its consistent relationship with positive states of mind and health (Arnold, 2017). However, the findings, thus far, of this dissertation suggest that transformational leadership may also offer an ameliorating role on negative states of mind. Arnold (2017) suggests a possible mechanism stating, "it appears transformational leaders change the conditions of work for employees, and through this process have an influence on employee well-being" (p. 389). To elaborate on this mechanism, from an appraisal perspective, the conditions of work also may refer to how employees interpret their work environment (Arnold \& Walsh, 2015). Transformational leaders thus can "change the conditions of work" by helping to alter the way in which situations are evaluated (i.e., reducing threat appraisals). In addition, employees who perceived a transformational leader also may perceive more social support. As Lyons and Schneider (2009) found in an experimental study, 
participants in the transformational leader condition reported greater perceptions of social support than those in the non-transformational condition. Viswesvaran et al. (1999) report that "[social support] reduce[d] the strength of the stressors themselves...alleviat[ing] the effects of stressors on strains" (p. 329). Therefore, the ameliorating effects of transformational leadership can be observed through the prism of appraisal and support.

Interpersonal locus of control did not moderate. While two previous studies have found evidence for the moderating effect of interpersonal locus of control on the relationship between NTO and CWB (Nixon et al., 2013; Rodriguez \& Bruk-Lee, 2016b), the results here failed to replicate the previous findings. The interpretation of this result is difficult, although one possibility could be that control was misspecified. Other studies of control have investigated such aspects as work locus of control (e.g., Sprung \& Jex, 2012). Conceptualizing control from an interpersonal perspective may have missed work-specific dimensions of control that may be pertinent to the experience of interpersonal conflict at work, especially conflict rooted in disputes over organizational policy. Further research is needed to clarify the function and extent of control as a moderator of this relationship.

\section{Trust in Leadership Does Not Mediate}

Even though previous studies have found trust in leadership to be associated with various well-being outcomes and conflict in organizations (e.g., Harvey et al., 2003; Kelloway et al., 2012), the results of my dissertation were not able to replicate previous findings. Initial levels of trust in leadership predicted subsequent reports of NTO ( $\beta=$ $.17, p=.023)$ only. However, initial levels of transformational leadership were not 
related to subsequent perceptions of trust in leadership; therefore, all further analyses of trust as a mediator were rendered non-significant. A few possibilities are available to explain the lack of findings with trust in leadership. First, despite there being reliable measures of trust (e.g., Mayer \& Davis, 1999), a standard measurement of trust has not emerged. For example, Kelloway et al. (2012) used only four items drawn from an eightitem measure of trust. Harvey et al. (2003) took six items from the same eight-item measure Kelloway et al. used. Therefore, it is unclear if past findings were the result of the true measurement of trust or artifacts of measurement error.

In addition, the trust literature has not been consistent in the conceptualization of the construct itself. For example, Kramer and Tyler (1995) argue that trust is based on a rational framework that results in calculations of risk. In this context then trust can be understood from a social exchange perspective (i.e., cost-benefits). Moreover, according to Burke, Sims, Lazzara, and Salas (2007), trust also can be conceptualized as either a trait (i.e., propensity to trust), an emergent state (i.e., dynamic and varies as a function of its context), or as a process (i.e., through which other mechanisms are enhanced or attenuated).

Another reason for the lack of predicted findings could be that trust works through different causal mechanisms than those predicted. Measurement issues aside, it is possible that the conceptualization of trust may be related to other, more attitudinallybased, organizational phenomena not measured in this dissertation (e.g., job satisfaction; see Braun, Peus, Weisweiler, \& Frey, 2013; Yang, 2014). Moreover, trust may be related to other well-being outcomes (i.e., burnout, see Arnold, 2017) that were not the focus of this dissertation. And last, participants may have had difficulty differentiating the 
constructs of trust and transformational leadership. The literature often stated that transformational leaders inspire trust in their employees (Bass, 1998); however, as Knippenber and Sitkin (2013) pointed out, a problem with transformational leadership research is the ill-defined concept of leadership along with the theoretical overlap with mediators. The correlation between trust and transformational leadership was above .80, indicating the possibility of collinearity. Additionally, a post hoc check of model fit of the two constructs suggests inadequate fit $\left(\chi^{2}=818.99, \mathrm{df}=456 p<.000, \mathrm{TLI}=.90, \mathrm{CFI}\right.$ $=.91$, RMSEA $=.08$, PClose $=.000$, SRMR $=.10)$.

\section{The Effects of Communication Climate}

Communication climate and stressor-strain. This area of the dissertation represents wholly unchartered territory. While previous studies have investigated the role of climate on CWBs (Ehrhart \& Raver, 2014), none have focused specifically on communication climate (i.e., expectations of communicative acts). The results suggested that initial higher perceptions of a supportive communication climate generally ameliorated subsequent reports of NTO and CWB $(\beta=-.15$ for both, $p=.041$ and .013 , respectively). However, defensive communication climate was not related to subsequent NTO or CWB. As the name implies, supportive communication may hint at a climatelevel dimension of social support that would explain its alleviating function on both stressor and strain (Visveswaran et al., 1999).

Transformational leadership and communication climate. Interestingly, transformational leadership was only predictive of subsequent perceptions of a defensive communication climate $(\beta=-.19, p=.011)$. It did not predict subsequent supportive communication climate. While the correlation between transformational leadership at 
Time 1 and supportive communication climate at Time 2 was strong $(r=.54, p<.05)$, when the effects of Time 1 supportive communication climate were controlled, this relationship became tenuous. Initial levels of transformational leadership were strongly correlated with initial level of supportive communication climate $(r=.71, p<.05)$ indicating the possibility of issues related to multicollinearity, though these changes may also represent temporal issue in measurement. It is possible that the two-time points were not enough to capture the full temporal development of a supportive communication climate. In addition, it is possible that the effects of transformational leadership on the appraisals of a supportive communication climate are more immediate.

Although supportive communication climate predicted both subsequent NTO and CWB, there was no support for its role as a mediator of the tested relationships. In addition, even though transformational leadership predicted perceptions of a defensive communication climate, there was no support for the influence of defensive communication climate on either NTO or CWB.

These findings suggest that perceptions of transformational leadership may be independent of appraisals of the communication climate. It is possible that communication climate is influenced by organizational matters beyond the leader's control. Some researchers have argued that overall organizational communication (a different but related construct) may be viewed from a metonymic perspective (Christensen \& Cornelissen, 2011); that is, organizational communication is seen as being representative of the whole organization, not just the leader. In this same vein, communication climate, especially supportive communication climate, may have more metonymic properties: it may be perceived as being representative of the whole 
organization. Thus, the communication climate may provide employees with an implicit meta-message about the organization (Hoogervorst, van der Flier, \& Koopman, 2004).

Though it seemed theoretically appealing to view supportive communication climate as being the result of transformational leadership, the empirical evidence did not support this notion. Aside from further research needed to replicate or refute this finding, another theoretical perspective may place transformational leadership as a moderator of the supportive communication climate-outcome relationship. Wegge, Shemla, and Haslam (2014) argue that there are several pathways by which leadership affects health; one such path is termed moderating action. According to Wegge et al. (2014), "leader behavior (and presence) can have an especially significant role to play in serving either as a buffer against contextual factors that might otherwise be a source of strain (e.g., high work demands) or as an amplifier of pre-existing organizational or personal resources (e.g., various forms of support) that can be drawn upon in ways that protect and promote health" (p. 15). From this perspective, the perception of transformational leadership may serve as a moderator by enhancing the relationship between a supportive communication climate and outcomes such as NTO or CWB (i.e., by reducing their expression).

No evidence for serial mediation. From the review above, it is clear why no evidence of serial mediation was found. First, as just reviewed, trust in leadership did not itself mediate any relationship and was only predictive of one variable (i.e., NTO). Additionally, though supportive communication climate did predict subsequent NTO and CWB, nonetheless, it was not itself predicted by perceptions of transformational leadership. Conversely, even though defensive communication climate was predicted by transformational leadership, the full mediation model was not significant. As previously 
stated, these null findings could indicate a misspecification of the theory: communication climate may have a different etiology than originally theorized.

\section{Limitations}

The findings of this dissertation reveal interesting areas for further inquiry; however, it is necessary to address some of the limitations to better contextualize the results. Four major areas of limitations are reviewed below: design and methodological issues, unaccounted or misspecified variables, "newness" of communication climate, and theoretical issues underpinning transformational leadership.

However, it first must be mentioned that the sample for this study was drawn primarily from administrators in the field of higher education. Data were gathered at the end of the spring semester; thus, it is unclear if stressors at the end of the semester may have exacerbated the perception of conflict. This may limit the generalization of the findings.

Design and methodological issues. Although attempts were taken to separate the collection of predictor from criterion by employing a two-wave research design, this may not have been a sufficient number of time points to test for multiple mediators. According to Cole and Maxwell (2003), there should be as many time points as there are variables (i.e., predictors, mediators, and outcomes). However, there is no clear rule of thumb as to how much time must elapse before the next wave of data should be collected. The time intervals needed between waves of data collection can vary widely (Ford, Matthews, Wooldridge, Mishra, Kakar, \& Strahan, 2014). In addition, it is difficult to determine the causal ordering of mediators. A possible solution for both is offered by Mathieu and Taylor (2006): 
no statistical analysis can unequivocally differentiate one causal sequence from another. Theorists and researchers must then rely on other means to justify the sequence of effects. The most valuable bases to advance such inferences come from 1) experimental design, 2) temporal precedence, and 3) theoretical rationale. (p. 1033) While theoretical rationale was used in the causal ordering of the mediators and time intervals of this dissertation, the temporal ordering and window may have been misspecified. Therefore, although some of the findings are promising, further research is needed to determine the appropriate length of time for the testing of causal mediation. Ford et al. (2014), in a meta-analysis of the longitudinal relationships between stressors and strains, found the "cross-sectional correlations between stressors and strains tended to increase over time in longitudinal studies, with this increase becoming larger when there was a longer period of time between measurement occasions" (p. 23). Moreover, they reported that the lagged effects of strains can increase for up to three years before declining. Given that the time interval was approximately four weeks, the results may not provide a sufficient understanding of the time dimension undergirding the causal effects.

Although controlled experimentation is the vanguard of establishing causal effects, in applied research, such ideal settings may be elusive. Even though randomized assignment to experimental and control groups may not be feasible in applied research, steps should be taken to consider how the design of the study will affect the interpretation of the outcomes of the study. Stone-Romero and Rosopa (2008) forcefully argue for the careful wording of the interpretation of non-experimentally designed tests of mediation. They state that it is misleading for researchers to connote causal relationships using non- 
experimental design because of the possibility of model misspecification and the existence of other, more accurate, models.

Unaccounted and misspecified variables. This dissertation attempted to understand the role of social stressors at work (i.e., interpersonal conflict) as opposed to more traditionally studied stressors (e.g., role stress and work overload). It is possible that by not including these traditionally studied variables, an important causal link may have been missed. For example, Jaramillo, Mulki, and Boles (2011) found that role stress (i.e., role conflict and role ambiguity) and work overload were antecedents to the experience of interpersonal conflict. Specifically, as role stress increased (i.e., greater role conflict and ambiguity), perceptions of work overload also increased, which in turn lead to higher reports of interpersonal conflict with coworkers. It is also possible that a crucial link was missed between transformational leadership and role stress. Russ, McNeilly, and Comer (1996) reported that employees who worked under leaders exhibiting a more transformational style experienced less overall role stress than those who worked under a more laissez-faire or avoidant leader.

Role stress (specifically, role conflict) may have been an overlooked variable in the plausible causal chain. Jex and Britt (2008) have construed role conflict as, "result[ing] from inconsistent information or conflicting demands provided by different members of an employees' role set" (p. 211). Thought the data of my dissertation did not support the notion that transformational leadership influences perceptions of a supportive communication climate, there was some support for the defensive aspects of communication climate. Communication climate may influence the experience of role conflict. For example, a more supportive communication climate may reduce employee 
perceptions of receiving inconsistent messages about their roles because the communicative expectations are such that employees feel encouraged and expected to seek role clarification.

In addition, some researchers have suggested that perceptions of injustice at work also may be construed as a stressor. Fox, Spector, and Miles (2001) found that perceptions of injustice (i.e., both procedural and distributive), as well as interpersonal conflict, were related to reports of counterproductive work behaviors. They claimed that, "perceptions of injustice can be conceptualized as a form of perceived job stress." (p. 303). Other studies have found transformational leadership may reduce perceptions of procedural injustice (e.g., Kim \& Kim, 2015; Wang, Ma, Zhang, 2014).

Last, communication climate may need to be considered within the larger framework of organizational communication. According to Lammers (2011), organizational communication can refer to the ways in which organizational messages are disseminated. Hartman and Johnson (1990) had previously noted organizational communication as having two dimensions: formal and informal. Formal organizational communication typically refers to the official channels of message dissemination (Rodriguez \& Bruk-Lee, 2016a). Contrastingly, informal communication refers to informal social networks, the so-called grapevine (Krackhardt \& Hanson, 1993). Communication climate, as representing the expectations of communicative acts in the workplace, may be influenced by and emerge from these formal and informal aspects of the larger organizational communication. As Hoogervorst et al. (2004) have argued, the organizational context can send implicit messages to employees about the norms and expectations that subsequently influence their behavior. Moreover, Christensen and 
Cornelissen (2011) have argued that the organization should be seen "as a single unit in communication with its stakeholders. It is not individual managers, buildings, advertising campaigns or interactions with employees that communicate in and of themselves. Rather these are seen as parts or fragments of the same communicating organization...” (p. 388). Organizational messages may influence individual behavior as messages can transmit the principles, ideals, and identity of an organization (Lammers, 2011). Communication climate, particularly its supportive dimension, then may have an etiology outside of the direct influence of leaders, no matter how transformational they may be. Rodriguez and Bruk-Lee (2016a) found that employees who reported the organization as utilizing more formal channels to disseminate organizationally relevant information also reported less non-task organizational conflict. There may then be a relationship between supportive communication climate and having access to formal channels of organizational communication.

"Newness" of communication climate measure. The concept of communication climate has not received much attention in communication or organizational scholarship. As a facet-specific form of climate, it serves as an interesting way of conceptualizing specific workplace norms. While Gibb's (1961) exposition on the matter was ostensibly based on his interpretation of the results of field studies using taped recordings of human relations training sessions, he offered no data to support his convictions. Later, Costigan and Schmeidler (1984) provided an instrument, the Communication Climate Inventory (CCI), based on Gibb's characteristics of supportive and defensive communication climates. Unfortunately, it is not clear how Costigan and Schmeidler created their inventory, nor if they conducted any psychometric testing of the 
properties of the inventory. While the measure had been previously used (e.g., Larsen \& Folgero, 1993), it was not until Forward et al. (2011) that the inventory was submitted to confirmatory testing. And while Forward et al. were able to produce the two dimensions (i.e., supportive and defensive), they failed to produce the original 12 -factors as proffered by Gibb (1961). Moreover, in this dissertation, the factors purported to be found by Forward et al. (2011) were not replicated for supportive communication climate. Instead, supportive communication climate evidenced a four-factor underlying model. Therefore, issues with instrumentation and operationalization of the construct may have attenuated some of the results. Replication of the four-factor supportive communication climate construct will be needed to verify this structure.

Last, there was little agreement in the literature about what communication climate constitutes. While Gibb's conceptualization has been invoked without use of the Communication Climate Inventory (e.g., Bradley \& Campbell, 2016), other ways of operationalizing communication climate have been used, namely Dennis's (1976). Dennis's operationalization of communication climate was distinct from Gibb's. While Dennis's measure included an aspect of supportive communication, other factors included reliability of information and upward communication opportunities. In light of the previous discussion of organizational communication, it seems that further theoretical exposition might differentiate communication climate from organizational communication. Gibb's approach tends to focus on expectations toward communicative acts at work. Dennis's approach considers access to and quality of information. While both use the term "communication climate" they seem to be referring to wholly different phenomena. 
Theoretical issues underpinning transformational leadership. Finally, the construct of transformational leadership may itself have been a limitation. While massive numbers of empirical studies have explored the effects of transformational leadership, there is a dearth of elucidation on the theory of transformational leadership. An early critique by Yukl (1999) pointed out a few of its weaknesses. Yukl argues that previous writings on the theoretical underpinnings of transformational leadership leave an ambiguity as to the underlying influence processes. Previous theory has not adequately described the specific causal mechanisms and mediating variables that would lead to specific outcomes. Also, the theory and measurement of transformational leadership has been ambiguous about the actual transformational behaviors themselves or has omitted important behaviors (e.g., task-oriented behavior). Finally, Yukl points to the insufficient specification of situational variables in the measurement of transformational leadership. According to Yukl, "situational variables may increase the likelihood of transformational leadership or moderate its effects" (p. 291).

In a more recent critique, Knippenberg and Sitkin (2013) offer two additional weaknesses: lack of configurational theory of the model and defining leadership by its effects. They argue that most of the instruments used to measure transformational leadership assume, a priori, an additive model. That is, rather than investigate the unique contributions of any one dimension of transformational leadership, most studies combine the response set in an additive way and work with one global measure of transformational leadership. Theory lacks in this area to guide research. The additive model is an assumption that may obfuscate other relationships that may exist between the dimensions of transformational leadership. They argue that, 
"the additive model in principle treats [the dimensions] as independent influences on outcomes. If, however, these influences are interactive rather than additive, by taking the additive model for grated without conceptual justification, we are seriously limiting our potential for theory development.” (p. 13).

The five-factor model proposed by Rafferty and Griffin (2004) was successfully reproduced with the data set of this dissertation. However, much like their initial findings, the factors were highly inter-correlated. These high inter-factor correlations, across different measures of transformational leadership, have generally led to the use a global summative score. By not investigating the "different dimensions [that] combine to affect outcomes," (Knippenberg \& Sitkin, 2013, p. 13), this dissertation may have been limited in understanding the various mechanisms by which leadership may influence communication climate and its specific dimensions. In addition, it is possible that one of the leadership factors could have accounted for the lion's share of variance in explaining the models tested in this dissertation. However, without further development of a configurational theory of transformational leadership, these ideas are left to speculation and thus may limit the interpretations of the findings.

Finally, Knippenberg and Sitkin (2013) claim a major weakness of transformational leadership theory is that transformational leadership is defined by its effects. This may help to explain the lack of findings for trust in leadership in this dissertation. Previous research has found trust in leadership to be an important outcome of transformational leaders (e.g., Liu et al., 2010). However, others have stated that transformational leadership entails the building of trust; that is, transformational leaders are by definition, trustworthy (Bass, 1998). In addition, Knippenberg and Sitkin (2013) 
point to a major methodological shortcoming of transformational leadership research design: 'the inclusion of perceptions of leadership's effects on the predictor side, while similar perceptions are included on the outcome side.” (p. 15). This may serve as a significant limitation, not only in attenuating results but rendering findings difficult to interpret.

\section{Future Research and Directions}

The limitations previously described, in concert with the findings, reveal various opportunities for future research. What follows is an attempt to provide some guidance as to the possible avenues of future research and outline additional theoretical considerations.

Further exploration of communication climate. Further research could facilitate understanding of communication climate. By focusing on the expectations of communicative acts, future research will be needed to establish its psychometric properties. The measure developed by Costigan and Schmeidler (1984) and revised by Forward et al. (2011) seemed reliable (according to the Cronbach alphas); nonetheless, its construct validity could benefit from further exploration. Future studies should consider developing new items, as the original 12 factor-model purported by Gibb (1961) and later developed into an inventory by Costigan and Schmeidler (1984) was not supported (Forward et al., 2011; nor by the results of this study). Careful inspection of the items proffered by Costigan and Schmeidler revealed possible overlap with concepts of organizational justice, specifically interactional justice. Interactional justice refers to the interpersonal treatment received from others in the workplace (Bies, 2001). The factor analysis carried out in this study discovered supportive communication to have four 
underlying factors. One of the new factors (i.e., equality) had five items that all related to workplace treatment (see Appendix $\mathrm{C}$ for full list of items). To further validate the concept of supportive communication climate, future research could assess if the construct is distinct from perceptions of interactional justice and develop new items that target the specific expectations of communicative acts.

Furthermore, future research may want to consider the interrelationship between supportive and defensive communication climates. It is possible that one can attenuate the effects of the other; what are the affects on organizational outcomes in conditions under which both dimensions are high or low? Could one be a mediator or moderator of the other? In relation to the variables of study in this dissertation, it could be that the relationship between supportive communication climate and NTO or CWB is enhanced under conditions of a less defensive climate. Contrastingly, the relationship between a defensive communication climate and NTO or CWB may be mitigated by the influence of a high supportive communication climate. Therefore, while my original argument is that communication climate precedes the experience of stressors and strains, future research might test the notion that climate itself may buffer or exacerbate such experiences.

Trust as a moderator of the stressor-strain relationship. While trust did not seem to be an antecedent to the perception of non-task organizational conflict (NTO), it is possible that it could moderate the effects of NTO on CWBs. Under conditions of high trust, it is possible that the stressor-strain relationship would weaken, as trust might be construed as an aspect of social support. Harvey et al. (2003) found that trust in management buffered the relationship between perceptions of work overload and 
burnout. Though they caution that trust may have a limited effect, based on the results of the slopes in their sample. Trust buffered the effects of work overload to a degree, so long as employees did not perceive the workload to be excessive. In a study of relationship conflict and organizational citizenship behavior, Kacmar et al. (2011) found that trust moderated that relationship but only for conflict between subordinates. It is possible then that trust may serve as a boundary condition. The two studies cited above are but a handful that look into the role of trust in the mitigation of negative outcomes. Previous studies have focused on the mediating role of trust and its positive organizational effects, such as citizenship behaviors (e.g., Zhu \& Akhtar, 2014). The results of this study point to an interesting new line of research for trust in leadership by questioning its role in the causal mechanisms that lead up to the experience of stressors and strains. Future research in stressors and strains would benefit from understanding the role of trust then as a boundary condition and its potential mitigating effects.

Expand the realm of possible stressors. In the limitations, the unmeasured influence of role stress was raised as a possible explanation for the findings. Future studies should directly address this, especially within the context of communication climate. As previously stated, role stress seems to have a dimension that is based on how an employee obtains relevant information about his/her role within the organization. A defensive communication climate may discourage an employee from seeking role clarification, thus increasing role stress, which in turn may lead to engagement in CWB (according to frustration-aggression theory). Similarly, future research may consider how role stress may lead to higher perceptions of NTO. Jaramillo et al. (2011) found role stress (particularly role conflict) predicted interpersonal conflict among employees. 
Future research might look at the relationship between role conflict and this other form of interpersonal stressor (i.e., NTO), within the context of the communication climate.

\section{Implications for Practice}

The results of this dissertation may have practical implications for those in leadership positions. A few salient points are worth mentioning here that may help leaders to improve their practice and the well-being of their employees. First, it is clear that leaders need to consider how their employees perceive their environment and the role said leader has in shaping that perception. This dissertation used self-reported perceptions of leadership behavior from the subordinate's perspective. Despite how leaders believe they are behaving, the meaning of that behavior is deciphered by the employees. Employees ascribe meaning to actions taken (Pfeffer, 1977). How leaders communicate and behave can have a fundamental influence on how employees perceive their work and the organization (Arnold \& Walsh, 2015). The results of this dissertation documented that the perception of a leader behaving transformationally (e.g., taking interest in the employees' personal growth, communicating a vision) had across-time effects on the employees' subsequent perceptions of conflict with co-workers by reducing the negative experience of said conflict. While it may seem intuitive, what leaders say and do, and particularly what subordinates think they see and hear, can alter perceptions for the better. In a longitudinal study, Nielsen, Randall, Yarker, and Brenner (2008) found transformational leadership to influence well-being through its affects on work characteristics. They claimed that transformational leaders change the way employees perceived their work characteristics (a latent variable created from perceptions of role clarity, meaningful work, and opportunities for development). As Nielsen, et al. (2008) 
propound, leaders can be taught to change the way they interact with their employees. In addition, the exhibiting of transformational characteristics may be included in the selection and promotion of leaders. Leaders can be the translators of institutional messages. In this study, interpersonal conflict was operationalized using the construct of non-task organizational conflict. This type of conflict is wholly different from the traditionally studies forms in that NTO conflict is rooted in disputes over organizational policies and procedures. That transformational leaders may be able to prevent the expression of such conflict is a testament to their ability to help shape employee perceptions. When employees are frustrated by the "system" they may decide to lash out at others and/or the organization. Transformational leadership can directly as well as indirectly influence employees' decision to engage in this behavior by altering employees' perceptions for the better.

Supportive communication climates tended to reduce the perception of conflict and subsequent strain reaction. Supportive communication climate referred to the general perceptions employees had of the norms and expectations of communicative acts. It is possible that individual-level supportive communication behaviors could be trained to then influence the overall expression of the communication climate. Human resources training could focus on the development of more supportive communication interactions between employees. In an early study, Alexander (1979) was able to experimentally manipulate participants' training in the use of supportive communicative acts. The research reported, "dyads which were trained to use the... 'supportive' types of communication resolved conflict significantly more effectively than did untrained dyads" p.131. More recently, High and Solomon (2016) found messages high in verbal person- 
centeredness (i.e., supportive message content) had both indirect and invisible effects (i.e., the recipient of the supportive message was not aware of having received a supportive message) on subsequent reports of social support. They proffered that, "perhaps individuals can be trained to appreciate the elements of effective supportive conversations, thereby enhancing their message processing ability" (p. 213). In this sense, all employees would benefit from better communication training that focuses on the development of better verbal skills to learn how to construe more supportive messages. Contrastingly, by pointing out what makes a message supportive, one also can see what makes a message defensive. Such training could include a discussion of the elements of defensive communication and how to reduce such utterances. Through the training of individual employees in better communication practices, the overall communication climate could improve as interactions between employees become less defensive and more supportive.

Last, reduction of counterproductive work behaviors has important practical implications as these types of behaviors can be costly to organizations and individuals. While much of the literature on transformational leadership has focused on its uplifting dimensions (Arnold, 2017), the results of this study show that it can also ameliorate negative behavior. Such an outcome has important practical implications for leaders, especially when considering employees' motives for engaging in destructive behavior. Pragmatically speaking, leaders are in a place to help employees reframe the experience of frustration at work and thus mitigate the engagement in aggressive actions. Leadership training could focus specifically on helping leaders develop the skills to identify frustration in employees. The development of a supportive communication climate also 
may assist in the reduction of appraisals of frustration (a factor that leads to the engagement in CWBs because it may be construed as a threat). While the specific causal mechanisms may be difficult to pinpoint, there is still a clear relationship between leadership and CWB, as well as a supportive communication climate and CWB. Practitioners interested in mitigating destructive behaviors in their workplace may benefit from considering the frame alignment aspects of transformational leadership and the sense of social support possibly provided by a supportive communication climate.

\section{Conclusion}

In their critical analysis of transformational leadership theory, Kippenberg \& Sitkin (2013) stated, "what is missing from theory development in...transformational leadership is a mediation model that is specific to the outcome and level of analysis under consideration" (pg. 19). This dissertation has made an attempt to fill this theoretical gap in the leadership research. While all hypotheses implying mediation were not supported, some key ones were, specifically, the role of interpersonal conflict in mediating the relationship between transformational leadership and counterproductive work behaviors. In addition, the use of appraisal theory helped to organize and bridge two previously separate streams of organizational research: leadership and stressor-strain. Placing transformational leadership within an appraisal theory of stressors and strains addressed the calls by others to "explain the ways through which leadership can influence follower perceptions of meaningful work and, correspondingly, their attitudes, performance, and well-being” (Barling, Christie, \& Hoption, 2011 p. 208). While many unanswered questions remain, the results of this dissertation have filled some gaps in the leadership and stressor-strain literature. For leadership researchers, it is important to investigate 
how positive leadership as exhibited by the transformational leadership style can not only be uplifting, as Arnold (2017) claims, but also can serve to ameliorate negative outcomes. For occupational health researchers, it is important to consider the symbolic and pragmatic role that leaders play in shaping employee perceptions about their work and reactions to the work environment. 


\section{REFERENCES}

Albrecht, S., \& Travaglione, A. (2003). Trust in public-sector senior management. International Journal of Human Resource Management, 14, 76-92.

Alexander, E. R. (1979). The reduction of cognitive conflict: effects of various types of communication. The Journal of Conflict Resolution, 23, 120-138.

Ashforth, B. E. (1985). Climate formation: Issues and extensions. Academy of Management Review, 10, 837-847.

Arnold, K. A. (2017). Transformational leadership and employee psychological wellbeing: a review and directions for future research. Journal of Occupational Health Psychology, 22, 381-393. doi: 10.1037/ocp0000062

Arnold, K. A., \& Walsh, M. M. (2015). Customer incivility and employee well-being: testing the moderating effects of meaning, perspective taking and transformational leadership. Work \& Stress, 29, 362-378. doi: 10.1080/02678373.2015.1075234

Baraldi, A. N., \& Enders, C. K. (2010). An introduction to modern missing data analysis. Journal of School Psychology, 48, 5-37. doi: 10.1016/j.jsp.2009.10.001

Barling, J., Christie, A., \& Hoption, C. (2011). Leadership. In S. Zedeck (Ed), APA handbook of industrial and organizational psychology (pp. 183-240). Washington, DC: American Psychological Association.

Barki, H., \& Hartwick, J. (2004). Conceptualizing the construct of interpersonal conflict. International Journal of Conflict Management, 15, 216-336.

Bartels, J., Pruyn, A., de Jong, M., \& Joustra, I. (2007). Multiple organizational identification levels and the impact of perceived external prestige and communication climate. Journal of Organizational Behavior, 28, 173-190.

Bass, B. M. (1998). Transformational leadership: Industrial, military, and educational impact. Mahwah, NJ: Erlbaum.

Bass, B. M., \& Avolio, B. J. (1994). Improving organizational effectiveness through transformational leadership. Thousand Oaks, CA: Sage.

Ben-Zur, H., Yagil, D., \& Oz, D. (2005). Coping strategies and leadership in the adaptation to social change: the Israeli kibbutz. Anxiety, Stress, and Coping, 18, 87-103. doi: 10.1080/10615800500093702

Bies, R. J. (2001). Interactional (in)justice: The sacred and the profane. In J. Greenberg 
\& R. Cropanzano (Eds.), Advances in organizational justice (pp. 89-118). Stanford, CA: Stanford University Press.

Bono, J. E., \& Judge, T. A. (2003). Self-concordance at work: toward understanding the motivational effects of transformational leaders. Academy of Management Journal, 46, 554-571.

Braun, S., Peus, C., Weisweiler, S., \& Frey, D. (2013). Transformational leadership, job satisfaction, and team performance: a multilevel mediation model of trust. Leadership Quarterly, 24, 270-283.

Brown, T. A. (2006). Confirmatory factor analysis for applied research. New York: Guilford Press.

Brown, M. E., \& Treviño, L. K. (2006). Ethical leadership: A review and future directions. Leadership Quarterly, 17, 595-616. doi:10.1016/j.leaqua.2006.10.004

Brown, M. E., Treviño, L. K., \& Harrison, D. A. (2005). Ethical leadership: A social learning perspective for construct development and testing. Organizational Behavior and Human Decision Processes, 97, 117-134. doi:10.1016/j.obhdp.2005.03.002

Brüggen, A. (2015). An empirical investigation of the relationship between workload and performance. Management Decision, 53, 2377-2389. doi: 10.1108/MD-02-2015-0063

Bruk-Lee, V., Nixon, A. E., \& Spector, P. E., (2013). An expanded typology of conflict at work: Task, relationship and non-task organizational conflict as social stressors. Work \& Stress: An International Journal of Work, Health \& Organizations, 27, 339-350. doi:10.1080/02678373.2013.841303

Bruk-Lee, V., \& Spector, P. E., (2006). The social stressors-counterproductive work behaviors link: Are conflicts with supervisors and coworkers the same? Journal of Occupational Health Psychology, 11, 145-156. doi: 10.1037/1076-8998.11.2.145

Burke, C. S., Sims, D. E., Lazzara, E. H., \& Salas, E. (2007). Trust in leadership: a multilevel review and integration. Leadership Quarterly, 18, 606-632.

Buttigieg, S. C., \& West, M. A. (2013). Senior management leadership, social support, job design, and stressor-to-strain relationships in hospital practice. Journal of Health Organization and Management, 27, 171-192.

Bycio, P., Hackett, R. D., \& Allen, J. S. (1995). Further assessments of Bass's (1985) conceptualization of transactional and transformational leadership. Journal of Applied Psychology, 80, 468-478. 
Cascio, W. F., \& Aguinis, H. (2011). Applied psychology in human resource management $\left(7^{\text {th }}\right.$ ed.). Boston: Prentice Hall.

Christensen, L. T. \& Cornelissen, J. (2011). Bridging corporate and organizational communication: Review, development and a look to the future. Management Communication Quarterly, 25, 383-414. doi:10.1177/0893318910390194

Clapp-Smith, R., Vogelgesang, G. R., \& Avey, J. B. (2009). Authentic leadership and positive psychological capital. Journal of Leadership \& Organizational Studies, 15, 227-240. doi: 10.1177/1548051808326596

Clayton, T. M. (2013). Managers' communication style and the development of trustworthiness in a healthcare environment: a quantitative study (Doctoral dissertation). Retrieved from Proquest Dissertation Publishing. (UMI: 3607005).

Cole, D. A., \& Maxwell, S. E. (2003). Testing mediation models with longitudinal data: questions and tips in the use of structural equation modeling. Journal of Abnormal Psychology, 112, 558-577. doi: 10.1037/0021-848X.112.4.558

Cooper, C. L. (1998). Theories of organizational stress. New York: Oxford University Press.

Costigan, J. L., \& Schmeidler, M. A. (1984). Exploring supportive and defensive communication climates. In J. W. Pfeiffer \& L. D. Goodstein (Eds.), The 1984 handbook for group facilitators (pp. 112-114). San Diego, CA: University Associates.

Day, D. V., Griffin, M. A., \& Louw, K. R. (2014). The climate and culture of leadership in organizations. In B. Schneider \& K. M. Barbera (Eds.), The Oxford handbook of organizational climate and culture (pp. 101-117). New York: Oxford Press.

Denison, D. R. (1996). What is the difference between organizational culture and organizational climate? A native's point of view on a decade of paradigm war. Academy of Management Review, 21, 619-654.

Dennis, H. S. (1974). A theoretical and empirical study of managerial communication climate in complex organizations. (Doctoral dissertation). Retrieved from ProQuest Dissertations and Theses. (UMI: 7517179)

De Wit, F. R. C., Greer, L. L., \& Jehn, K. A. (2012). The paradox of intragroup conflict: a meta-analysis. Journal of Applied Psychology, 97, 360-390. doi: $10.1037 / \mathrm{a} 0024844$

De Wit, F. R. C., Jehn, K. A., \& Scheeper, D. (2013). Task conflict, information 
processing, and decision-making: the damaging effect of relationship conflict. Organizational Behavior and Human Decision Processes, 122, 177-189. doi: 10.1016/j.obhdp.2013.07.002

Den Hartog, D. N., \& Belschak, F. D. (2012). Work engagement and Machiavellianism in the ethical leadership process. Journal of Business Ethics, 107, 35-47. doi:10.1007/s10551-012-1296-4

Dirks, K. T., \& Ferrin, D. L. (2002). Trust in leadership: Meta-analytic findings and implications for research and practice. Journal of Applied Psychology, 87, 611628. doi: 10.1037//0021-9010.87.4.611

Dragoni, L. (2005). Understanding the emergence of state goal orientation in organizational work groups: the role of leadership and multilevel climate perceptions. Journal of Applied Psychology, 90, 1084-1095.

Dvir, T., Eden, D., Avolio, B. J., \& Shamir, B. (2002). Impact of transformational leadership on follower development and performance: a field experiment. Academy of Management Journal, 45, 735-744.

Ehrhart, M. G., \& Raver, J. L. (2014). The effects of organizational climate and culture on productive and counterproductive behavior. In B. Schneider \& K. M. Barbera (Eds.), The Oxford handbook of organizational climate and culture (pp. 153-176). Oxford: Oxford Press.

Ehrhart, M. G., Schneider, B., \& Macey, W. H. (2014). Organizational climate and culture: An introduction to theory, research, and practice. New York: Routledge.

Eisenbeiss, S. A., van Knippenberg, D., \& Boerner, S. (2008). Transformational leadership and team innovation: Integrating team climate principles. Journal of Applied Psychology, 93, 1438-1446. doi: 10.1037/a0012716

Field, A. (2009). Discovering statistics using SPSS. ( $3^{\text {rd }}$ ed.). Los Angeles: Sage.

Fox, S., \& Spector, P.E. (1999). A model of work frustration-aggression. Journal of Organizational Behavior, 20, 915-931.

Fox, S., \& Spector, P. E. (Eds.). (2005). Counterproductive work behavior: Investigations of actors and targets. Washington, DC: American Psychological Association.

Fox, S., Spector, P. E., \& Miles, D. (2001). Counterproductive work behavior (CWB) in response to job stressors and organizational justice: some mediator and moderator tests for autonomy and emotions. Journal of Vocational Behavior, 59, 291-309. 
Ford, M. T., Matthews, R. A., Wooldridge, J. D., Mishra, V., Kakar, U. M., \& Strahan, S. R. (2014). How do occupational stress-strain effects vary with time? A review and meta-analysis of the relevance of time lags in longitudinal studies. Work \& Stress, 28, 9-30. doi: 10.1080/02678373.2013.877096

Forward, G. L., Czech, K., \& Lee, C. M. (2011). Assessing Gibb's supportive and defensive communication climate: an examination of the measurement and construct validity. Communication Research Reports, 28, 1-15. doi: 10.1080/08824096.2011.541360

Gefland, M. J., Keller, K., Leslie, L. M., \& de Dreu, C. (2012). Conflict cultures in organizations: How leaders shape conflict culture and their organizational-level consequences. Journal of Applied Psychology, 97, 1131-1147. doi: $10.1037 / \mathrm{a} 0029993$

Gibb, J. R. (1961). Defensive communication. Journal of Communication, 11, 141-148.

Gillespie, N. A., \& Mann, L. (2004). Transformational leadership and shared values: The building blocks of trust. Journal of Managerial Psychology, 19, 588-607. doi: $10.1108 / 02683940410551507$

Guzley, R. M. (1992). Organizational climate and communication climate: Predictors of commitment to the organization. Management Communication Quarterly, 5, 379402.

Hahn, S. E. (2000). The effects of locus of control on daily exposure, coping and reactivity to work interpersonal stressors: a diary study. Personality and Individual Differences, 29, 729-748.

Harvey, S., Kelloway, E. K., \& Duncan-Leipier, L. (2003). Trust in management as a buffer of the relationships between overload and strain. Journal of Occupational Health Psychology, 8, 306-315. doi: 10.1037/1076-8998.8.4.30

Hayes, A. F. (2013). Introduction to mediation, moderation, and conditional process analysis: A regression-based approach. New York: Guilford.

Hershcovis, M. S., Turner, N., Barling, J., Inness, M., LeBlanc, M. M., Arnold, K. A., Dupré, K. E., \& Sivanathan, N. Predicting workplace aggression: a meta-analysis. Journal of Applied Psychology, 92, 228-238. doi: 10.1037/0021-9010.92.1.228

High, A. C., \& Solomon, D. H. (2016). Explaining the durable effects of verbal personcentered supportive communication: indirect effects or invisible support? Human Communication Research, 42, 200-220. doi: 10.1111/hcre.12077

Holten, A. L., \& Brenner, S. O. (2013). Leadership style and the process of 
organizational change. Leadership \& Organization Development Journal, 36, 216. doi: 10.1108/LODJ-11-2012-0155

Holtz, B. C., \& Harold, C. M. (2013). Effects of leadership consideration and structure on employee perceptions of justice and counterproductive work behavior. Journal of Organizational Behavior, 34, 42-519. doi:10.1002/job.1825

Hüttermann, H., \& Boerner, S. (2011). Fostering innovation in functionally diverse teams: the two faces of transformational leadership. European Journal of Work and Organizational Psychology, 20, 833-854. doi: $10.1080 / 1359432 X .2010 .524412$

Hurrell, J. J., \& Murphy, L. R. (1991). Locus of control, job demands, and health. In J. J. Hurrell \& L. R. Murphy (Eds.), Personality and stress: Individual differences in the stress process (pp. 133-149). Oxford, England: Wiley.

Ilies, R., Johnson, M. D., Judge, T. A., \& Keeney, J. (2011). A within-individual study of interpersonal conflict as a work stressor: dispositional and situational moderators. Journal of Organizational Behavior, 32, 44-64. doi: 10.1002/job.677

Jaramillo, F., Mulki, J. P., \& Boles, J. S. (2011). Workplace stressors, job attitudes, and job behaviors: is interpersonal conflict the missing link? Journal of Personal Selling and Sales Management, 31, 339-356.

Jehn, K. A. (1995). A multimethod examination of the benefits and detriments of intragroup conflict. Administrative Science Quarterly, 40, 256-282.

Jung, D. I., \& Avolio, B. J. (2000). Opening the black box: an experimental investigation of the mediating effects of trust and value congruence on transformational and transactional leadership. Journal of Organizational Behavior, 21, 949-964.

Kacmar, K. M., Bachrach, D. G., Harris, K. J., \& Noble, D. (2012). Exploring the role of supervisor trust in the associations between multiple sources of relationship conflict and organizational citizenship behavior. Leadership Quarterly, 23, 43-54. doi:10.1016/j.leaqua.2011.11.004

Karasek, R. A. (1979). Job demands, job decision latitude, and mental strain: implications for job redesign. Administrative Science Quarterly, 24, 285-308.

Keenan, A., \& Newton, T. J. (1984). Frustration in organizations: relationships to role stress, climate, and psychological strain. Journal of Occupational Psychology, 57, $57-65$.

Keenan, A., \& Newton, T. J. (1985). Stressful events, stressors and psychological strains in young professional engineers. Journal of Occupational Behavior, 6, 151-156. 
Kelloway, E. K., Turner, N., Barling, J., \& Loughlin, C. (2012). Transformational leadership and employee psychological well-being: The mediating role of employee trust in leadership. Work \& Stress, 26, 39-55. doi: $10.1080 / 02678373.2012 .660774$

Kessler, S. R., Bruursema, K., Rodopman, R., \& Spector, P. E. (2013). Leadership, interpersonal conflict, and counterproductive work behavior: An examination of the stressor-strain process. Negotiation and Conflict Management Research, 6, $180-190$.

Kisamore, J. L., Jawahar, I. M., Liguori, E. W., Mharapara, T. L., \& Stone, T. H. (2010). Conflict and abusive workplace behaviors: moderating effects of social competencies. Career Development International, 15, 583-600. doi: $10.1108 / 13620431011084420$

Kim, H., \& Kim, J. (2015). A cross-level study of transformational leadership and organizational affective commitment in the Korean local governments: Mediating role of procedural justice and moderating role of culture types based on competing values framework. Leadership, 11, 158-185.

Kline, R. B. (2011). Principles and practice of structural equation modeling. ( $3^{\text {rd }}$ ed.). New York: Guilford.

Knippenberg, D., \& Sitkin, S. B. (2013). A critical assessment of charismatictransformational leadership research: Back to the drawing board? Academy of Management Annals, 7, 1-60. doi: 10.1080/19416520.2013.759433

Koslowsky, M. (1998). Modeling the stress-strain relationship in work settings. London: Routledge.

Kozlowski, S. W. J., \& Doherty, M. L. (1989). Integration of climate and leadership: Examination of a neglected issue. Journal of Applied Psychology, 74, 546-553.

Krackhardt, D. \& Hanson, J. R. (1993). Informal networks: the company. Harvard Business Review, 71, 104-111.

Lammers, J. C. (2011). How institutions communicate: Institutional messages, institutional logics, and organizational communication. Management Communication Quarterly, 25, 154-182. doi:10.1177/0893318910389280

Larsen, S., \& Folgero, I. (1993). Supportive and defensive communication: a study of the communication climate in a cruise line company. International Journal of Hospitality Management, 5, 22-25.

Lazarus, R. S. (1991). Emotion and adaptation. New York: Oxford. 
Lazarus, R. S. (1999). Stress and emotion: A new synthesis. New York: Springer.

Lazarus, R. S., \& Folkman, S. (1984). Stress, appraisal and coping. New York: Springer.

Lewin, K., Lippit, R., \& White, R. (1939). Patterns of aggressive behavior in experimentally created social climates. Journal of Social Psychology, 10, 271299.

Liao, H., \& Chuang, A. (2007). Transforming service employees and climate: A multilevel, multisource examination of transformational leadership in building long-term service relationships. Journal of Applied Psychology, 92, 1006-1019. doi: 10.1037/0021-9010.92.4.1006

Lim, B. C., \& Ployhart, R. E. (2004). Transformational leadership: relations to the fivefactor model and team performance in typical and maximum contexts. Journal of Applied Psychology, 89, 610-621. doi: 10.1037/0021-9010.89.4.610

Liu, J., Siu, O. L., \& Shi, K. (2010). Transformational leadership and employee wellbeing: The mediating role of trust in the leader and self-efficacy. Applied Psychology: An International Review, 59, 454-479. doi: 10.1111/j.14640597.2009.00407.x

Lyons, J. B., \& Schneider, T. R. (2009). The effects of leadership style on stress outcomes. Leadership Quarterly, 20, 737-748.

Mahony, D. M., Klimchak, M., \& Morrell, D. L. (2012). The portability of career-long work experience: Propensity to trust as a substitute for valuable work experience. Career Development International, 17, 606-625. doi:10.1108/13620431211283779

Mathieu, J. E., \& Taylor, S. R. (2006). Clarifying conditions and decision points for mediational type inferences in organizational behavior. Journal of Organizational Behavior, 27, 1031-1056. doi: 10.1002/job.406

Marcus, B., \& Schuler, H. (2004). Antecedents of counterproductive behavior at work: a general perspective. Journal of Applied Psychology, 89, 647-660. doi:10.1037/0021-9010.89.4.647

Mayer, R. C., \& Davis, J. H. (1999). The effect of the performance appraisal system on trust for management: a field quasi-experiment. Journal of Applied Psychology, 84, 123-136.

Mayer, R. C., Davis, J. H., \& Schoorman, F. D. (1995). An integrative model of 
organizational trust. Academy of Management Review, 20, 709-734.

Mayer, R. C., \& Gavin, M. B. (2005). Trust in management and performance: who minds the shop while the employees watch the boss? Academy of Management Journal, $48,874-888$.

Mazzola, J. J., Schonfeld, I. S., \& Spector, P. E. (2011). What qualitative research has taught us about occupational stress. Stress and Health, 27, 93-110. doi:10.1002/smi.1386

McMillan, K., \& Albrecht, S. (2010). Measuring social exchange constructs in organizations. Communication Methods and Measures, 4, 201-220.

Meier, L. L., Gross, S., Spector, P. E., \& Semmer, N. K. (2013). Relationship and task conflict at work: Interactive short-term effects on angry mood and somatic complaints. Journal of Occupational Health Psychology, 18, 144-156. doi: $10.1037 / \mathrm{a} 0032090$

Menges, J. I., Walter, F., Vogel, B., \& Bruch, H. (2011). Transformational leadership climate: Performance linkages, mechanisms, and boundary conditions at the organizational level. Leadership Quarterly, 22, 893-909. doi: 10.1016/j.leaqua.2011.07.010

Mishra, A. K., \& Spreitzer, G. M. (1998). Explaining how survivors respond to downsizing: The roles of trust, empowerment, justice, and work design. Academy of Management Review, 23, 567-588.

Mitchell, M. S., \& Ambrose, M. L. (2012). Employees' behavioral reactions to supervisor aggression: An examination of individual and situational factors. Journal of Applied Psychology, 97, 1148-1170. doi: 10.1037/a0029452

Mulki, J. P., Jaramillo, J. F., \& Locander, W. B. (2008). Effects of ethical climate on turnover intention: Linking attitudinal and stress theory. Journal of Business Ethics, 78, 559-574. doi: 10.1007/s10551-007-9368-6

Nielsen, K., Randall, R., Yarker, J., \& Brenner, S. (2008). The effects of transformational leadership on followers' perceived work characteristics and psychological wellbeing: a longitudinal study. Work \& Stress, 22, 16-32.

doi:10.1080/02678370801979430

Nemanich, L. A., \& Keller, R. T. (2007). Transformational leadership in an acquisition: a field study of employees. Leadership Quarterly, 18, 49-68.

Newton, D. A., \& Burgoon, J. K. (1990). The use and consequences of verbal influence 
strategies during interpersonal disagreements. Human Communication Research, 16, 477-518.

Nixon, A. E., Rodriguez, J. F., \& Bruk-Lee, V. (2013, August). Mitigating CWBs: Roles of interpersonal locus of control and conflict. In M. K. Shoss \& L. M. Penney (Chairs), Understanding motives for counterproductive work behaviors. Symposium conducted at the 73rd Annual Meeting of the Academy of Management, Orlando, FL.

Ng, T. W. H., \& Feldman, D. C. (2015). Ethical leadership: Meta-analytic evidence of criterion-related and incremental validity. Journal of Applied Psychology, 100, 948-965. http://dx.doi.org/10.1037/a0038246

Ng, T. W. H., Sorensen, K. L., \& Eby, L. T. (2006). Locus of control at work: A metaanalysis. Journal of Organizational Behavior, 27, 1057-1087. doi: 10.1002/job.416

Paulhus, D. (1983). Sphere-specific measures of perceived control. Journal of Personality and Social Psychology, 44, 1253-1265.

Paulhus, D. L., \& Van Selst, M. (1990). The spheres of control scale: Ten years of research. Personality and Individual Differences, 11, 1029-1036.

Perlow, R. \& Latham, L. L. (1993). Relationship of client abuse with locus of control and gender: A longitudinal study. Journal of Applied Psychology, 78, 831-834.

Perrewé, P. L. \& Zellars, K. L. (1999). An examination of attributions and emotions in the transactional approach to the organizational stress process. Journal of Organizational Behavior, 20, 739-752.

Pfeffer, J. (1977). The ambiguity of leadership. Academy of Management Review, 2, 104112. doi: 10.5465/AMR.1977.4409175

Piccolo, R. F. \& Colquitt, J. A. (2006). Transformational leadership and job behaviors: the mediating role of core job characteristics. Academy of Management Journal, 49, 327-340.

Pinkley, R. L. (1990). Dimensions of conflict frame: disputant interpretations of conflict. Journal of Applied Psychology, 75, 117-126.

Podsakoff, P. M., MacKenzie, S. B., Lee, J. Y., \& Podsakoff, N. (2003). Common method bias in behavioral research: A critical review of the literature and recommended remedies. Journal of Applied Psychology, 88, 879-903. doi: 10.1037/0021-9010.88.5.879 
Podsakoff, P. M., MacKenzie, S. B., Moorman, R. H., \& Fetter, R. (1990).

Transformational leader behaviors and their effects on followers' trust in leader, satisfaction, and organizational citizenship behaviors. Leadership Quarterly, 1, $107-142$.

Preacher, K. J., \& Kelley, K. (2011). Effect size measures for mediation models: Quantitative strategies for communicating indirect effects. Psychological Methods, 16, 93-115. doi: 10.1037/a0022658

Quick, J. C., \& Tetrick, L. E. (Eds.). (2010). Handbook of occupational health psychology. Washington, DC: American Psychological Association.

Rafferty, A. E., \& Griffin, M. A. (2004), Dimensions of transformational leadership: conceptual and empirical extensions. Leadership Quarterly, 15, 329354. doi: 10.1016/j.leaqua.2004.02.009

Rapert, M. I., \& Wren, B. M. (1998). Reconsidering organizational structure: A dual perspective of frameworks and processes. Journal of Managerial Issues, 10, 287302.

Rodriguez, J. F., \& Bruk-Lee, V. (2016a, April). Job demands and resources: organizational communication and non-task organizational conflict. Poster session presented at the meeting of the Society for Industrial-Organizational Psychology, Anaheim, CA.

Rodriguez, J. F., \& Bruk-Lee, V. (2016b, October). The indirect effects of transformational leadership on counterproductive work behavior. In P.L. Perrewé and P.E. Spector (Chairs), Advances in Occupational Stress Research. Symposium submitted to the meeting of the Southern Management Association, Charlotte, NC.

Rogers, D. P. (1987). The development of a measure of perceived communication openness. The Journal of Business Communication, 24, 53-61.

Russ, F. A., McNeilly, K. M., \& Comer, J. M. (1996). Leadership, decision making and performance of sales managers: a multi-level approach. Journal of Personal Selling and Sales Management, 16, 1-15.

Rydstedt, L. W., Johansson, G., \& Evans, G. W. (1998). A longitudinal study of workload, health and well-being among male and female urban bus drivers. Journal of Occupational and Organizational Psychology, 71, 35-45.

Scarpero, D. (1999). The relationship of organizational communication climates and interpersonal conflict management. (Unpublished doctoral dissertation). California School of Professional Psychology, Los Angeles. 
Schneider, B., \& Reicher, A. E. (1983). On the etiology of climates. Personnel Psychology, 36, 19-39.

Scott, S. G., \& Bruce, R. A. (1994). Determinants of innovative behavior: A path model of individual innovation in the workplace. Academy of Management Journal, 37, $580-607$

Shamir, B., House, R. J., \& Arthur, M. (1993). The motivational effects of charismatic leadership: a self-concept based theory. Organization Science, 4, 577-594. doi: 10.1287/orsc.4.4.577

Smith, T. D., Eldrige, F., \& DeJoy, D. M. (2016). Safety-specific transformational and passive leadership influences on firefighter safety climate perceptions and safety behavior outcomes. Safety Science, 86, 92-97. doi: 10.1016/j.ssci.2016.02.019

Solansky, S. T., Singh, B., \& Huang, S. (2014). Individual perceptions of task conflict and relationship conflict. Negotiation and Conflict Management Research, 7, 8498 .

Spector, P. E. (1982). Behavior in organizations as a function of employee's locus of control. Psychological Bulletin, 91: 482-497.

Spector, P. E. (1998). A control model of the job stress process. In C. L. Cooper (Ed.), Theories of organizational stress (pp. 153-169). London: Oxford University Press.

Spector, P. E., Bauer, J. A., \& Fox, S. (2010). Measurement artifacts in the assessment of counterproductive work behavior and organizational citizenship behavior: Do we know what we think we know? Journal of Applied Psychology, 95, 781-790. doi: $10.1037 / \mathrm{a} 0019477$

Spector, P. E, \& Bruk-Lee, V. (2008). Conflict, health, and well-being. In C. K. W. De Dreu \& M. J. Gelfand (Eds.), The psychology of conflict and conflict management in organizations (pp. 267-288). New York, NY: Lawrence Erlbaum.

Spector, P. E., \& Fox, S. (2005). The stressor-emotion model of counterproductive work behavior. In S. Fox \& P. E. Spector (Eds.). Counterproductive work behaviors: Investigations of actors and targets (pp. 151-174). Washington, DC: American Psychological Association.

Spector, P. E., Fox, S., Penney, L. M., Bruursema, K., Goh, A., \& Kessler, K. (2006). The dimensionality of counterproductivity: are all counterproductive behaviors created equal? Journal of Vocational Behavior, 68, 446-460. doi: 10.1016/j.jvb.2005.10.005 
Spector, P. E., \& Jex, S. M. (1998). Development of four self-report measures of job stressors and strain: Interpersonal conflict at work scale, organizational constraints scale, quantitative workload inventory, and physical symptoms inventory. Journal of Occupational Health Psychology, 3, 356-367.

Spittal, M. J., Siegert, R. J., McClure, J. L., \& Walkey, F. H. (2002). The spheres of control scale: the identification of a clear replicable three-factor structure. Personality and Individual Differences, 32, 121-131.

Sprung, J. M., \& Jex, S. M. (2012). Work locus of control as a moderator of the relationship between work stressors and counterproductive work behaviors. International Journal of Stress Management, 19, 272-291. doi: 10.1037/a0030320

Stone-Romero, E. F., \& Rosopa, P. J. (2008). The relative validity of inferences about mediation as a function of research design characteristics. Organizational Research Methods, 11, 326-352. doi: 10.1177/1094428107300342

Sullivan, J. J. (1988). Three roles of language in motivation theory. Academy of Management Review, 13, 104-115.

Syrek, C. J., Apostel, E., \& Antoni, C. H. (2013). Stress in highly demanding IT jobs: Transformational leadership moderates the impact of time pressures on exhaustion and work-life balance. Journal of Occupational Health Psychology, 18, 252-261. doi: 10.1037/a0033085

Tabachnick, B. G., \& Fidell, L. S. (2013). Using multivariate statistics (6 $6^{\text {th }}$ ed.). Boston: Pearson.

Tafvelin, S., Armelius, K., \& Westerberg, K. (2011). Toward understanding the direct and indirect effects of transformational leadership on well-being: A longitudinal study. Journal of Leadership and Organizational Studies, 18, 480-492. doi: $10.1177 / 1548051811418342$

Viswesvaran, C., Sanchez, J. I., \& Fisher, J. (1999). The role of social support in the process of work stress: A meta-analysis. Journal of Vocational Behavior, 54, 314334.

Wang, X., Ma, L., \& Zhang, M. (2014). Transformational leadership and agency workers' organizational commitment: the mediating effect of organizational justice and job characteristics. Social Behavior and Personality, 42, 25-36.

Winer, S., \& Majors, R. E. (1981). A research note on supportive and defensive communication: An empirical study of three verbal interpersonal communication variables. Communication Quarterly, 29, 166-172. 
Yang, Y.F., (2014). Transformational leadership in the consumer service workgroup: Competing models of job satisfaction, change commitment, and cooperative conflict resolution. Psychological Reports: Employment Psychology \& Marketing, $114,33-49$.

Yao, Y. H., Fan, Y. Y., \& Guo, Y. X. (2014). Leadership, work stress and employee behavior. Chinese Management Studies, 8, 109-126. doi:10.1108/CMS-04-20140089

Yukl, G. (1999). An evaluation of the conceptual weaknesses in transformational and charismatic leadership theories. Leadership Quarterly, 10, 285-305.

Zhang, X., Cao, Q., \& Tjosvold, D. (2011). Linking transformational leadership and team performance: A conflict management approach. Journal of Management Studies, 48, 1586-1611. doi: 10.1111/j.1467-6486.2010.00974.x

Zhu, Y., \& Akhtar, S. (2014). How transformational leadership influences follower helping behavior: The role of trust and prosocial motivation. Journal of Organizational Behavior, 35, 373-392. doi: 10.1002/job.1884

Zohar, D., \& Tenne-Gazit, O. (2008). Transformational leadership and group interaction as climate antecedents: a social network analysis. Journal of Applied Psychology, 93, 744-757. doi: 10.1037/0021-9010.93.4.744 


\section{Appendix A}

Factor Loadings for Exploratory Factor Analysis with Varimax Rotation of Communication Climate Inventory

\begin{tabular}{|c|c|c|c|c|c|}
\hline Item & Authoritarian & Openness & Egalitarian & $\begin{array}{c}\text { Being } \\
\text { Uncritical }\end{array}$ & $\begin{array}{l}\text { Descriptive } \\
\text { Orientation }\end{array}$ \\
\hline $\begin{array}{l}\text { Think that they } \\
\text { are always right. }\end{array}$ & .72 & -.11 & -.34 & -.06 & -.14 \\
\hline $\begin{array}{l}\text { Need to be in } \\
\text { charge of the } \\
\text { situation. }\end{array}$ & .74 & -.01 & -.20 & -.05 & -.10 \\
\hline $\begin{array}{l}\text { Believe that if a } \\
\text { job is to be done } \\
\text { right, they will } \\
\text { need to oversee } \\
\text { it or do it. }\end{array}$ & .79 & .01 & -.08 & -.09 & -.02 \\
\hline $\begin{array}{l}\text { Are dogmatic; it } \\
\text { is useless to } \\
\text { voice an } \\
\text { opposing point } \\
\text { of view. }\end{array}$ & .59 & -.34 & -.13 & -.20 & -.19 \\
\hline $\begin{array}{l}\text { Make it clear } \\
\text { who is in } \\
\text { charge. }\end{array}$ & .73 & -.05 & -.14 & -.12 & -.10 \\
\hline $\begin{array}{l}\text { Believe they } \\
\text { must control } \\
\text { how other do } \\
\text { their work. }\end{array}$ & .73 & -.14 & -.34 & -.16 & -.14 \\
\hline $\begin{array}{l}\text { Try to change } \\
\text { each other's } \\
\text { attitudes and } \\
\text { behaviors to suit } \\
\text { their own. }\end{array}$ & .71 & -.19 & -.18 & -.04 & -.13 \\
\hline $\begin{array}{l}\text { Judge the } \\
\text { actions of each } \\
\text { other. }\end{array}$ & .66 & -.07 & -.21 & -.25 & -.23 \\
\hline $\begin{array}{l}\text { Participate in } \\
\text { meetings } \\
\text { without } \\
\text { projecting their } \\
\text { status or power. }\end{array}$ & -.31 & .19 & .75 & -.06 & .20 \\
\hline $\begin{array}{l}\text { Do not try to } \\
\text { make others feel } \\
\text { inferior. }\end{array}$ & -.40 & .18 & .69 & .05 & .10 \\
\hline $\begin{array}{l}\text { Respect others' } \\
\text { feelings and } \\
\text { values. }\end{array}$ & -.27 & .26 & .70 & .18 & .18 \\
\hline
\end{tabular}




\begin{tabular}{|c|c|c|c|c|c|}
\hline $\begin{array}{l}\text { Listen to each } \\
\text { other's } \\
\text { problems with } \\
\text { interest. }\end{array}$ & -.13 & .27 & .59 & .10 & .31 \\
\hline $\begin{array}{l}\text { Can express } \\
\text { their opinions } \\
\text { and ideas } \\
\text { honestly with } \\
\text { their } \\
\text { supervisors. }\end{array}$ & -.10 & .81 & .16 & .15 & .12 \\
\hline $\begin{array}{l}\text { Feel free to talk } \\
\text { to their } \\
\text { supervisors. }\end{array}$ & -.03 & .80 & .28 & .07 & .15 \\
\hline $\begin{array}{l}\text { Are allowed as } \\
\text { much creativity } \\
\text { as possible on } \\
\text { the job. }\end{array}$ & -.09 & .60 & .14 & .03 & .29 \\
\hline $\begin{array}{l}\text { Have to be } \\
\text { careful when } \\
\text { talking to the } \\
\text { supervisor so } \\
\text { that they will } \\
\text { not be } \\
\text { misinterpreted }\end{array}$ & -.19 & .69 & .15 & .21 & -.05 \\
\hline $\begin{array}{l}\text { Are allowed } \\
\text { flexibility on the } \\
\text { job. }\end{array}$ & -.02 & .65 & .24 & .01 & .15 \\
\hline $\begin{array}{l}\text { Try to describe } \\
\text { situations fairly } \\
\text { without labeling } \\
\text { them as good or } \\
\text { bad. }\end{array}$ & -.22 & .08 & .17 & -.001 & .60 \\
\hline $\begin{array}{l}\text { Present their } \\
\text { feelings and } \\
\text { perceptions } \\
\text { without } \\
\text { implying that a } \\
\text { similar response } \\
\text { is expected. }\end{array}$ & -.08 & .12 & .19 & .04 & .67 \\
\hline $\begin{array}{l}\text { Attempt to } \\
\text { explain } \\
\text { situations } \\
\text { clearly and } \\
\text { without personal } \\
\text { bias. }\end{array}$ & -.26 & .21 & .31 & -.001 & .75 \\
\hline $\begin{array}{l}\text { Define problems } \\
\text { so that they can } \\
\text { be understood } \\
\text { but don't insist }\end{array}$ & -.13 & .11 & .13 & .13 & .63 \\
\hline
\end{tabular}




\begin{tabular}{|l|l|l|l|l|l|}
\hline $\begin{array}{l}\text { that others } \\
\text { agree. }\end{array}$ & & & & & \\
\hline $\begin{array}{l}\text { Criticize each } \\
\text { other's work } \\
\text { without } \\
\text { allowing for } \\
\text { explanations. }\end{array}$ & -.31 & .16 & .28 & .55 & .15 \\
\hline $\begin{array}{l}\text { Twist and } \\
\text { distort what } \\
\text { each other say } \\
\text { when they speak } \\
\text { what is really on } \\
\text { their minds. }\end{array}$ & -.29 & .35 & .31 &. $\mathbf{6 5}$ & .12 \\
\hline $\begin{array}{l}\text { Criticize each } \\
\text { other's work in } \\
\text { the presence of } \\
\text { others. }\end{array}$ & -.19 & .09 & .16 & .51 & .12 \\
\hline $\begin{array}{l}\text { Try to } \\
\text { manipulate each } \\
\text { other to get } \\
\text { what they want } \\
\text { or to make } \\
\text { themselves look } \\
\text { good. }\end{array}$ & -.40 & .23 & .40 & .54 & .11 \\
\hline
\end{tabular}

Note. Factor loadings $>.50$ are in boldface. 


\section{Appendix B}

\section{List of Hypotheses}

\begin{tabular}{|c|c|c|}
\hline Hypothesis & Description & Supported \\
\hline $\mathrm{H} 1 \mathrm{a}$ & NTO positively predicts CWB & Supported \\
\hline $\mathrm{H} 1 \mathrm{~b}$ & ILOC moderates NTO $\rightarrow$ CWB & Not \\
\hline $\mathrm{H} 2 \mathrm{a}$ & TL negatively predicts NTO & Supported \\
\hline $\mathrm{H} 2 \mathrm{~b}$ & TL negatively predicts CWB & Supported \\
\hline $\mathrm{H} 2 \mathrm{c}$ & Mediation: $\mathrm{TL} \rightarrow \mathrm{NTO} \rightarrow \mathrm{CWB}$ & Supported \\
\hline $\mathrm{H} 3 \mathrm{a}$ & TL positively predicts Trust & Not \\
\hline $\mathrm{H} 3 \mathrm{~b}$ & TR negatively predicts NTO & Supported \\
\hline $\mathrm{H} 3 \mathrm{c}$ & Mediation: $\mathrm{TL} \rightarrow \mathrm{TR} \rightarrow \mathrm{NTO}$ & Not \\
\hline $\mathrm{H} 3 \mathrm{~d}$ & TR negatively predicts CWB & Not \\
\hline $\mathrm{H} 3 \mathrm{e}$ & Mediation: $\mathrm{TL} \rightarrow \mathrm{TR} \rightarrow \mathrm{CWB}$ & Not \\
\hline $\mathrm{H} 4 \mathrm{a}$ & SCC negatively predicts NTO & Supported \\
\hline $\mathrm{H} 4 \mathrm{~b}$ & SCC negatively predicts CWB & Supported \\
\hline $\mathrm{H} 4 \mathrm{c}$ & DCC positively predicts NTO & Not \\
\hline $\mathrm{H} 4 \mathrm{~d}$ & DCC positively predicts CWB & Not \\
\hline H5a & TL positively predicts SCC & Not \\
\hline $\mathrm{H} 5 \mathrm{~b}$ & Mediation: $\mathrm{TL} \rightarrow \mathrm{SCC} \rightarrow \mathrm{NTO}$ & Not \\
\hline H5c & Mediation: $\mathrm{TL} \rightarrow \mathrm{SCC} \rightarrow \mathrm{CWB}$ & Not \\
\hline $\mathrm{H} 5 \mathrm{~d}$ & TL negatively predicts DCC & Supported \\
\hline $\mathrm{H} 5 \mathrm{e}$ & Mediation: $\mathrm{TL} \rightarrow \mathrm{DCC} \rightarrow \mathrm{NTO}$ & Not \\
\hline H5f & Mediation: $\mathrm{TL} \rightarrow \mathrm{DCC} \rightarrow \mathrm{CWB}$ & Not \\
\hline H6a & Serial Mediation: $\mathrm{TL} \rightarrow \mathrm{TR} \rightarrow \mathrm{NTO} \rightarrow \mathrm{CWB}$ & Not \\
\hline $\mathrm{H} 6 \mathrm{~b}$ & Serial Mediation: $\mathrm{TL} \rightarrow \mathrm{SCC} \rightarrow \mathrm{NTO} \rightarrow \mathrm{CWB}$ & Not \\
\hline H6c & Serial Mediation: $\mathrm{TL} \rightarrow \mathrm{DCC} \rightarrow \mathrm{NTO} \rightarrow \mathrm{CWB}$ & Not \\
\hline
\end{tabular}

Abbreviation of Variables

\begin{tabular}{|l|l|}
\hline TL & Transformational Leadership \\
\hline NTO & Non-task Organizational Conflict \\
\hline CWB & Counterproductive Work Behavior \\
\hline TR & Trust in Leadership \\
\hline SCC & Supportive Communication Climate \\
\hline DCC & Defensive Communication Climate \\
\hline
\end{tabular}




\section{Appendix C}

\section{List of all Measures and Instructions}

\section{Transformational Leadership, Rafferty and Griffin (2004)}

1. Has a clear understanding of where we are going.

2. Has a clear sense of where he/she wants our unit to be in 5 years.

3. Has no idea where the organization is going. (Requires reverse coding)

4. Says things that make employees proud to be a part of this organization.

5. Says positive things about the work unit.

6. Encourages people to see changing environments as situations full of opportunities.

7. Challenges me to think about old problems in new ways.

8. Has ideas that have forced me to rethink some things that I have never questioned before.

9. Has challenged me to rethink some of my basic assumptions about my work.

10. Considers my personal feelings before acting.

11. Behaves in a manner that is thoughtful of my personal needs.

12. Sees that the interests of employees are given due consideration.

13. Commends me when I do a better than average job.

14. Acknowledges improvement in my quality of work.

15. Personally compliments me when I do outstanding work.

Instructions: Please indicate how much you agree with each statement when rating the effectiveness of your direct supervisor.

$1=$ Strongly disagree

$2=$ Disagree

$3=$ Neither agree nor disagree

$4=$ Agree

$5=$ Strongly agree

Note: Subscales are as follow: vision (1-3), inspirational communication (4-6), intellectual stimulation (7-9), supportive leadership (10-12), and personal recognition (13-15).

\section{Trust in Leadership, Mayer and Davis (1999)}

1. My supervisor is very capable of performing its job.

2. My supervisor is known to be successful at the things it tries to do.

3. My supervisor has much knowledge about the work that needs to be done.

4. I feel very confident about My supervisor's skills.

5. My supervisor is well qualified.

6. My supervisor has specialized capabilities that can increase our performance.

7. My supervisor is very concerned about my welfare.

8. My supervisor would not knowingly do anything to hurt me.

9. My supervisor really looks out for what is important to me. 
10. My supervisor will go out of its way to help me.

11. My needs and desires are very important to my supervisor.

12. My supervisor has a strong sense of justice.

13. I never have to wonder whether my supervisor will stick to its word.

14. My supervisor tries hard to be fair in dealings with others.

15. My supervisor actions and behaviors are not very consistent (Requires reverse coding)

16. I like my supervisor's values.

17. Sound principles seem to guide my supervisor's behavior.

Instructions: Please indicate to what extent you agree with the following statements about your direct supervisor.

$1=$ Strongly disagree

$2=$ Disagree

$3=$ Neither agree nor disagree

$4=$ Agree

$5=$ Strongly agree

Note: Subscales are as follow: ability (1-6), benevolence (7-11), and integrity (12-17).

\section{Communication Climate Inventory, Costigan and Scheilder (1984); Forward, Czech, and Lee (2011)}

1. Treat each other with respect.

2. Respect others' feelings and values.

3. Do not try to make others feel inferior.

4. Can express their opinions and ideas honestly with their supervisors.

5. Do not have hidden motives in dealing with each other.

6. Feel free to talk to their supervisors.

7. Twist and distort what each other say when they speak what is really on their minds. (Requires reverse coding)

8. Listen to each other's problems with interest.

9. Can be honest and straightforward with each other.

10. Are allowed as much creativity as possible on the job.

11. Try to make each other feel inadequate. (Requires reverse coding)

12. Criticize each other's work in the presence of others. (Requires reverse coding)

13. Are allowed flexibility on the job.

14. participate in meetings without projecting their status or power.

15. Have to be careful when talking to the supervisor so that they will not be misinterpreted. (Requires reverse coding)

16. Try to manipulate each other to get what they want or to make themselves look good. (Requires reverse coding)

17. Understand the problems encountered in the job.

18. Criticize each other's work without allowing for explanations. (Requires reverse coding)

19. Are willing to try new ideas and to accept other points of view. 
20. Think that they are always right.

21. Need to be in charge of the situation.

22. Believe that if a job is to be done right, they will need to oversee it or do it.

23. Are dogmatic; it is useless to voice an opposing point of view.

24. Make it clear who is in charge.

25. Believe they must control how other do their work.

26. Try to change each other's attitudes and behaviors to suit their own.

27. Judge the actions of each other.

28. Try to describe situations fairly without labeling them as good or bad.

29. Present their feelings and perceptions without implying that a similar response is expected.

30. Attempt to explain situations clearly and without personal bias.

31. Define problems so that they can be understood but don't insist that others agree.

32. Cannot admit that they have made mistakes. (Requires reverse coding)

33. Are not interested in each other's personal problems. (Requires reverse coding)

34. Become involved in each other's conflicts

35. Define problems and make other aware of them. (Requires reverse coding)

Instructions: To what extent do you agree with the following statements about your work environment? Employees in my unit who report to the same supervisor...

$1=$ Strongly disagree

$2=$ Disagree

$3=$ Neither agree nor disagree

$4=$ Agree

$5=$ Strongly agree

Note: Subscales are as follow: Collaboration—supportive communication (1-19), Authoritarianism - defensive communication (20-27), Descriptive Orientationsupportive communication (28-32), Manipulation-defensive communication (33-35).

\section{Non-task Organizational Conflict, Bruk-Lee, Nixon, and Spector (2013)}

1. Are you in a dispute with someone at work caused by differences in organizational power?

2. Are you in a disagreement with someone at work because of a company policy?

3. Do you disagree with someone about the hiring decisions in your organization?

4. Do you disagree with someone over organizational-related issues that do not pertain to a specific work task? (i.e. policies, organizational culture, benefits)

5. Do you dispute with someone at work because of poor organizational leadership?

Instructions: The following questions ask about your interpersonal relationships at work. Please indicate how often you experience each of the following events in your present job.

$1=$ Never

$2=$ Once or Twice

$3=$ Once or Twice a Month 
$4=$ Once or Twice a Week

$5=$ Every Day

\section{Interpersonal Locus of Control, Paulhus and Van Selst (1990)}

1. In my personal relationships, the other person usually has more control over the relationship than I do. (Requires reverse coding)

2. I have no trouble making and keeping friends.

3. I'm not good at guiding the course of a conversation with several others. (Requires reverse coding)

4. I can usually develop a close personal relationship with someone I find appealing.

5. I can usually steer a conversation toward the topics I want to talk about.

6. When I need assistance with something, I often find it difficult to get others to help. (Requires reverse coding)

7. If there's someone I want to meet, I can usually arrange it.

8. I often find it hard to get my point of view across to others. (Requires reverse coding)

9. In attempting to smooth over a disagreement, I sometimes make it worse. (Requires reverse coding)

10. I find it easy to play an important part in most group situations.

Instructions: Indicate how much you agree with each statement.

$1=$ Strongly disagree

$2=$ Disagree

$3=$ Neither agree nor disagree

4= Agree

$5=$ Strongly agree

\section{Counterproductive Work Behaviors, Spector, Bauer, and Fox (2010)}

1. Purposely wasted your employer's materials/supplies.

2. Complained about insignificant things at work.

3. Told people outside the job what a lousy place you work for.

4. Came to work late without permission.

5. Stayed home from work and said you were sick when you weren't.

6. Insulted someone about their job performance.

7. Made fun of someone's personal life.

8. Ignored someone at work.

9. Started an argument with someone at work.

10. Insulted someone at work.

Instructions: How often have you done each of the following things on your present job?

$1=$ never

$2=$ once or twice

$3=$ once or twice a month

$4=$ once or twice a week

$5=$ everyday 
VITA

\title{
JOSÉ FRANCISCO RODRÍGUEZ
}

\author{
Born, Torrance, California
}

2001

B.S.C., Communication and Psychology

University of Miami

Coral Gables, Florida

2001

Academic Advisor

Department of Psychology, University of Miami

Coral Gables, Florida

2003

M.S.Ed., Higher Education \& Enrollment Management

University of Miami

Coral Gables, Florida

2005

Academic Advisor

College of Business, Florida International University

Miami, Florida

2006

Director of Academic Advising

School of Journalism, Florida International University

Miami, Florida

2008

Assistant Dean

Honors College, Florida International University

Miami, Florida

2015

M.S., Industrial/Organizational Psychology

Florida International University

Miami, Florida

2016

Faculty Fellow

Honors College, Florida International University

Miami, Florida

$2015-2018$

Doctoral Candidate, Industrial/Organizational Psychology

Florida International University

Miami, Florida 


\section{PUBLICATIONS AND PRESENTATIONS}

Orrego, V. \& Rodríguez, J. F. (2001). Family Communication and College Adjustment: The effects of communication and conflict on the separation-individuation process of college students. Journal of Family Communication, 1, 175-189.

Waldrup, J., Rodríguez, J. F., \& Bruk-Lee, V. (2013, April). Embrace yourself at work: disclosure and authenticity among LGB employees. Presented at the 24th Annual Meeting of the Society of Industrial and Organizational Psychology. April 2013, Houston, TX.

Nixon, A.E., Rodríguez, J. F., \& Bruk-Lee, V. (2013, August). Mitigating CWBs: roles of interpersonal locus of control and conflict. In M. K. Shoss and L. M. Penney (Chairs), Understanding motives for counterproductive work behaviors. Symposium conducted at the 73rd Annual Meeting of the Academy of Management, Orlando, FL.

Harari, M. B., Naemi, B., Viswesvaran, C., Roberts, R. D., \& Rodríguez, J. F. (2014, August). The validity of conscientiousness and its facets: Stable or dynamic across time? Paper presented at the annual meeting of the Academy of Management, Philadelphia, PA.

Harari, M. B., Rodríguez, J. F, Viswesvaran, C., \& O'Rourke, R. (2014, August). Gender differences in work sample assessments: Not all tests are created equal. Paper presented at the annual meeting of the Academy of Management, Philadelphia, PA.

Ashley E. Nixon, Julie J. Lanz, Archana Manapragada, Valentina Bruk-Lee, April Schantz \& Jose F. Rodriguez (2015): Nurse safety: How is safety climate related to affect and attitude?, Work \& Stress, DOI: 10.1080/02678373.2015.1076536

Rodríguez, J. F. \& Bruk-Lee, V. (2016, March). The indirect effects of transformational leadership on counterproductive work behaviors. Oral presentation given at the annual scholarly forum of the Graduate Student Appreciation Week of Florida International University, Miami, FL.

Rodríguez, J. F. \& Bruk-Lee, V. (2016, April). Job Demands and Resources: organizational communication and non-task organizational conflict. Poster presented at the annual meeting of the Society for Industrial-Organizational Psychology, Anaheim, CA.

Rodríguez, J. F. \& Bruk-Lee, V. (2016, October). The indirect effects of transformational leadership on counterproductive work behavior. In P.L. Perrewé and P.E. Spector (Chairs), Advances in Occupational Stress Research. Symposium submitted to the Annual Meeting of the Southern Management Association, Charlotte, NC. 